\title{
Phase I ResonantSonic CRADA Report
}

Prepared for the U.S. Department of Energy Office of Environmental Restoration and Waste Management

\section{(2) Westinghouse Hanford Company Richland, Washington}

Hanford Operations and Engineering Contractor for the

U.S. Department of Energy under Contract DE-AC06-87AL10930 


\section{DISCLAIMER}

This report was prepared as an account of work sponsored by an agency of the United States Government. Neither the United States Government nor any agency thereof, nor any of their employees, make any warranty, express or implied, or assumes any legal liability or responsibility for the accuracy, completeness, or usefulness of any information, apparatus, product, or process disclosed, or represents that its use would not infringe privately owned rights. Reference herein to any specific commercial product, process, or service by trade name, trademark, manufacturer, or otherwise does not necessarily constitute or imply its endorsement, recommendation, or favoring by the United States Government or any agency thereof. The views and opinions of authors expressed herein do not necessarily state or reflect those of the United States Government or any agency thereof. 


\section{DISCLAIMER}

Portions of this document may be illegible in electronic image products. Images are produced from the best available original document. 


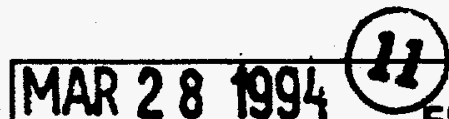

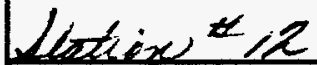

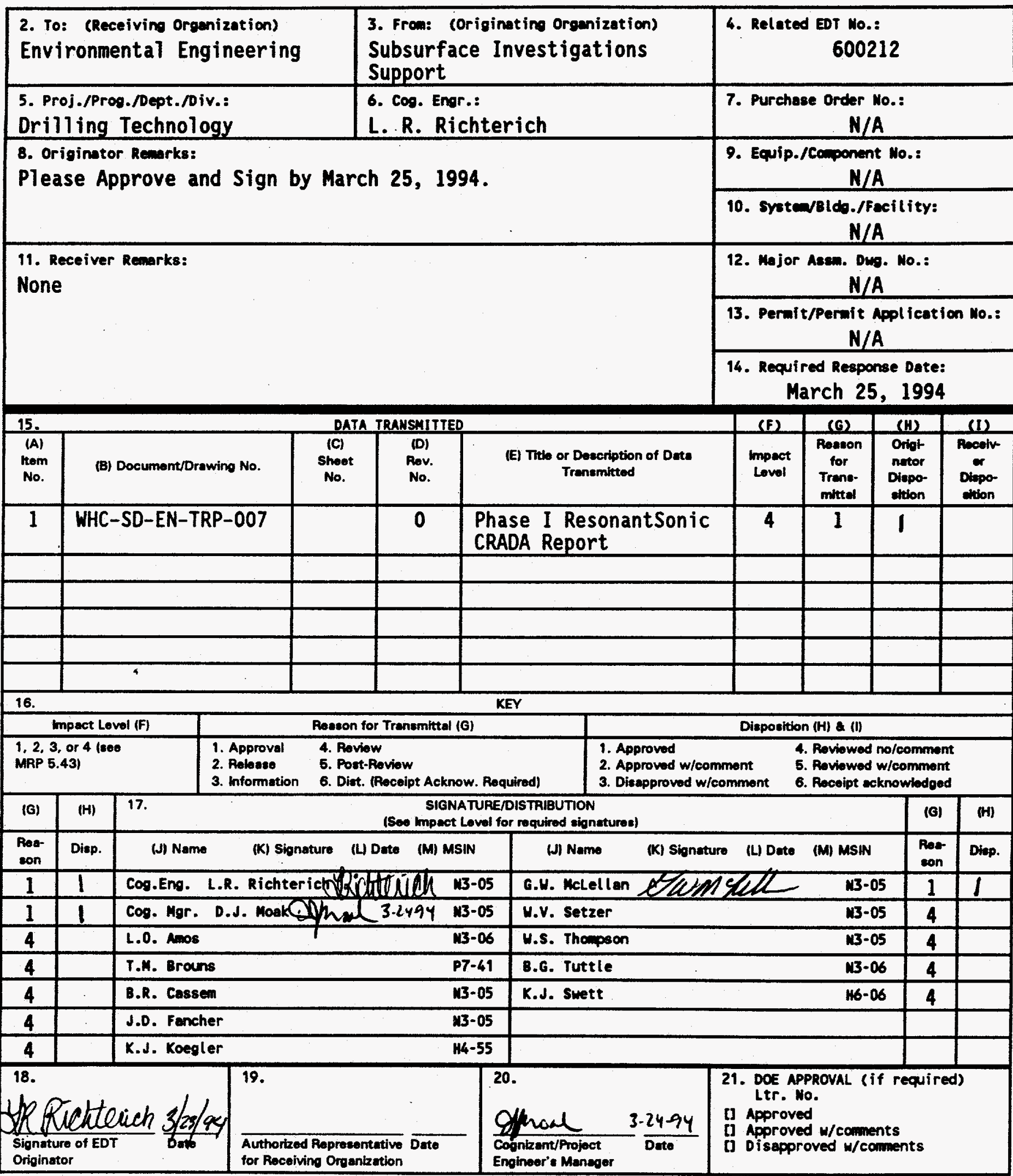

BD-7400-172-2 (07/91) GEF097 


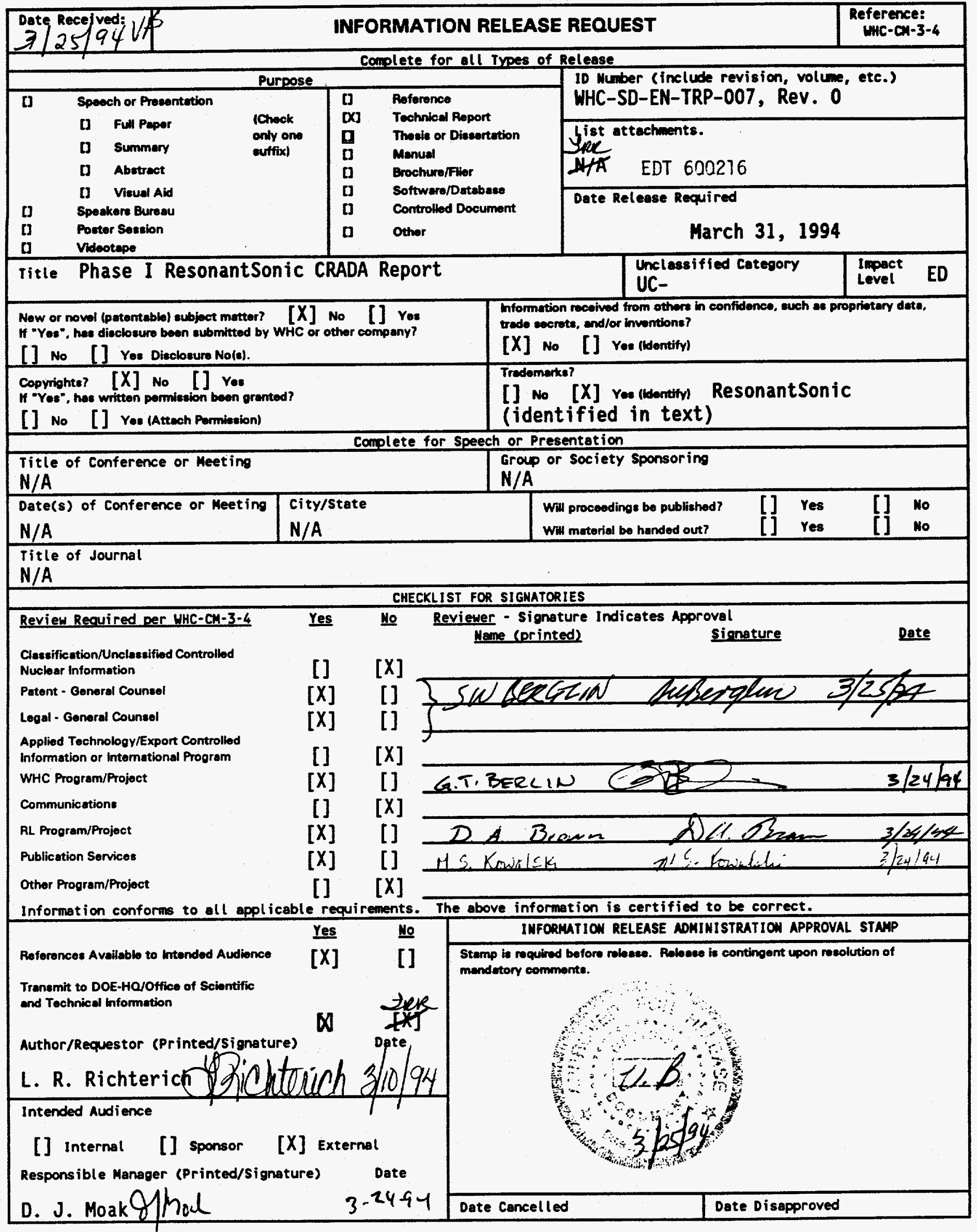




2. Title
Phase I ResonantSonic CRADA Report

5. Key Hords

ResonantSonic, Cooperative Research and Development Agreement (CRADA), drilling, VOC-Arid ID, sonic

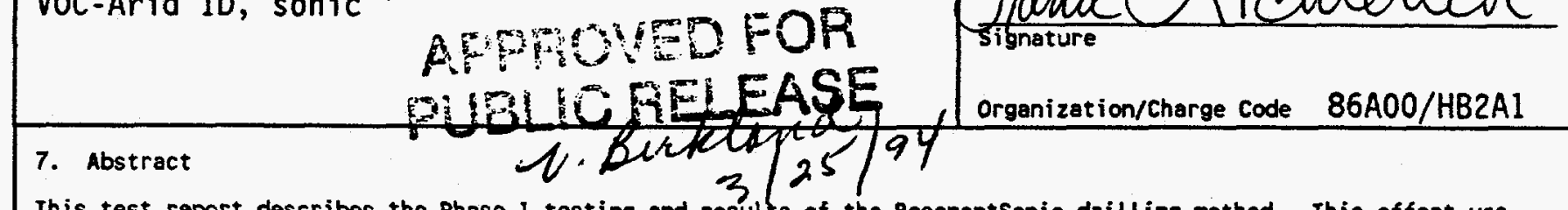

This test report describes the Phase 1 testing and results of the ResonantSonic drilling method. This effort was conducted as part of a Cooperative Research and Development Agreement (CRADA) between the U.S. Department of Energy, Pacific Northwest Laboratory, Westinghouse Hanford Company and Weter Development Corporation. The purpose of this demonstration was to evaluate the Hater Development Corporation's ResonantSonic drilling system, modify components as necessary and determine compatible drilling applications for the ResonantSonic drilling method for use at facilities in the DOE complex and private industry.

Initially, the ResonantSonic drill was used to drill several test holes at the Drilling Technology Test site to assess the feasibility of drilling vertical and angle holes. After this initial phase, a 45 degree angle vapor extraction well was drilled to a depth of 168 feet at the 200 West Carbon Tetrachloride Site. This well was drilled and completed in nine days. Extensive geologic and vapor sampling were conducted while drilling this well. In addition, testing was also conducted at the test site to evaluate drilling with larger diameter casing (8 $5 / 8$ inch).

Evaluation of the ResonantSonic drilling method will be continued during the Phase 11 portion of testing to determine if improvements to the ResonantSonic system will make it a more viable method for drilling and sampling.

Richterich, L.R., 1994, Phase I ResonantSonic CRADA Report, WHC-SD-EN-TRP-007, Rev. O, Westinghouse Hanford Company, Richland, Washington.

8. PURPOSE AND USE OF DOCUMENT - This dafument was prepared for use with the U.S. Department of Epergy and its contractors. It is to be used only to perform direct, or integrate work under U.S. Depalkment of Energy tontracts. This dowment is noy approved for public rafease unt in reviewed.

PATENT STATUS - his document copy, since it transmitted in advance of patent charance, is made availabte in confidence solely for use in performence of work yoder contracts with the U.S. Deportment of Energx. This docyont is not to be published nor its contents otherwise ditseminatod or used for purposes other than speelfied above before patent approval for such release or use has been secured, upon request, from the Patent Counsel, U.S. Department of Energy Field office, Richland, WA.

DISCLAIMER - This report was prepared as an account of work sponsored by an agency of the United States Government. Neither the United States Goverment nor any agency thereof, nor any of their employees, nor any of their contractors, subcontractors or their employees, makes any warranty, express or implied, or assumes any legal liability or responsibility for the accuracy, completeness, or any third party's use or the results of such use of any information, apparatus, product, or process disclosed, or represents that its use would not infringe privately owned rights. Reference herein to any specific commercial product, process, or service by trade name, trademark, manufacturer, or otherwise, does not necessarily constitute or imply its endorsement, recommendation, or favoring by the United States Government or any agency thereof or its contractors or subcontractors. The views and opinions of authors expressed herein do not necessarily state or reflect those of the United States Goverment or any agency thereof.

9. Impact Level 4
10.
RELEASE STAMP

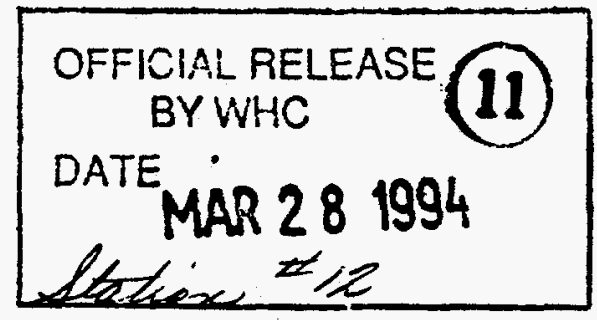


WHC-SD-EN-TRP-007, Rev. 0.

\section{Phase I ResonantSonic CRADA Report}

\section{L.R. RICHTERICH}

L.O. AMOS

J.D. FANCHER

G.W. MCLELLAN

W.V. SETZER

B.G. TUTTLE

Westinghouse Hanford Company

R.L. HOCKEY

R.H. FERRIS

D.M. RIECHERS

\section{S.G. PITMAN}

Pacific Northwest Laboratory

WATER DEVELOPMENT CORPORATION Industry CRADA Partner

Woodland, California

Date Published

MARCH 1994 
WHC-SD-EN-TRP-007, Rev. 0

\section{EXECUTIYE SUMAARY}

This test report describes the results of Phase I testing conducted under a Cooperative Research and Development Agreement (CRADA) between the U.S. Department of Energy, Water Development Corporation (WDC), Pacific Northwest Laboratory (PNL), and Westinghouse Hanford Company (WHC). The WHC and PNL portion of the CRADA was funded by the U.S. Department of Energy's Office of Technology and Development (EM-50) through the Volatile Organic Compounds Arid Site Integrated Demonstration. In addition, WDC has also made a significant contribution to the program under the CRADA. The purpose of this CRADA is to further develop the ResonantSonic drilling technology. Phase I testing was conducted from July 1993 to the beginning of December 1993.

The twelve objectives of the ResonantSonic drill test were outlined in the Integrated Test Plan for the Sonic Drilling Method on the Hanford Site Fy $1993^{2}$. These objectives are summarized below:

1. Demonstrate the efficiency and reliability of the ResonantSonic drill head in penetrating variable geologic conditions.

2. Demonstrate angle drilling capabilities with the ResonantSonic method and determine areas for improvements.

3. Develop and install an instrumentation system on the ResonantSonic drill to electronically record the resonant drilling process.

4. Correlate recorded drilling measurements with geology encountered.

5. Test and evaluate sampling equipment and sample handing methods to determine acceptable systems for both vertical and angle drilling modes.

6. Demonstrate that ResonantSonic drilling can meet safety standards at the Hanford Site for drilling operations.

7. Demonstrate the ability to maintain contamination control and minimize generated waste so the drilling system could be used for vadose zone characterization borings.

8. Demonstrate compliance with Ecology regulations for completion of wells (e.g., filter pack, annular seals, etc.).

9. Demonstrate the ability to maintain minimal disturbance (comparable to cable tool) to soil samples during drilling and demonstrate the

\footnotetext{
'ResonantSonic is a Service Mark of Water Development Corporation, Woodland, California.

${ }^{2}$ McLellan, G. W., 1993, Integrated Test Plan for the Sonic Drilling Method on the Hanford Site FY 1993, WHC-SD-EN-TP-028, Rev. 0, Westinghouse Hanford Company, Richland, Washington.
} 
ability to achieve borehole depths and diameters consistent with project requirements.

10. Evaluate cost effectiveness of the ResonantSonic drill versus cable tool drill when used for characterization of hazardous waste sites.

11. Determine the radial distance from the borehole of vibrations generated by the ResonantSonic method.

12. Drill and install multi-screened interval 10.2-cm (4-in.) vapor extraction well.

To date, seven objectives, $1,2,5,6,7,8$, and 9 , have been completed. These objectives are summarized below.

Objective one, demonstrate ResonantSonic head reliability, was completed. The head was used to drill over $274 \mathrm{~m}(900 \mathrm{ft})$ during Phase I testing. Several vertical and angle test bores were conducted with minimal down time related to head failure.

The ResonantSonic drilled and completed a 45 degree angle 7.6-cm (3-in.) vapor extraction well to complete objective two. Using the 300 horsepower (hp) ResonantSonic drill head, the 45 degree angle well was begun September 16, 1993 and drilled to $51.3 \mathrm{~m}(168.24 \mathrm{ft})$ in less than eight working days. The average drill rate was $7.3 \mathrm{~m} / \mathrm{day}(24 \mathrm{ft} / \mathrm{day})$. In one working day, the $7.6-\mathrm{cm}(3-\mathrm{in}$.$) stainless steel screen was installed and the$ well was completed.

To achieve objective five, various types of sampling equipment and methods were tested. Most methods were examined in both the vertical and horizontal drilling modes. No method was exclusively beneficial to one drilling mode.

While on the Hanford Site, the ResonantSonic was demonstrated to be a safe drilling technology to complete objective six. All drilling activities complied with Hanford health and safety standards and applicable federal regulations.

Objective seven, to maintain contamination control and minimize generated waste, was achieved. The ResonantSonic drilling method does not require circulating media to drill, so minimal waste is generated. This in turn decreases the amount of cuttings that must be drummed on a hazardous waste site.

The ResonantSonic also demonstrated the ability to comply with Washington Administrative Codes (WAC) to accomplish objective eight. All vertical and angle test bores were abandoned in accordance with the WAC. The 45 degree angle well was completed with the required $5-\mathrm{cm}(2-i n$.$) annular seal. This$ was accomplished by manufacturing a $17.8-\mathrm{cm}(7-\mathrm{in}$.$) outer diameter casing bit$ to work in conjunction with the $16.8-\mathrm{cm}$ (6 5/8-in.) casing.

Objective nine, to maintain minimal disturbance to soil samples and achieve borehole depths and diameters, was achieved. Drilling techniques were modified to minimize soil disturbance during sampling and coring. To do this, 
frequencies and rotations were reduced during split spoon and core barrel sampling of various lithologies.

Completion of the 45 degree angle vapor extraction well met the project borehole depths and required diameter. The well was completed as a 3-in. vapor extraction well to a depth of $51.2 \mathrm{~m}(168 \mathrm{ft})$.

In another task lasting three days, the ResonantSonic was for maintenance of an existing groundwater monitoring well. First, tools previously lost downhole were retrieved. Then, the well as cleared of $12.2 \mathrm{~m}$ (40 ft) of caved in material. Finally, a 10.2-cm (4-in.) stainless steel screen was installed at the bottom.

Four objectives, 3, 4, 10, and 11 have been moved to the Phase II portion of testing. These activities are discussed in the following paragraphs.

Instrumentation for the 300 hp ResonantSonic drill head is currently being developed. This instrumentation will be field tested during the Phase II portion of testing. Testing will consist of recording selected drill rig and drilling performance parameters, and assisting in drill pipe design. Once the rig is instrumented, then various drilling measurements can be correlated with the geology encountered. Completion of these activities will accomplish objectives three and four.

Most activities focused on drilling vertical and angle test bores, a side-by-side comparison between the baseline, cable tool, and the ResonantSonic was not conducted. However, during the Phase II testing, objective ten, a cost comparison between cable tool and the ResonantSonic, will be conducted.

In a Phase II test vibration test, extensometers and accelerometers will be installed in a preselected radial array. A ResonantSonic drilled hole will be installed in the center of the array. Measurements recorded will help determine the distance and intensity of resonant energy transfer to the surrounding soils and the potential impact to surrounding structures.

Objective twelve, drill and install a multi-screened interval 4-in. vapor extraction well, was eliminated. Expedited Response Action personnel determined installing another $10.2-\mathrm{cm}(4-\mathrm{in.})$ vertical vapor extraction well was unnecessary.

Phase I testing at the Hanford Site indicates that the ResonantSonic method has potential to be a viable environmental tool. As part of the existing CRADA, improvements to system components will be promulgated during Phase II testing. These results will be reported in the Phase II CRADA report. 
WHC-SD-EN-TRP-007, Rev. 0

This page is intentionally left blank. 
CONTENTS

1.0 INTRODUCTION . . . . . . . . . . . . . . . . . . 1

1.1 PURPOSE AND SCOPE ..................... . . . . 1

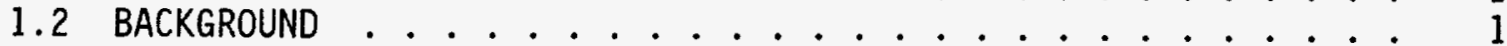

1.2.1 Sonic Drilling System ............... . . 1

1.2.2 Volatile Organic Compound-Arid Site Integrated Demonstration Project ............. . . 3

1.2.3 Volatile Organic Compound-Arid Site Integrated Demonstration Project ............. 3

1.3 DESCRIPTION OF TEST SITES.................. . . . . . 3

1.3.1 Hanford Site Geology .................. . . 5

1.3 .2200 West Area Carbon Tetrachioride ERA . . . . . . . . . . . 5

1.3.3 Drilling Technology Test Site . . . . . . . . . . 5

2.0 TECHNOLOGY DESCRIPTION .................... 5

3.0 DEMONSTRATION OBJECTIVES AND MEASURES OF SUCCESS . . . . . . . . . 12

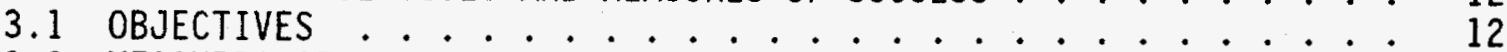

3.2 MEASURES OF SUCCESS.......................... . . . . . . 13

3.3 SAMPLING ACTIVITIES . . . . . . . . . . . . . . . . . . . 14

4.0 OPERATIONS DEMONSTRATION . . . . . . . . . . . . . . . . . 14

5.0 PERFORMANCE DATA AND EVALUATION . . . . . . . . . . . . . . 16

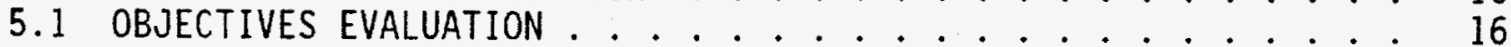

5.1.1 Sonic Drill Head Performance . . . . . . . . . . . 16

5.1.2 Angle Drilling Capabilities ............ . 17

5.1.3 Instrument Development and Instaliation . . . . . . . 17

5.1.4 Correlation Between Drilling Measurement and Geology . 19

5.1.5 Sampling Equipment and Methods . . . . . . . . . 19

5.1.6 Hanford Safety Standards . . . . . . . . . . . . . . 22

5.1.7 Contamination Control and Waste Minimization . . . . 23

5.1.8 WAC 173-160 Compliance ............. 23

5.1 .9 Quality Soil Samples ............... 24

5.1.10 Cost Effectiveness ............... 25

5.1.11 Soil Vibration Test . . . . . . . . . . . . . . . 25

5.1.12 Multi-Screened Four-Inch Vapor Extraction We11 . . . 25

5.1.13 Sonic Drill Pipe Analysis............ . 25

6.0 CONCLUSIONS AND RECOMMENDATIONS . . . . . . . . . . . . . 29

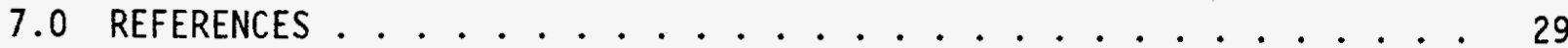


WHC-SD-EN-TRP-007, Rev. 0

\section{FIGURES}

1 Hanford Site Map and Location of ResonantSonic Test Sites . . . . . 4

2 General Geologic Cross-Section of the Hanford Site . . . . . . . 6

3 VOC-Arid ID Site - ResonantSonic Angle Well Location . . . . . . . 7

4 Drilling Technology Test Site ............... 8

5 ResonantSonic Drilling Method .............. 9

6 ResonantSonic Drill Head ............... 11

\section{TABLES}

1 ResonantSonic Chronology of Events FY 93 . . . . . . . . . . 15

2 ResonantSonic Borehole Summary . . . . . . . . . . . . . . 16

3 ResonantSonic 45 Degree Vapor Extraction We11 \#299-W15-223 . . . . 18

4 ResonantSonic Drill Pipe Fractures . . . . . . . . . . . 27

5 Wet Magnetic Particle Inspection Summary . . . . . . . . . 26 


\subsection{INTRODUCTION}

\subsection{PURPOSE AND SCOPE}

This report details the results of field tests of the ResonantSonic ${ }^{\mathrm{sm}}$ (ResonantSonic refers to testing conducted during 1993) dri17ing method July 1993 and December 1993 at the Hanford Site, and represents the completion of Phase I test activities. This document refers to some of the Phase II tests, but those scheduled for 1994 will be detailed in a follow-up report. This testing program supports a Cooperative Research and Development Agreement, referred to as a CRADA.

A CRADA is a contractual process enacted by Congress in 1989 to pursue technology development between private industry and government subcontractors. The primary goal of the CRADA process is to provide a flexible mechanism that enables the timely development of mutually beneficial technologies. The main purpose of this CRADA is to allow the U.S. Department of Energy (DOE) Pacific Northwest Laboratory (PNL), Westinghouse Hanford Company (WHC), and Water Development Corporation (WDC) to pursue enhancements to the ResonantSonic drilling technology.

During testing conducted from September 1991 to May 1992, the ResonantSonic method was identified as a possible alternative to the cable tool drilling method for waste site drilling at the Hanford Site. The sonic (sonic refers to testing conducted during FY 1991-1992) system provided continuous core samples, minimized waste, and maintained excellent contamination control because no circulation media was required. The sonic system also demonstrated penetration rates that substantially exceeded cable tool drilling rates. Equipment failures during the initial test emphasized the need for additional testing and component upgrades.

Necessary technology development and improvements have focused on increasing (1) drilling and sampling efficiency and (2) system component reliability. Specific 1993 objectives were (1) testing the system's angle drilling capability, (2) improving the performance of drilling components, and (3) testing alternative sampling methods and drilling bits.

During field tests, a 45 degree angle $7.6-\mathrm{cm}$ (3-in.) vapor extraction well was installed. In addition, several angle and vertical test borings were drilled and an existing groundwater monitoring well was rehabilitated. The goal of this ResonantSonic drilling technology development program is to transfer this technology to Environmental Restoration (ER) and Waste Management (WM) programs at the Hanford Site, other U.S. Department of Energy (DOE) facilities and the private sector.

\footnotetext{
${ }^{1}$ ResonantSonic is a Service Mark of Water Development Corporation, Woodland, Cal ifornia.
} 
WHC-SD-EN-TRP-007, Rev. 0

\subsection{BACKGROUND}

\subsubsection{FY 1991-1992 Sonic Drilling Demonstration}

Westinghouse Hanford Company is tasked with developing, testing, and demonstrating drilling methods that are environmentally acceptable, safe, more efficient, and cost effective, than the cable tool method when drilling and sampling in hazardous and radioactive waste sites. The sonic drilling system was tested in FY 1991-1992 under the Drilling Technology Development Program and the ER Program. The Drilling Technical Test Plan is administered and funded through the office of Technology Development.

The Integrated Test Plan for Demonstration of a Sonic Drilling System and the SEAMIST System (Rohay and McLellan 1992) specified that the sonic system would be used to drill three deep monitoring/extraction wells near the carbon tetrachloride disposal sites in the 200 West Area in 1991-1992. Because of equipment problems with the contractor's sonic drilling system, only one deep well was drilled. The remaining two wells were drilled with the cable tool method.

In addition to the 200 West Area Carbon Tetrachloride Expedited Response Action (ERA) drilling, the sonic drill was used to collect site characterization data at several other sites including (1) the 100-D Area Resource Conservation and Recovery Act (RCRA) site, (2) the 300-FF-5 Comprehensive Environmental Response, Compensation, and Liability Act (CERCLA) Operable Unit, (3) the 300 Area Underground Storage Tank Program, and (4) the Hanford Waste Vitrification Plant Baseline Characterization Program.

Field testing of the sonic drilling method was initiated at the 300-FF-5 Operable Unit in September 1991. The services of the sonic drilling contractor, Harrison Western Drilling, Inc. (HWD), of Lakewood, Colorado, were obtained through a subcontract. The testing was conducted using a trailer-mounted 1976 model of a Hawker-Siddeley sonic drill owned by HWD.

The sonic system was used to drill and complete eight groundwater wells, one carbon tetrachloride vapor extraction/monitoring well, and two vadose characterization boreholes. The wells/borings ranged from $9 \mathrm{~m}$ to $69 \mathrm{~m}$ (30 ft to $227 \mathrm{ft}$ ) in depth.

The average of eleven wells and borings drilled using the sonic method were compared with ten nearby wells completed using the cable tool method. The penetration rate with the sonic drill was approximately twice that of the cable tool drill. In addition, less soil had to be drummed because the sonic drill used no fluid or air for drilling. The sonic drill system experienced pipe failures and drill head failures, which limited its performance.

Downtime resulting from equipment related failures averaged 28 percent for the sonic rig and four percent for cable tool. Sti1l, the sonic method reduced drilling costs by approximately 20 percent (Volk, McLellan, and King 1992).

After the test program was complete, a lessons learned meeting was held, and the report was written. WHC and DOE agreed that equipment components needed to be enhanced. The preferred process to develop and test these improvements would be through a CRADA with an industrial partner. 
WHC-SD-EN-TRP-007, Rev. 0

\subsubsection{CRADA Background}

A CRADA approved by DOE was established in February 1993 between PNL and industry ResonantSonic contractor Water Development Corporation of Woodland, California. PNL then designated WHC as the technical manager.

During the past three years, WDC has been the leader in developing upgrades and more reliable components for the ResonantSonic system. The CRADA is structured around joint contributions from the DOE and WDC. The first phase of this agreement focused on improvements to ResonantSonic drill pipe, the drilling head, soil sampling equipment, drilling bits, and the evaluation of a)ternative uses of the ResonantSonic method to support characterization and remediation projects. If improvements in the ResonantSonic system components can be made, the system will become a more viable method for drilling and sampling at waste sites.

Work conducted under this CRADA has been integrated with activities related to ResonantSonic drilling currently being performed by WDC at Sandia National Laboratories (SNL) and other laboratories. Drilling results from both sites were evaluated to assess the effects of various geologic conditions on the longevity and performance of drilling components such as drill pipe, drill bits, sampling equipment, and the ResonantSonic drill head.

\subsubsection{Volatile Organic Compound-Arid Site Integrated Demonstration Project (VOC-Arid ID)}

The ResonantSonic drilling CRADA and test program are being conducted as part of the VOC-Arid ID. The VOC-Arid ID is one of several DOE integrated demonstrations designed to support the testing of emerging environmental management and restoration technologies. The purpose of the VOC-Arid ID is to identify, develop, and demonstrate new and innovative technologies to support environmental restoration. These technologies may be used to characterize, remediate, and/or monitor arid or semi-arid sites containing Vocs (e.g., carbon tetrachloride) with or without associated metal and radionuclide contamination. Initially, the VOC-Arid ID activities will focus primarily on the carbon tetrachloride contamination and associated contamination found in the 200 West Area of the Hanford Site. Testing the ResonantSonic method may be considered at other sites.

\subsection{DESCRIPTION OF TEST SITES}

Testing was conducted at two major areas, the 200 West Carbon Tetrachloride ERA and the Drilling Technology Test Site (DTTS), on the Hanford Site. The location of the Hanford Site can be found in Figure 1 . Because the ResonantSonic rig is owned by an offsite contractor, testing was conducted in areas known to be free of radiological contamination. The following sections describe Hanford Site geology and the two test sites. 
Figure 1. The Hanford Site.

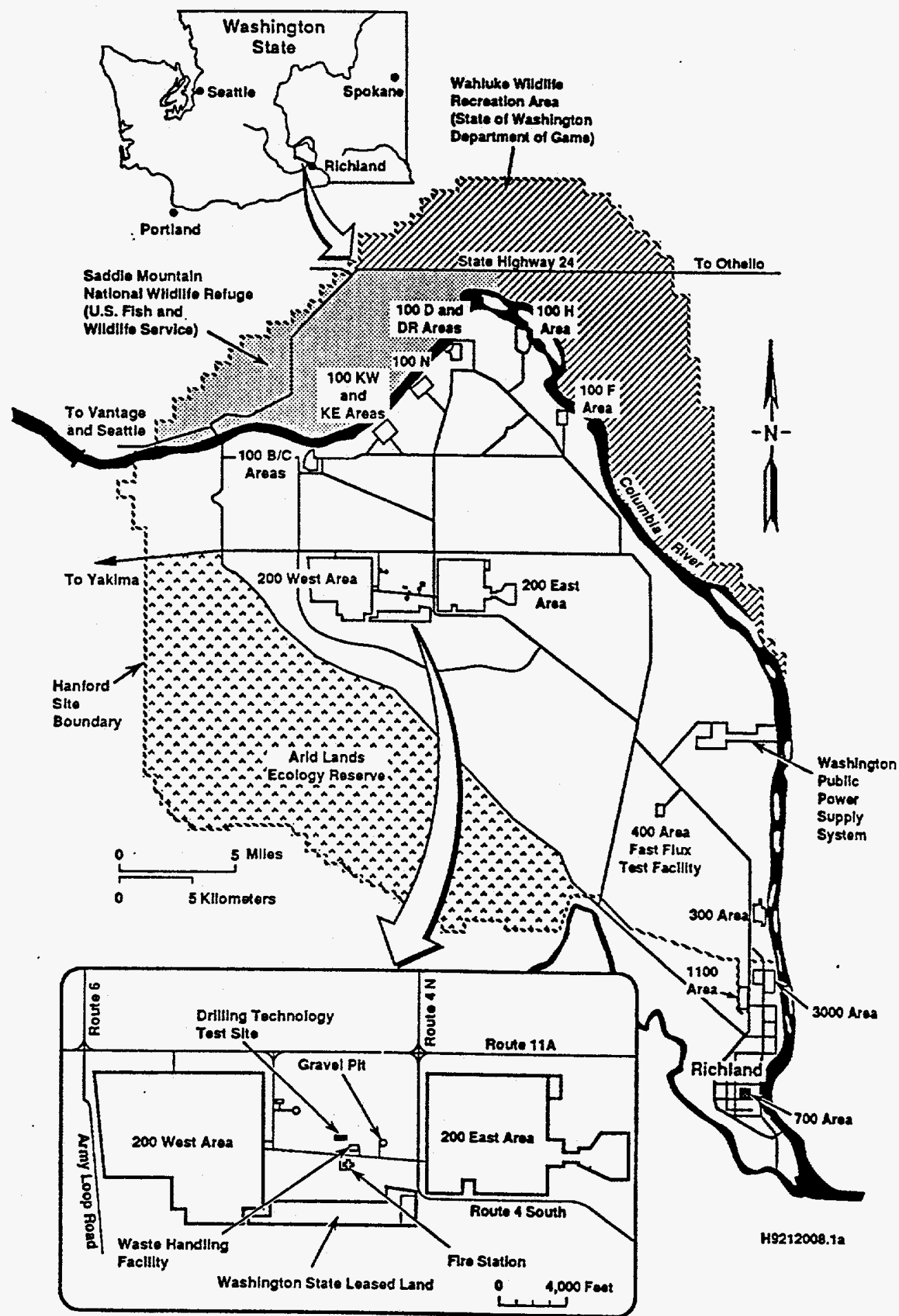


WHC-SD-EN-TRP-007, Rev. 0

\subsubsection{Hanford Site Geology}

The upper geologic unit of the Hanford formation beneath the 200 West Area consists of two facies (1) coarse-grained sand and granule-to-boulder gravel from which matrix is commonly lacking, and (2) fine-to-coarse-grained sand and silt that commoniy display normally graded rhythmites a few centimeters to several decimeters thick. In general, the coarse facies is composed of approximately 50 percent sand and gravel, 45 percent cobble, and five percent boulder, and ranges in thickness from $6 \mathrm{~m}(19.7 \mathrm{ft})$ to greater than $60 \mathrm{~m}$ (197 ft). The underlying fine facies consists of $1.5 \mathrm{~m}(4.9 \mathrm{ft})$ to $18 \mathrm{~m}(59 \mathrm{ft})$ of silts and fine sands, which in turn are underlain by PlioPleistocene and Ringold formation sediments. Figure 2 represents a general cross-section of the geology on the Hanford Site.

\subsubsection{West Area Carbon Tetrachloride ERA}

The DOE is conducting the Expedited Response Action at the direction of the Environmental Protection Agency (EPA) and Washington State Department of Ecology (Ecology). The ERA is a removal action under the Comprehensive Environmental Response, Compensation, and Liability Act (CERCLA) that allows expedited response to be taken where early remediation will abate imminent hazards or prevent significantly increased degradation that might occur if action was delayed until completion of a remedial investigation/feasibility study and record of decision.

The ERA is based on concern that the carbon tetrachloride residing in the soils underlying the 200 West Area is continuing to serve as a source of contamination to the ground water. Thus, the purpose of the ERA is to minimize contaminant migration within the unsaturated soils in the 200 West Area by removing the carbon tetrachloride. Soil vapor extraction is being used to remove the carbon tetrachloride followed by above ground treatment. A network of soil vapor extraction vadose wells give access to the carbon tetrachloride residing in the soils. The location of the 45 degree ResonantSonic angle well site can be found in Figure 3.

\subsubsection{Drilling Technology Test Site}

The DTTS is located approximately $610 \mathrm{~m}(2,000 \mathrm{ft})$ northwest of the 200 Areas fire station, between the 200 East and 200 West Areas of the Hanford Site, as shown in Figure 4 . This site was used because there is no known contamination and the geology is fairly representative of the Hanford Site.

\subsection{TECHNOLOGY DESCRIPTION}

The WDC ResonantSonic drilling system (Figure 5) uses a combination of mechanically generated vibrations and rotary power to penetrate the soil. The oscillator or drill head consists of two counter-rotating rollers that cause the drill pipe to vibrate. The rollers are synchronized to ensure that the 
WHC-SD-EN-TRP-007, Rev. 0

Figure 2. General Geologic Cross-Section of the Hanford Site.

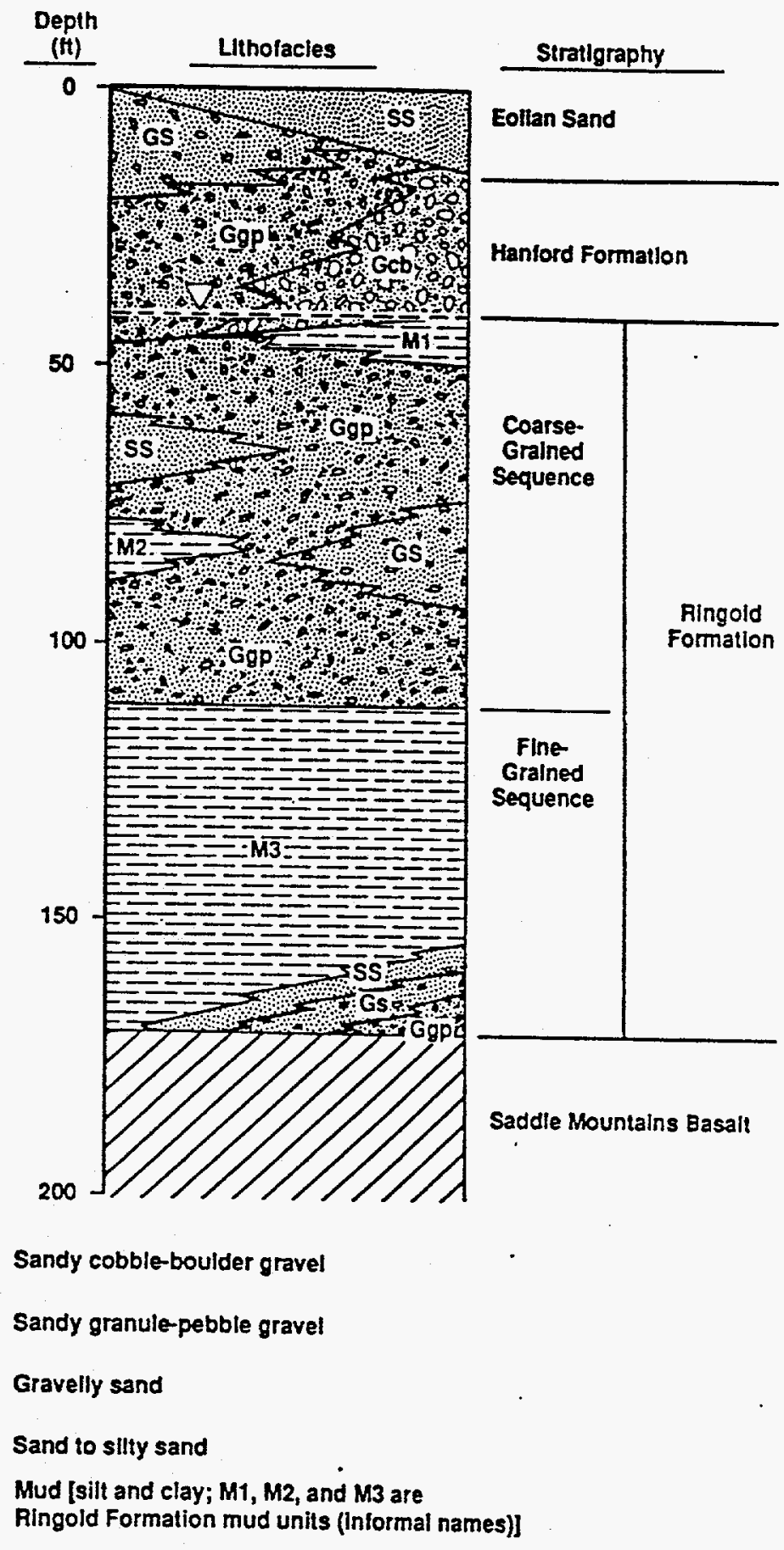


WHC-SD-EN-TRP-007, Rev. 0

Figure 3. VOC-Arid ID Site - ResonantSonic Angle Well Location.

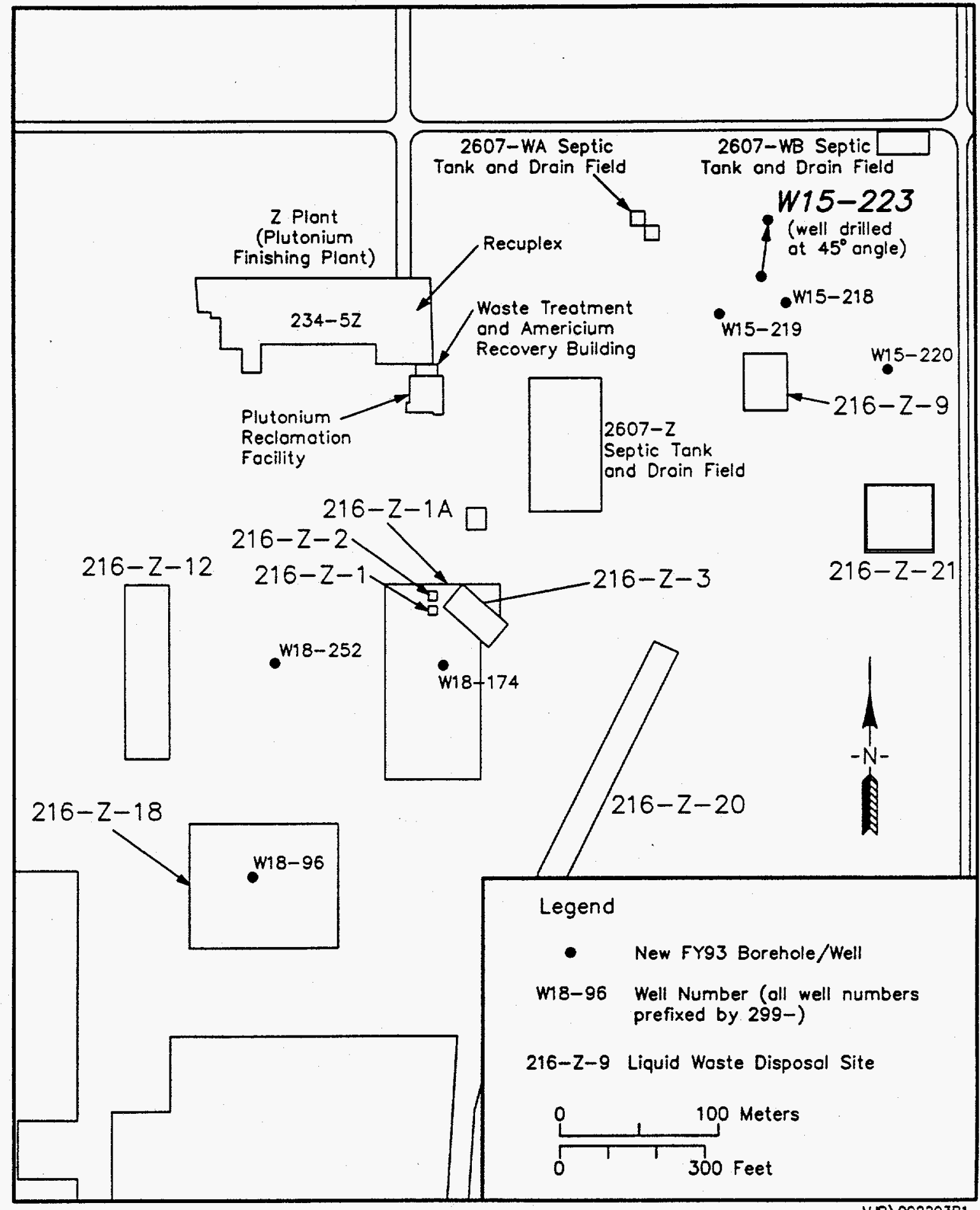


WHC-SD-EN-TRP-007, Rev. 0

Figure 4. Drilling Technology Test Site.

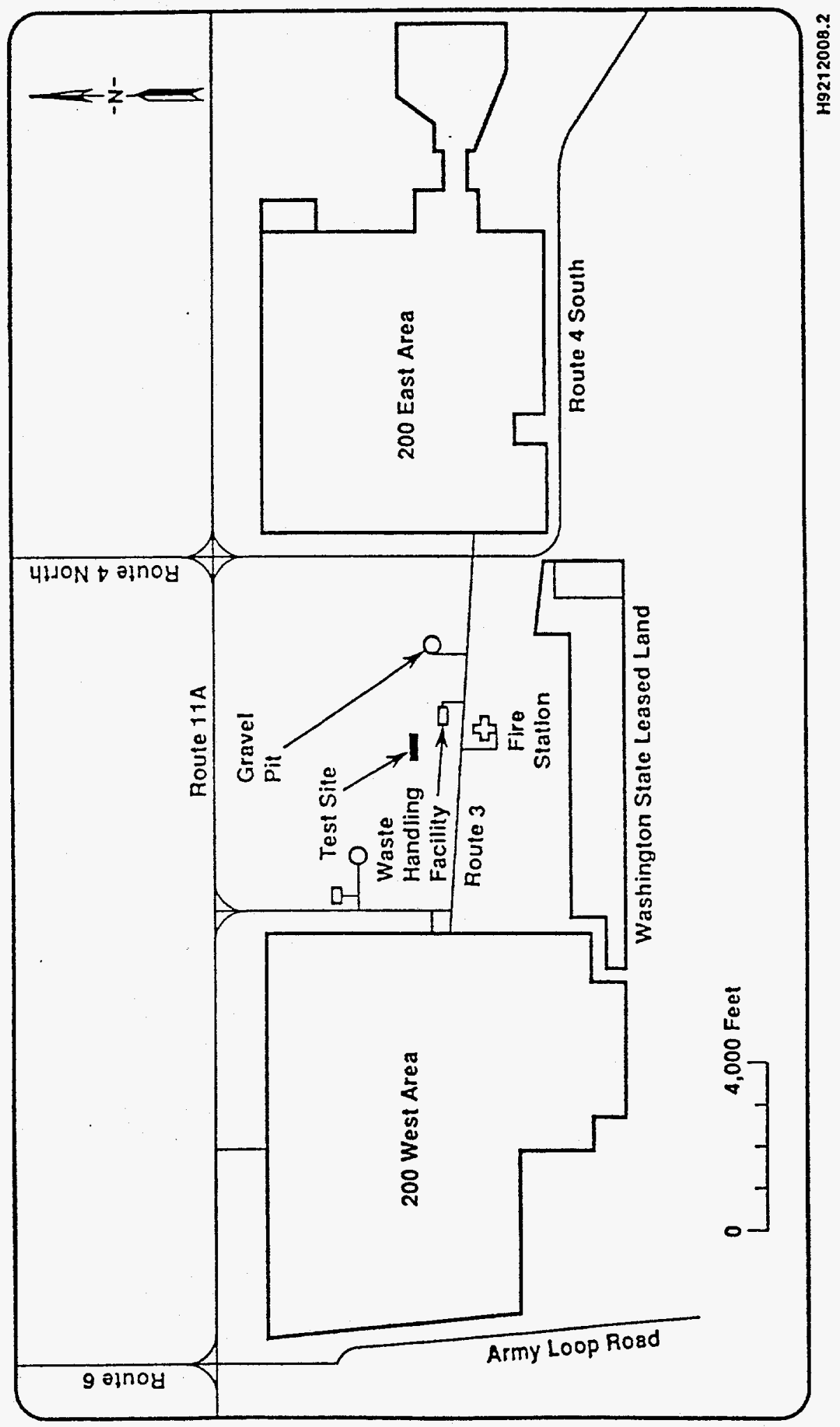


Figure 5. ResonantSonic Drilling Method.

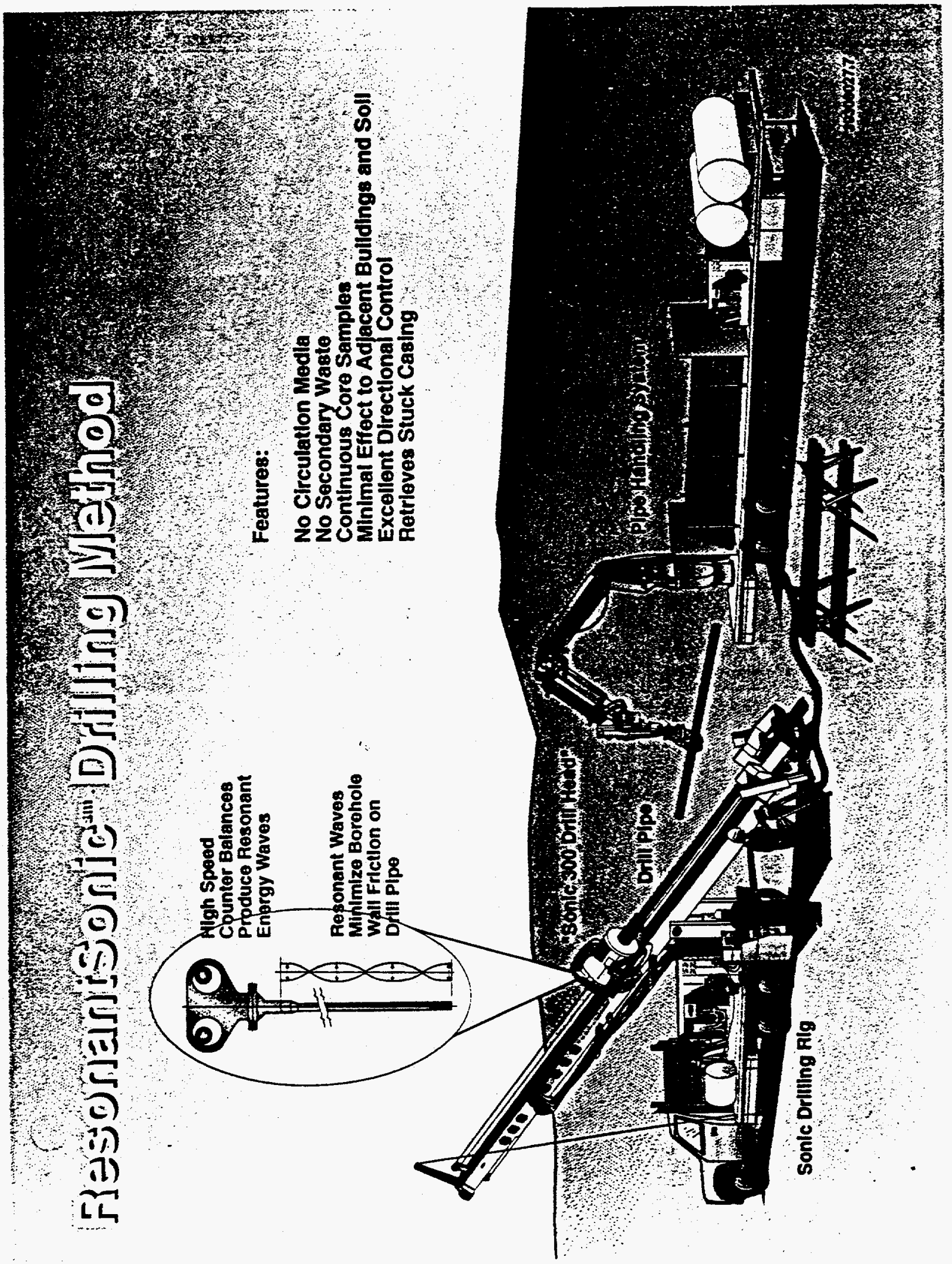


vertical force component is transmitted downward through the drill pipe or core barrel (Figure 6). The vibrations are isolated from the rig structure by the use of an air spring. When the drill pipe is in resonance, the maximum displacements (elasticity) of the pipe are occurring. Resonance is the term used to describe the condition when the frequency of the vibrations is equal to the natural frequency of the drill pipe. The vibration of the drill pipe, coupled with the weight of the drill pipe, and downward thrust of the drill head, allows penetration of the formation. Concurrent with the resonant energy, the drill head can be rotated to assist in formation penetration and to ensure that the formation is always adjacent to the cutting surfaces of the drill bit. The vibrations generated in the drill string by the sonic drill range from 0 to 150 hertz and create up to $21,780 \mathrm{~kg}(48,0001 \mathrm{bs})$ of force.

With the rotational and vibrational energy being generated, the drill pipe is advanced into the ground, since the vibrational component literally causes the formation to yield beneath the drill bit. The drill string is advanced using minimal weight that is applied hydraulically with the drill head. The drill rig can generate a maximum of $4,500 \mathrm{~kg}(10,000 \mathrm{lbs})$ thrust, however, rapid penetration rates are commonly achieved with less than $450 \mathrm{~kg}$ (1,000 ibs) of downward thrust. The resonant energy emitted along the length of the drill pipe, substantially reduces the amount of friction between the dri11 pipe and the borehole wal1. The method also has proven to be successful in extracting previously stuck drill pipe from other drill methods including cable-tool. During the 1991-92 sonic drilling program, stuck casing in a cable-tool drilled hole [ $46 \mathrm{~m}(150 \mathrm{ft}), 25 \mathrm{~cm}$ (10 in.) diameter] was removed and the well was successfully completed using the sonic method.

As the hole is advanced, additional sections of drill pipe (typically five or ten foot lengths) are added and drilling continues. The soil enters the drill string through and open-face (core-type) dri11 bit and is contained in an inner core tube.

A continuous core of the formation is obtained without the use of a circulation media (e.g., fluid or air). As is common with a core drilling process, the length of core retrieved each time is dependent on the stability of the formations encountered. With the sonic method, frequently the amount (feet) of core retrieved is greater (core growth) than the distance drilled, due to the displacement of the soil to the path of least resistance. Borehole integrity is maintained by the threaded carbon steel drill pipe, which remains in the ground while the coring string is removed.

Instead of the weighting system, WDC uses an internal drill string to secure the coring string in the drill bit. This method keeps the tube from lifting out of the bit when core resistance occurs and prevents short core runs, grinding of the sample, and core loss. Depending on the performance of the WDC system, other coring systems may be tested. 
WHC-SD-EN-TRP-007, Rev. 0

Figure 6. ResonantSonic Drill Head.

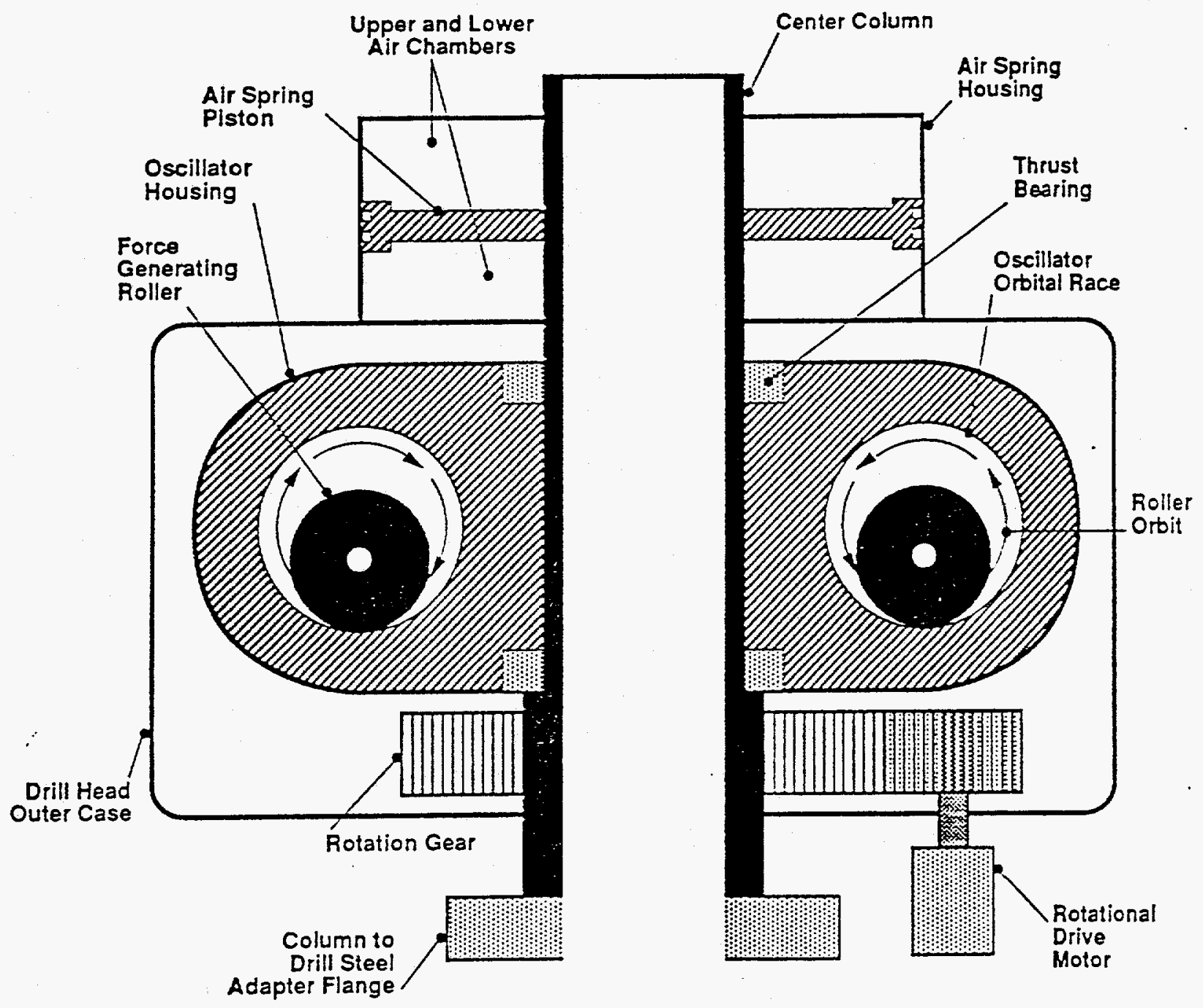


WHC-SD-EN-TRP-007, Rev. 0

\subsection{DEMONSTRATION OBJECTIVES AND MEASURES OF SUCCESS}

\subsection{OBJECTIVES}

The 1993 testing of the ResonantSonic drilling method has expanded on previous field tests during FY 1991-1992 test. Investigators sought to improve the performance and reliability of various components in the ResonantSonic drilling system including the drill head, drill pipe, drill bits, and sampling tools. In parallel with the field testing effort, ongoing laboratory analyses continued in the areas of metallurgical analyses, fatigue testing, and thread configuration to determine alternate drill pipe configurations for field testing later in this project (Appendices B and C). Testing involved both vertical and angle boreholes. Performance objectives from the Integrated Test Plan for the Sonic Drilling Method on the Hanford Site FY 1993 (McLellan 1993) were as follows:

1. Demonstrate the efficiency and reliability of the ResonantSonic dritl head in penetrating variable geologic conditions.

2. Demonstrate angle drilling capabilities with the ResonantSonic method and determine areas for improvements.

3. Develop and install an instrumentation system on the ResonantSonic drill to electronically record the resonant drilling process.

4. Correlate recorded drilling measurements with geology encountered.

5. Test and evaluate sampling equipment and sample handling methods to determine acceptable systems for both vertical and angle drilling modes.

6. Demonstrate that ResonantSonic drilling can meet safety standards at the Hanford Site for drilling operations.

7. Demonstrate the ability to maintain contamination control and minimize generated waste so the drilling system could be used for vadose zone characterization borings.

8. Demonstrate compliance with Ecology regulations for completion of wells (e.g., filter pack, annular seals, etc.).

9. Demonstrate the ability to maintain minimal disturbance (comparable to cable tool) to soil samples during drilling and demonstrate the ability to achieve borehole depths and diameters consistent with project requirements.

10. Evaluate cost effectiveness of the ResonantSonic drill versus cable tool drill when used for characterization of hazardous waste sites. 
WHC-SD-EN-TRP-007, Rev. 0

11. Determine the radial distance from the borehole of vibrations generated by the ResonantSonic method.

12. Drill and install multi-screened interval four-inch vapor extraction well.

\subsection{MEASURES OF SUCCESS}

1. Achieve penetration rates which exceed performance recorded during 1991-1992 sonic test. Achieve equipment downtime rates equivalent to cable tool drilling. Document downtime specifics including component description and repair/replacement action.

2. Drill a 45 degree angle hole, and complete as a three-inch vapor extraction well to approximately $49 \mathrm{~m}(160 \mathrm{ft})$. Maintain directional control within plus/minus two degrees of stated angle requirements. Record operational activities with angle hole drilling including time cycles for drill pipe handling, sample retrieval, penetration rates, performance of the ResonantSonic dri7l head, containment of contaminants, and secondary waste generated.

3. Record defensible (calibrated instrumentation and recording devices) performance outputs from the ResonantSonic drilling head including rotational speeds, thrust, and vibration levels, and wave amplitude and velocity, to assist in drill pipe design and improve the reliability of the drill head.

4. Obtain soil samples of equivalent quality as cable tool samples, and consistent with requirements noted in Sampling $P$ lans [WHC-SD-EN-AP-109 (Rohay et a1. 1992), for the angle well and WHC-SD-EN-AP-114 (Rohay and Cameron 1992) for the vertical wells].

5. The measurement of success will be the selection of viable alternative sampling equipment and methods. Test sampling equipment and core retrieval and handling methods. Record performance data including sample quality, length of runs versus soil type, average run length, ease of handling, contamination control, retrieval and handling times, and evaluation of sampling equipment and handling methods, to determine acceptable systems for both vertical and angle drilling.

6. Achieve a target of zero reportable accidents. Evaluate the safety of both angle and vertical drilling operations, record and correct any potential hazards, near misses and safety related occurrences.

7. Achieve containment and generated waste performance which improves upon the current baseline for drilling operations. Document and control waste containment related items and waste generated. Note drilling formations versus waste generated, rinsate volumes from 
decontamination processes, total waste from drilled holes (including well/boring depth, diameter and core sample size). Collect data from adjacent cabie tool wells for comparison.

8. Perform and document the completion of holes consistent with Washington Administrative Code (WAC) 173-160. Conduct drilling, completion, and abandonment activities in compliance with the WAC.

9. Maintain and record core sample temperatures and work to prevent degradation of volatile organic compounds. Meet depth, dimensional, and angle drilling requirements for each project. Document bit performances (including wear rates and temperature data)

ResonantSonic impacts to sample quality.

10. Record times for ResonantSonic drilling and well completion process including but not limited to: drilling rates, drill pipe handling times, sample retrieval times, operational downtime due to equipment failures, and downtime from Hanford Site impacts (note organizational discipline imposing delay, specifics of issue to resolve, and interim and/or final resolution). Achieve drilling cost performance which exceeds previous ResonantSonic test (1991-92) rates by 20 percent.

11. Successfully record data via a radial array of subsurface sensing devices (using the ResonantSonic method to install sensors), the distance and respective levels of vibrations transmitted from the drill pipe to the surrounding soils.

12. Completion of regulatory compliant groundwater well to greater than $61 \mathrm{~m}(200 \mathrm{ft})$, in comparable time as cable tool drilled we 11.

\subsection{SAMPLING ACTIVITIES}

Sampling activities during this testing focused on the unsaturated zone directly beneath the carbon tetrachloride disposal site in the vicinity of the 216-Z-9 Crib and the DTTS. The sampling analysis data from the angle well (299-W15-223) will be used to (1) to refine the conceptual model of the site, (2) assist in the development of sampling and sensing equipment for the ResonantSonic system, and (3) optimize the removal of the carbon

tetrachloride. Sampling activities for the angle well were conducted in accordance with requirements noted in the FY 1993 site Characterization Workplan for the Volatile Organic Compounds - Arid Integrated Demonstration and the 200 West Area Carbon Tetrachioride Expedited Response Action, Rev. 2 (Rohay et al. 1993).

\subsection{OPERATIONS DEMONSTRATION}

Table 1 provides a chronological summary of primary ResonantSonic activities and results for the Phase I test period. 
Table 1. ResonantSonic Chronology of Events FY 93.

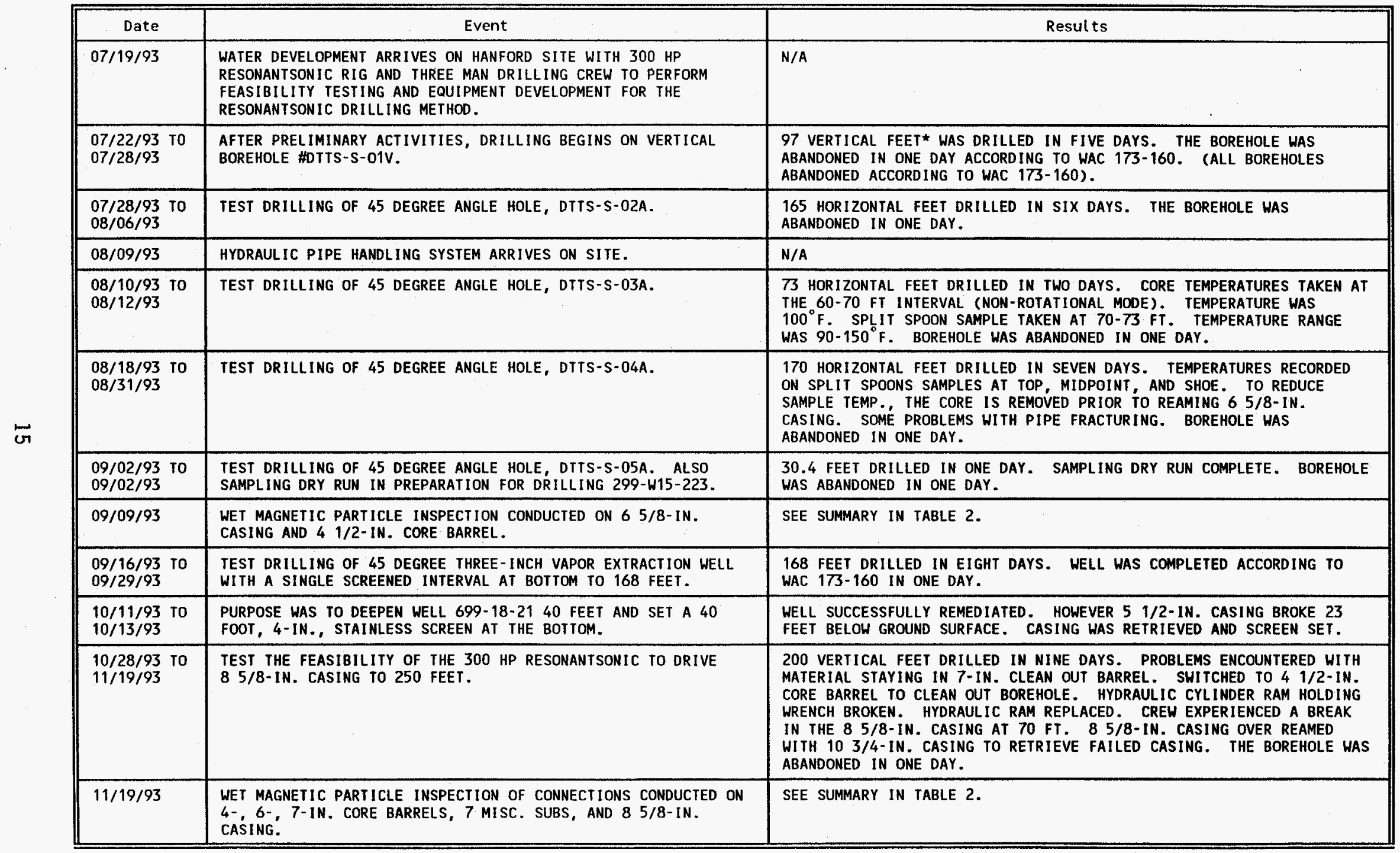

*DRILLING DAYS NOTED ARE ACTUAL DRILL DAYS. 
WHC-SD-EN-TRP-007, Rev. 0

\subsection{PERFORMANCE DATA AND EVALUATION}

\subsection{OBJECTIVES EVALUATION}

In this section, objectives are evaluated using the measures of success 1isted in Section 3.2. Not all objectives were addressed during this phase of testing. The Phase II CRADA report will discuss objectives not discussed in this report.

\subsubsection{ResonantSonic Drill Head Performance}

The $300 \mathrm{hp}$ ResonantSonic drill rig and head were generally reliable throughout the Phase I testing period from July 1993 to December 1993. A total of $274 \mathrm{~m}(900 \mathrm{ft})$ were drilled with the ResonantSonic rig at the DTTS and the Carbon Tetrachloride ERA Site (see Table 2). Two seal replacements were required in the drill head; however, these were replaced during routine preventive maintenance checks and did not cause downtime during the job. During FY 1991-1992 drilling and testing, head failures, air springs and bearings were a frequent source of failure and downtime.

Table 2. ResonantSonic Borehole Summary.

\begin{tabular}{|c|c|c|c|c|c|c|c|c|c|}
\hline \multirow{2}{*}{ Area } & \multirow{2}{*}{$\begin{array}{l}\text { Borehole } \\
\text { number }\end{array}$} & \multirow{2}{*}{$\begin{array}{l}\text { Well } \\
\text { type }\end{array}$} & \multicolumn{2}{|c|}{ Casing size } & \multirow{2}{*}{$\begin{array}{l}\text { Depth } \\
\text { (feet) }\end{array}$} & \multirow{2}{*}{$\begin{array}{l}\text { Drilling } \\
\text { days** }\end{array}$} & \multirow{2}{*}{ Ft/Day } & \multirow{2}{*}{$\begin{array}{c}\text { Completion/ } \\
\text { abandonment } \\
\text { days }\end{array}$} & \multirow{2}{*}{$\begin{array}{l}\text { Completion/ } \\
\text { abandonment } \\
\text { ft/day }\end{array}$} \\
\hline & & & $\begin{array}{c}\text { Core } \\
\text { barrel }\end{array}$ & Casing & & & & & \\
\hline DTTS & DTTS-S-01V & VERTICAL & $51 / 2^{\prime \prime}$ & $65 / 8^{\prime \prime}$ & 97 & 5 & 19.4 & $A \cdot 1$ & 97 \\
\hline DTTS & DTTS-S-02A & ANGLE & $41 / 2^{\prime \prime}$ & $65 / 8^{\prime \prime}$ & 165 & 6 & 27.5 & $A-1$ & 165 \\
\hline DTTS & DTTS-S-03A & ANGLE & $41 / 2 "$ & $65 / 8^{\prime \prime}$ & 73 & 2 & 36.5 & $A-1$ & 73 \\
\hline DTTS & DTTS-S-04A & ANGLE & $41 / 2^{\prime \prime}$ & $65 / 8 "$ & 170 & 6 & 28.3 & $A-1$ & 170 \\
\hline DTTS & DTTS-S-O5A & ANGLE & $41 / 2^{\prime \prime}$ & $65 / 8 "$ & 30.4 & 1 & 30.4 & $A-1$ & 30.4 \\
\hline $200 W$ & $\begin{array}{c}299-W 15- \\
223\end{array}$ & ANGLE & $41 / 2 "$ & $65 / 8^{\prime \prime}$ & 168 & 8 & 24.0 & $C-1$ & 168 \\
\hline $200 \mathrm{~W}$ & DW-1 & VERTICAL & $7^{\prime \prime}$ & $85 / 8 "$ & 200 & 8 & 25.0 & A-1 & 200 \\
\hline
\end{tabular}

-DOWNTIME INCLUDED

During the month of November, the rig was tested with 22-cm (8 5/8-in.) drill pipe at the DTTS to a depth of $61 \mathrm{~m}(200 \mathrm{ft})$. The rig was successfully used to install and remove the $22-\mathrm{cm}(85 / 8-i n$.$) casing. However, shortly$ after completing the borehole, failures occurred in the main hydraulic system that resulted in two days of downtime. It was surmised that the overheating of the main hydraulic oil and/or heat or cold of the main head oil contributed to component failures in the head. 
Following the hydraulic system repairs, a bearing in the transmission failed, causing 1.5 days of downtime. After this failure, WDC demobilized the rig to its Woodland, California, headquarters to perform an inspection and overhaul of the drill rig.

To prevent further failures of the head, a dynamic hydraulic preload was performed on the main bearing system to prevent and/or detect failure. A diagnostic sensing system was added to monitor the performance of the hydraulic system and provide early detection of potential problems. An oil pre-heater was added to the hydraulic system to minimize cold weather impacts, and circumvent running the head until the hydraulic oil temperature had reached the operating range.

Interlocks were installed to shutdown the drill system to minimize damage to components. Low pressure sensors were installed for oil temperature and pressure, air pressure in the air spring housing, and pre-load pressure on the main bearing system. High temperature shut downs were also added for the main engine and hydraulic system. Detection lights will indicate the problem circuit.

Finally, various lubrication ports in the hydraulic system were added. Also being investigated are backup and tertiary lubrication systems.

\subsubsection{Angle Drilling Capabilities}

To demonstrate angle drilling capability, a 7.6-cm- (3-in.-) diameter vapor extraction well (299-W15-223) was drilled and completed to support the carbon tetrachloride ERA site. Using the $300 \mathrm{hp}$ ResonantSonic drill, the 45 degree angle well was begun September 16, 1993 and drilled to a length of $51.3 \mathrm{~m}$ (168.24 ft) in less than eight working days. The average drill rate was $7.3 \mathrm{~m} /$ day $(24 \mathrm{ft} /$ day). In one working day, the $7.6-\mathrm{cm}(3-\mathrm{in}$.) stainless steel screen was installed and the well was completed. Downtime related to equipment and pipe failures was minimal. Table 3 summarizes various drilling activities for well 299-W15-223.

Comparisons were made between this test hole and well 299-W15-217, an adjacent vertical well drilled using the cable tool method. This well required 15 working days to dril1 $37.4 \mathrm{~m}(123 \mathrm{ft})$ and five working days for completion.

Vapor extraction of carbon tetrachloride was conducted on the 45 degree angle well. The well yielded satisfactory flow rates as compared to an adjacent cable tool well. Consequently, the installation of the well met ERA needs for vapor extraction.

\subsubsection{Instrument Development and Installation}

Instrumentation for the 300 hp ResonantSonic drill head is currently being developed. This instrumentation will be field tested during the Phase II portion of testing. Testing will consist of recording selected drill rig and drilling performance parameters, assisting in drill pipe design, and assessing the feasibility and need for a control module for remote rig 
Table 3. ResonantSonic 45 Degree Vapor Extraction We11 \#299-W15-223.

\begin{tabular}{|c|c|c|c|c|c|c|c|c|c|c|c|c|}
\hline Date & $\begin{array}{l}\text { Start } \\
\text { depth }\end{array}$ & $\begin{array}{l}\text { End } \\
\text { depth }\end{array}$ & $\begin{array}{l}\text { Total } \\
\text { depth } \\
\text { (per } \\
\text { day) }\end{array}$ & $\begin{array}{l}\text { Total } \\
\text { time } \\
\text { (hr) }\end{array}$ & $\begin{array}{l}\text { Drill } \\
\text { time } \\
\text { (hr) }\end{array}$ & $\begin{array}{l}\text { Average } \\
\text { trip } \\
\text { time in } \\
(m i n)\end{array}$ & $\begin{array}{c}\text { Average } \\
\text { trip } \\
\text { time } \\
\text { out } \\
\text { (min) }\end{array}$ & $\begin{array}{c}\text { Sample } \\
\text { time } \\
(\mathbf{h r})^{*}\end{array}$ & $\begin{array}{l}\text { Down } \\
\text { time } \\
\text { (hr) }\end{array}$ & $\begin{array}{c}\text { Drill } \\
\text { average } \\
\text { (ft/hr) }\end{array}$ & $\begin{array}{l}\text { Total } \\
\text { average } \\
\text { (ft/hr) }\end{array}$ & Comments \\
\hline $9 / 16 / 93$ & 0 & 40.92 & 40.92 & 6.73 & 4.37 & $\begin{array}{l}\text { NO } \\
\text { DATA }\end{array}$ & $\begin{array}{l}\text { NO } \\
\text { DATA }\end{array}$ & 1.23 & 1.13 & 9.36 & 6.08 & NONE \\
\hline 9/17/93 & 40.92 & 79.45 & 38.53 & 7.00 & 4.50 & 5.17 & 9.42 & .50 & 2.00 & 8.56 & 5.50 & PIPE FRACTURE \\
\hline $9 / 18 / 93$ & 79.45 & 109.18 & 29.73 & 7.03 & 5.11 & 7.78 & 11.96 & 1.00 & 0.92 & 5.82 & 4.23 & RADIATOR OVERHEATED \\
\hline 9/20/93 & 109.18 & 129.85 & 20.67 & 8.50 & 5.18 & 8.82 & 13.53 & 2.12 & 1.20 & 4.00 & 2.43 & SEAMIST ${ }^{2}$ \\
\hline $9 / 21 / 93$ & 129.85 & 139.47 & 9.62 & 7.75 & 4.75 & 10.98 & 13.43 & 1.38 & 1.62 & 2.00 & 1.24 & 6" LEXAN SECTIONS, SEAMIST \\
\hline $9 / 22 / 93$ & 139.47 & 149.22 & 9.75 & 8.42 & 3.90 & 10.70 & 15.38 & 1.85 & 2.67 & 2.50 & 1.16 & REPAIRS-BREAKOUT WRENCH WELDED \\
\hline $9 / 23 / 93$ & 149.22 & 168.24 & 19.02 & 7.23 & 4.05 & 13.27 & 15.72 & 3.18 & $\cdots$ & 4.70 & 2.63 & PIPE FRACTURE \\
\hline $9 / 27 / 93$ & 168.24 & 168.24 & N/A & 2.83 & 2.83 & 13.5 & 21.5 & N/A & $\cdots$ & $\cdots$ & $\cdots$ & $\begin{array}{l}\text { DRIVE CASING } \\
\text { TO TOTAL DEPTH }\end{array}$ \\
\hline
\end{tabular}

Average feet/day $=24.03$.

- Sample time includes down time for split spoon, drive barrel and SEAMIST sampling.

- Drill average $\mathrm{ft} / \mathrm{hr}=($ total depth/dy)/drill time.

- Total average $\mathrm{ft} / \mathrm{hr}=($ total depth/dy)/(down time + sample time + drill hrs $)$

${ }^{2}$ Science \& Engineering Associates Membrane Instrumentation and Sampling Technique (SEAMIST) is a registered trademark of Science \& Engineering Associates, Inc., Santa Fe, New Mexico. 
operations in high-level waste sites. Instrumentation of the rig will also decrease the amount of operator experience required. This, in turn, will aid in future technology transfer because of the greater availability of manpower.

\subsubsection{Correlation Between Drilling Measurement and Geology}

Once the $300 \mathrm{hp}$ ResonantSonic drill rig is instrumented, a study will be conducted to equate various drilling measurements to specific geology encountered. This is important because without an accurate measurement system, varying geologic conditions can create a wide range of dynamic conditions within the drill string possibly leading to failure.

\subsubsection{Sampling Equipment and Methods}

Various types of sampling equipment and methods were tested during the FY 93 deployment of the ResonantSonic drilling system. Most methods were tried in both the vertical and angle drilling modes. No method was exclusively beneficial to one drilling mode (vertical or angle). It should be noted that the split tube samplers and core barrel liner sampling methods can be used on hazardous waste sites and would be considered acceptable in many mixed and radioactive waste sites. The core tray method however should only be used on non-hazardous, non-radioactive sites.

5.1.5.1 Core Tray. Initial sampling used the 11.4-cm (4 1/2-in.) oD drill pipe. After the pipe was drilled to the desired depth, all but the last 3-m (10-ft) length of pipe was removed. The final (lowest) length remained attached to the drill rig. The drill head swiveled out to approximately $55^{\circ}$ from vertical. The drill bit was removed, and a core tray made of polyvinyl chloride (PVC) pipe $1.5 \mathrm{~m}(5 \mathrm{ft})$ long was slid over the drill pipe. The PVC pipe had been split lengthwise and covered with plastic tubing. The driller then gently added vibration to the pipe, and the soil came out the end of the drill pipe. As the soil came out, the core tray was pulled back until the length of the tray was filled. The same procedure was used with a second tray to contain the remaining soil. This method worked well for lithologic characterization purposes.

5.1.5.2 Split Tube Samplers. A $1.5-\mathrm{m}$ (5-ft-) 1ong, 14-cm (4.5-in.) OD split tube sampler fabricated by WDC was tested at DTTS test borings. The sampler was constructed of $0.63-\mathrm{cm}(0.25-\mathrm{in}$.$) carbon steel tubing and had tapered$ threads on each end. Initially after driving the sampler, the casing was overreamed to the bottom of the borehole. After the sampler was removed, it was discovered that threads on both ends were galled and the sampler was ruined. Further testing where the sampler was removed before overreaming proved successfut.

A special crossover connection was used to test the standard Hanford split tube sampler with the ResonantSonic drill. The Hanford split tube sampler is a $0.6-\mathrm{m}-(2-\mathrm{ft}-)$ long, $13-\mathrm{cm}$ (5-in.) 00 sampler constructed of $1.3-\mathrm{cm}(0.5-i n$.$) carbon steel tubing with flat threads on each end. The$ Hanford split tube sampler was used successfully at every site where the ResonantSonic drill was used. On the Hanford sampler, two thread gallings occurred. 
Special extended length split tube samplers were fabricated for the Hanford sampler to obtain a sample farther away from the heated soil at the end of the drive casing. Samplers in 0.9- and 1.2-m (3- and 4-ft) lengths were successfully used. Extended length samplers were also made by coupling together two $0.6-\mathrm{m}(2-\mathrm{ft})$ samplers or a $0.6-\mathrm{m}(2-\mathrm{ft})$ and a $0.3-\mathrm{m}(1-\mathrm{ft})$ sampler to create $0.9-$ and $1.2-\mathrm{m}(3-$ and $4-\mathrm{ft})$ samplers. Even though longer splits were heavier the additional effort required to handle them was offset and eased by the greater distance apart handlers could work. Breakdown times for the extended length samplers were comparable to the $0.6-\mathrm{m}(2-\mathrm{ft})$ samplers in all cases except when 2-ft and 1-ft splits were combined to make a $0.9-\mathrm{m}$ $(3-\mathrm{ft})$ split. In this case, problems were encountered breaking out the connector or sleeve.

5.1.5.3 Core Barrel Liner Sampling. An alternative to the core tray recovery method was successfully used at borehole 299-w15-223. A 3-m- (10-ft-) long, $0.6-\mathrm{cm}(0.25-\mathrm{in}$.$) liner of polycarbonate was used to line the lowest length of$ drill pipe (core barrel). After the lowest length of drill pipe was retrieved and the bit was removed, the $3-\mathrm{m}(10-\mathrm{ft})$ liner was removed. The $3-\mathrm{m}(10-\mathrm{ft})$ liner was placed on horizontal pipe racks and capped, and intervals were marked. The advantage of this method was a continuous core of in situ soil with little disturbance. This core could then be sub-sampled for various analyses. For collection of soil vapor analysis samples, a portable drill was used to drill a small hole in the liner to create access for sampling with a hand held photo-ionization detector (PID) or for collecting syringe samples analyzed by a mobile lab gas chromatograph. Soil samples were collected for field screening analys is from the 3-m (10-ft) liners by drilling a 1-in.diameter hole in the liner and inserting a hand corer to retrieve a small sample.

One problem associated with handling the 3-m (10-ft) polycarbonate liners was the occasional deformation of the liner where it nested inside the drill bit, which created problems in removing the bit from the liner. Another problem involved collecting intact core samples by cutting the $3-\mathrm{m}(10-\mathrm{ft})$ liner into smaller sections. A standard $61-\mathrm{cm}(24-$ in.) circular pipe cutter was used to cut the liner. The cutter blade was designed for metal pipe, and therefore did not penetrate the liner easily until considerable pressure was applied. This pressure deformed the liner and often disturbed the sample.

A current disadvantage of using the $3-m(10-f t)$ liners for chemical sampling were the limitations imposed by the amount of decontamination performed on the liner and core barrel. The 3-m (10-ft) liner and core barrel is capable of being decontaminated to a lower protocol decontamination (soap and water, steam cleaning) that is acceptable for physical properties samples and chemical samples that do not require stringent EPA protocols. Currently, ER activities at the Hanford Site do not have the capability for acid/base immersion or $100^{\circ} \mathrm{C}\left(212^{\circ} \mathrm{F}\right)$ drying for objects $3-\mathrm{m}(10 \mathrm{ft})$ long. These stringent decontamination procedures are currentiy required for most chemical analysis samples. Further investigation into developing equipment and/or methods to decontaminate the $3-\mathrm{m}$ (10 ft) liners is necessary.

Another disadvantage of using the $3-\mathrm{m}(10-\mathrm{ft})$ polycarbonate liners was fogging caused by soil moisture inside the liners. This made lithologic observations of the soil in the uncut liner difficult at times. A better method for lithologic observation was to cut the liner lengthwise with a 
portable circular saw. Excellent detail was available, including the observation of very small geologic features such as minor stratification within the formation. Use of the $3-\mathrm{m}(10-\mathrm{ft})$ liner allowed for more defined particle size distribution and sorting and more accurate measurement of contact depths. The filled liners were retained at the drill site on horizontal pipe racks in order of removal. Display of the liners in this manner created an excellent synoptic overview of the entire borehole lithology.

Core expansion is a problem associated with lithologic logging of the core barrel polycarbonate liners. The soil within the liner would often expand in volume [i.e., 3-m (10-ft) run may yield $3.6-\mathrm{m}$ (12 ft of core)]. It appeared this expansion was more prevalent at the top and bottom of the liner. Expansion was probably caused by uptake of borehole slough (top of liner) and the ResonantSonic oscillation (top and bottom of liner). Core expansion, however, was not consistent. Core runs which exhibited core expansion at the top and bottom were normalized. However, core runs which were largely disturbed by core expansion were difficult to $10 \mathrm{~g}$. At times, the entire run would be discarded.

During drilling for purely lithologic characterization purposes core recovery was more variable than during drilling at DTTS-S-04A and 299-W15-223. Geologists noted a thin coating of very fine silt on the outer surface of the soil core (inside the liner) causing soil to easily slide from the liner. The core appeared relatively intact. In some core runs what appeared to be drag folds were seen in the liners. The bedding was actually horizontal, and folding was caused by the drilling itself. Initial runs were 3-m (10 ft). When $1.5-m(5-\mathrm{ft})$ runs were instituted, the quality of soil in the liners improved. Compared to cable tool driliing, ResonantSonic drilling produced a much better quality of lithologic characterization soil cores. Depending on the level of geologic detail required, and considering the increased costs involved, shorter runs [i.e., $1.5 \mathrm{~m}(5 \mathrm{ft})$ ] may be used to improve lithologic characterization.

Further study of factors such as lithology, penetration rates, amount of vibration, and rotation, should be studied in detail to improve the quality of the core runs.

5.1.5.4 Sample Temperatures Recorded. Extensive measurements of core sample temperatures were made at the DTTS and borehole 299-W15-223. Careful temperature measurement identified the location of the highest temperatures. This information, coupled with modifications to the drilling technique and special sampling methods, led to significant decreases in sample temperature. Initial sample temperatures routinely exceeded $38^{\circ} \mathrm{C}\left(100^{\circ} \mathrm{F}\right)$. After modifying the drilling technique and implementing special sampling methods, sample temperatures were greatly reduced. An example was borehole 299-W15-223, with an average sample temperature of $25.5^{\circ} \mathrm{C}\left(77.9^{\circ} \mathrm{F}\right)$. A detailed account of temperature measurements can be found in Appendix $A$ of this report.

5.1.5.5 Adequate Sample Temperatures. Many actions were taken to maintain samples collected for $V O C$ analysis at an acceptable temperature. Actions included modifying drilling techniques, using extended length split tube samplers, lining samplers with material having a low thermal conductivity, and 
WHC-SD-EN-TRP-007, Rev. 0

pre-chilling the samplers with dry ice in special coolers. Specific methods used to lower sample temperatures are described in Appendix $A$ of this report.

5.1.5.6 Crew Size. Because of the rapid penetration rate of the ResonantSonic dri11, the sampling crew needed at least two personnel for extensive chemical sampling. Generally, the typical crew size for hazardous waste investigation included: a field team leader, a geologist, a site safety officer, a sampling scientist, and two sampling technicians.

\subsubsection{Manford Safety Standards}

Applicable safety standards were the Occupational Safety and Health Act (OSHA) 1910 General Industry Standards as well as other industry standards required by DOE Order 5480.4. Contractor personnel adhered to their corporate safety program in addition to Hanford standards.

Because some of the work involved drilling on a hazardous waste site in the 200 West Area, WHC developed a site-specific Health and Safety Plan. This was in accordance with Code of Federal Regulations (CFR) 1910.120 for hazardous waste site investigations. The site-specific safety plan addressed expected contaminants, possible health risks, monitoring strategies and actions required when contaminants were encountered. This plan also addressed general safety hazards common to working around drilling equipment. The sitespecific safety plan coupled with the contractors safety program and procedures provided adequate safety and health controls during drilling.

Compliance with health and safety standards was a part of regular daily operations. For example, drilling equipment and associated tools were inspected, compressed gases and flammable liquids were handled and stored properly, proper lifting technique was emphasized, and proper hoisting and rigging equipment was used. Regular work site housekeeping was performed. Mandatory Level D personal protective equipment was used where required by the site-specific health and safety plan. Level D personal protective equipment consists of blue work coveralls, steel-toe work boots, hard hat, leather gloves, and safety glasses.

During the drilling demonstration, one contractor employee experienced an OSHA recordable injury. The drilling assistant lacerated his finger on a piece of drill casing. A wear spot on the outer end of the thread resulted in a sharp area, and the injury occurred while the casing was being rolled on the pipe racks. The employee was wearing leather gloves. The injury required three sutures to close the wound. No lost time resulted and the drilling assistant was able to continue his regular duties. No other injuries or incidents occurred during the ResonantSonic drilling demonstration.

The site safety officer regularly visited the site to evaluate compliance with safety requirements. Site safety officer coverage occurred part time on non-hazardous waste sites and full time at hazardous waste sites. These visits indicated that both angle and vertical drilling operations were carried out in compliance with the required safety standards. Drill pipe and casing were handled using a hydraulic arm. This reduced personnel exposure to potential pinching/crushing injuries. Some below-the-hook lifting devices 


$$
\text { HHC-SD-EN-TRP-007, Rev. } 0
$$

owned by the drilling contractor must be upgraded before being used at Hanford. Information was provided to the contractor to assist in meeting these requirements.

Monitoring for hazardous constituents at hazardous waste sites was carried out using chlorinated hydrocarbon detectors. Monitoring strategies were developed to primarily address and evaluate breathing zone readings and differentiate from borehole readings. This allowed work to continue even when chlorinated hydrocarbons were detected in the borehole. The instruments used could detect lower chlorinated hydrocarbon concentrations than those normally used in cable tool drilling at the Hanford Site. This significantly increased productivity because no work was performed in level B (supplied air) protection.

Noise surveys were also conducted to establish hearing protection levels and boundaries. While the ResonantSonic was drilling, hearing protection was required for personnel within $24 \mathrm{~m}(80 \mathrm{ft})$ of the rig. The ResonantSonic time weighted average for noise levels ranged from 86 to 92 decibels. In comparison, the time weighted averaged for a cable tool ranges from 84 to 92 decibels.

There are no apparent safety or health issues that would prevent ResonantSonic drilling activities from complying with Hanford health and safety standards and applicable federal regulations.

\subsubsection{Contamination Control and Maste Minimization}

Using the ResonantSonic drilling method, the amount of waste generated at a well site can be minimized because no circulating media is required. Waste may also be minimized by reaming the casing over the core barrel. During drilling, the ResonantSonic drill commonly advances a core run to a depth of $3 \mathrm{~m}(10 \mathrm{ft})$ past the bottom of the casing. The casing is then advanced by the reaming process and then the core is removed. This pushes the excess material back into the formation which leaves only a $8.9-\mathrm{cm}(31 / 2-\mathrm{in}$.$) diameter core$ of material. However in some instances, the core is advanced and removed prior to reaming the casing.

During the drilling of the 45 degree angle vapor extraction well, minimal secondary drilling waste contaminated with carbon tetrachloride was generated: a total of one 208-liters plus 19-1iters (55-galions drum plus 5 galions) in a second drum. Waste containment with the ResonantSonic was excellent. A continuous core taken from the top to the bottom of the hole and was contained in the 8.9-cm (3.5-in.) OD $\times 3-\mathrm{m}(10-\mathrm{ft})-1$ ong polycarbonate liners. Unwanted contaminated soil was vibrated out of the core barrel into a drum. In comparison, an adjacent cable tool well 299-W15-217, generated six drums of waste soil.

Five 208-L (55-gal) drums of rinsate water were collected from decontaminating the ResonantSonic casing, core barrels, and equipment. The rinsate was first collected in a decontamination trough and then pumped into drums. This volume can be decreased by reducing the amount of steam cleaning and by washing some of the equipment by hand. In comparison, well 299-W15-217 generated one drum of rinsate fluid. 
The ResonantSonic could be used in vadose zone characterization borings because of its ability to fully contain the material and minimize the waste during the drilling of a borehole.

\subsubsection{WAC 173-160 Compliance}

A standard Hanford groundwater monitoring well has stainless steel permanent casing and screen installed before removal of the temporary steel drill pipe. The permanent casing and screen are lowered inside the drill pipe and are seated on the bottom of the well. As the drill pipe is removed, the bottom screened interval is surrounded by a filter pack. Then an annular seal (such as bentonite clay) is placed between the permanent casing and the formation to prevent downward migration of contaminants along the annulus of the well (Volk 1993).

The vapor extraction well was completed in accordance with WAC 173-160. All boreholes were abandoned according to WAC. In addition to the WACs, the following WHC specifications were also adhered to: Generic Well Specifications-Groundwater Monitoring Wells, (Reynolds 1993), and Specifications for Drilling Geotechnical Test Borings (Ledgerwood 1993).

In order to comply with WAC 173-160, two issues had to be resolved. The first issue involved meeting the $7.6 \mathrm{-cm}$ (3-in.) completion requirement while using the $16.8-\mathrm{cm}(65 / 8-i n$.$) diameter casing. To accomplish this, a 17.8-\mathrm{cm}$ (7-in.) OD casing bit (drive shoe) was manufactured. This allowed for the required $5.0-\mathrm{cm}(2-\mathrm{in}$.$) annular seal.$

The other issue involved drilling with a larger diameter casing so that a $10.2-\mathrm{cm}(4-\mathrm{in}$.$) well completions could be installed. This was solved when$ WDC manufactured an 22-cm (8 5/8-in.) OD casing.

\subsubsection{Quality Soil Samples}

A major objective during the testing of the ResonantSonic system in FY 1993 was the modification of drilling techniques to minimize soil disturbance during sampling and coring. At the DTTS, the WDC drilling team was introduced to typical Hanford Site formations; various boreholes were drilled, both vertical and angle. To minimize soil disturbance, resonant frequencies and drill string rotations were reduced during split spoon and core barrel sampling of various lithologies. Information was relayed between the samplers and the driller on sample quality and on potential actions (changes in frequency and rotation) to improve sample quality based on current lithology. After testing was complete, the rig was moved to the 200 West Area Carbon Tetrachloride ERA site to implement the drilling modifications on angle wellbore 299-W15-223.

Observations made during the ResonantSonic drilling and sampling of wellbore 299-W15-223 indicated that soil disturbance seemed comparable to samples taken using cable tool methods. The first sample viewed was a $3-m$ $(10-\mathrm{ft})$ coring in the polycarbonate 1 iner, and although the cable tool does not have this coring capability, observations of this coring aided in analyzing normal $0.6-\mathrm{m}(2-\mathrm{ft})$ split spoon samples. 
The initial observation of this core, made through the liner, revealed some stratification of soils resulting from vibration and rotation. However, when the temperature probes were inserted into the core ends the soils proved to be compact and undisturbed. In other liners displaying the stratification, holes were cut into the liner allowing volatile organic analysis (VOA) samples to be taken using a hand core. Hand coring the sample revealed an extremely thin loose layer of soil followed by very compact, tight soil consistent with the core ends where the temperature probes were being placed.

Two conditions noticed in FY 1991-1992 sonic drilling samples were not found in these samples: concentric stratifications and looseness of soils. All of the hand cores taken from the $0.6 \mathrm{~m}(2-\mathrm{ft})$ splits were compact and tight according to their lithology. Later sampling employed $0.9-$ and $1.2-\mathrm{m}$ (3- and 4-ft) split spoons using polycarbonate liners, which allowed side viewing of the samples. Again, slight stratification was visible on the outer edges although inner soils appeared tight and consistent with soils sampled using the cable tool method.

Visual monitoring indicated that the new drilling techniques greatly reduced disturbance to soil during sampling and coring.

\subsubsection{Cost Effectiveness}

During this phase of testing, there were no side-by-side cost comparisons conducted between the baseline and ResonantSonic method. The primary focus of this initial phase of testing was to improve the performance and reliability of various components in the ResonantSonic drilling system including the drill head, drill pipe, drill bits, and sampling tools. During the Phase II portion of testing, a cost comparison between cable tool and the ResonantSonic will be conducted.

\subsubsection{Soil Vibration Test}

In this Phase II test, extensometers and accelerometers will be installed in a preselected radial array. A ResonantSonic drilled hole will be installed in the center of the array. Measurements recorded will help determine the distance and intensity of resonant energy transfer to the surrounding soils and the potential impact to surrounding structures.

\subsubsection{Multi-Screened Four-Inch Vapor Extraction We11}

The installation of a multi-screened 10.2-cm (4-in.) vapor extraction well was not performed. ERA personnel determined installing another vertical vapor extraction well was unnecessary. However with the development of the $22-\mathrm{cm}$ (8 5/8-in.) casing, the ResonantSonic has the potential to do a $10.2 \mathrm{~cm}$ (4 in.) completion. 


\subsubsection{ResonantSonic Drill Pipe Analysis}

During Phase I testing, a wide variety of drill pipe and casing materials were tested to decrease the probability of failure. Various diameters, wall thicknesses, thread configurations, and material strengths were involved. In addition, field tests were performed comparing non-welded (1 piece) drill pipe with composite mid-body ( 3 piece).

However, pipe failures continued to occur while using the ResonantSonic drilling method (Table 4). In an attempt to decrease the probability of failure, two laboratory tests were conducted by Pacific Northwest Laboratory.

This first feasibility test involved using eddy currents to detect abnormal electric or magnetic features in the threaded fastener region, where pipe failure occurs most often. The results of this study showed that eddy currents could be used to detect cracking beneath a threaded surface. A more comprehensive overview of this test can be found in Appendix B.

The second test, failure analysis of ResonantSonic drill pipe, was conducted to evaluate the stresses responsible for failure in the drill pipe. The crack orientation and fracture surfaces were examined in an attempt to evaluate the stress state in the failed joint and to determine the approximate stress intensity by measuring the spacing of fatigue striations. Analysis of the pipe failures determined that there was a distinct difference in pipe that was threaded directly and in pipe that utilized threaded tool pieces. However, further analys is of the drill pipe is necessary before any conclusive statements can be made. Results of this test can be found in Appendix $C$.

In a separate field test, a wet magnetic particle inspection of the various drill strings were conducted on two separate occasions. The results of these tests can be found in Table 5. It should be noted that the 11.4-cm (4 1/2-in.) was used to dril1 more than $4570 \mathrm{~m}(15,000 \mathrm{ft})$ before its use on the Hanford Site. The 16.8-cm (6 5/8-in.) and 22-cm ( $85 / 8-i n$.$) casings were$ new1y manufactured. 
WHC-SD-EN-TRP-007, Rev. 0

Table 4. ResonantSonic Drill Pipe Fractures.

\begin{tabular}{|c|c|c|c|}
\hline Well number & $\begin{array}{l}\text { Core barrel (CB)/ } \\
\text { casing (C) size }\end{array}$ & Feet drilled & Fracture interval/point \\
\hline \multirow[t]{3}{*}{ DTTS-S-01V } & $51 / 2^{\prime \prime} \mathrm{CB}$ & $50 \mathrm{FT}$ & N/A \\
\hline & $41 / 2^{n} \mathrm{CB}$ & 47 & N/A \\
\hline & $65 / 8^{n} \mathrm{C}$ & 97 & N/A \\
\hline \multirow[t]{2}{*}{ DTTS-S-02A } & $41 / 2^{\prime \prime} \mathrm{CB}$ & 165 & $60-80 \mathrm{FT}$ \\
\hline & $65 / 8^{\prime \prime} \mathrm{C}$ & 165 & N/A \\
\hline \multirow[t]{2}{*}{ DTTS-S-03A } & $41 / 2^{\prime \prime} \mathrm{CB}$ & 73 & $N / A$ \\
\hline & $65 / 8^{\prime \prime} \mathrm{CB}$ & 73 & $N / A$ \\
\hline \multirow[t]{3}{*}{ DTTS-S-04A } & \multirow[t]{2}{*}{$41 / 2^{\prime \prime} \mathrm{CB}$} & \multirow[t]{2}{*}{170} & $0-20 \mathrm{FT}$ \\
\hline & & & $20-48 \mathrm{FT}$ \\
\hline & $65 / 8^{\prime \prime} \mathrm{CB}$ & 170 & N/A \\
\hline \multirow[t]{2}{*}{ DTTS-S-05A } & $41 / 2 " \mathrm{CB}$ & 30.4 & N/A \\
\hline & $65 / 8^{n} \mathrm{C}$ & 30.4 & N/A \\
\hline \multirow[t]{2}{*}{$\begin{array}{l}\text { WET MAGNETIC } \\
\text { PARTICLE INSPECTION } \\
\text { RESULTS 09/09/93: }\end{array}$} & $\begin{array}{l}4141 / 2 " \text { CB JOINTS } \\
\text { INSPECTED }\end{array}$ & $\begin{array}{l}37 \text { NON- } \\
\text { DEFECTIVE } \\
4 \text { CRACKED }\end{array}$ & SEE TABLE 5 \\
\hline & $\begin{array}{l}2065 / 8 \text { " C JOINTS } \\
\text { INSPECTED }\end{array}$ & $\begin{array}{l}15 \text { NON- } \\
\text { DEFECTIVE } \\
5 \text { CRACKED }\end{array}$ & \\
\hline \multirow[t]{3}{*}{$299-W 15-223$} & \multirow[t]{2}{*}{$41 / 2^{\prime \prime} \mathrm{CB}$} & \multirow[t]{2}{*}{$168 \mathrm{FT}$} & $79.46 \mathrm{FT}$ \\
\hline & & & $157 \mathrm{FT}$ \\
\hline & $65 / 8^{\prime \prime} \mathrm{C}$ & $168 \mathrm{FT}$ & N/A \\
\hline \multirow[t]{8}{*}{$\mathrm{DW}-1$} & \multirow[t]{7}{*}{$41 / 2^{\prime \prime} \mathrm{CB}$} & \multirow[t]{7}{*}{$200 \mathrm{FT}$} & $60 \mathrm{FT}$ \\
\hline & & & $110 \mathrm{FT}$ \\
\hline & & & $120 \mathrm{FT}$ \\
\hline & & & $140 \mathrm{FT}$ \\
\hline & & & $140 \mathrm{FT}$ \\
\hline & & & $150 \mathrm{FT}$ \\
\hline & & & $155 \mathrm{FT}$ \\
\hline & $85 / 8 " \mathrm{C}$ & $200 \mathrm{FT}$ & $\begin{array}{l}70 \mathrm{FT} \text { WHILE BACKPULLING } \\
\text { CASING (BOTTOM OF } \\
\text { CASING AT } 170 \mathrm{FT} \text { ) }\end{array}$ \\
\hline $\begin{array}{l}\text { WET MAGNETIC } \\
\text { PARTICLE } \\
\text { INSPECTION } \\
\text { RESULTS } 11 / 19 / 93 \text { : }\end{array}$ & $85 / 8^{\prime \prime} \mathrm{C}$ & \multicolumn{2}{|c|}{$\begin{array}{l}20 \text { LENGTHS } 10^{\prime} \text { LONG INSPECTED } \\
\text { 11 NON-DEFECTIVE } \\
9 \text { CRACKED }\end{array}$} \\
\hline
\end{tabular}


Table 5. Wet Magnetic Particle Inspection Summary.

\begin{tabular}{|c|c|c|c|c|c|}
\hline $\begin{array}{l}\text { Date of } \\
\text { inspection }\end{array}$ & $\begin{array}{l}\text { Pipe size } \\
\text { (inchies) }\end{array}$ & $\begin{array}{l}\text { Pipe } \\
\text { length }\end{array}$ & $\begin{array}{l}\text { Number of pipes } \\
\text { inspected }\end{array}$ & $\begin{array}{c}\text { Number of } \\
\text { defective pipes }\end{array}$ & Defect description \\
\hline \multirow[t]{4}{*}{$09 / 09 / 93$} & \multirow{4}{*}{$\begin{array}{l}41 / 2 " 1 \text { OD } \\
\text { CORE BARREL }\end{array}$} & \multirow[t]{4}{*}{$10 \mathrm{FT}$} & \multirow[t]{4}{*}{41} & \multirow[t]{4}{*}{4} & 1 - CRACKED PIN \\
\hline & & & & & 2 - CRACKED BOXES \\
\hline & & & & & 1 - CRACKED PIN AND BOX \\
\hline & & & & & NOTE: ALL 4 ABOVE CRACKS FOUND IN WELD AREAS \\
\hline \multirow[t]{3}{*}{$09 / 09 / 93$} & \multirow[t]{3}{*}{$65 / 8 "$ OD CASING } & \multirow[t]{3}{*}{$10 \mathrm{FT}$} & \multirow[t]{3}{*}{20} & \multirow[t]{3}{*}{5} & 3 - CRACKED IN PIN THREADS \\
\hline & & & & & 1 - GALLED PIN THREADS \\
\hline & & & & & 1 - GALLED BOX THREADS \\
\hline $11 / 19 / 93$ & $\begin{array}{l}65 / 8 " 110 D \\
\text { CASING }\end{array}$ & $10 \mathrm{FT}$ & 15 & 0 & $\overline{N / A}$ \\
\hline $11 / 19 / 93$ & $\begin{array}{l}65 / 811 \text { OD } \\
\text { CASING }\end{array}$ & $5 \mathrm{FT}$ & 12 & 0 & N/A \\
\hline $11 / 19 / 93$ & $\begin{array}{c}71 \prime \text { OD } \\
\text { CORE BARREL }\end{array}$ & $10 \mathrm{FT}$ & 3 & 1 & 1 - CRACKED PIN \\
\hline $11 / 19 / 93$ & $\begin{array}{c}\text { 7" OD } \\
\text { CORE BARREL }\end{array}$ & $5 \mathrm{FT}$ & 1 & 0 & N/A \\
\hline \multirow[t]{2}{*}{$11 / 19 / 93$} & \multirow{2}{*}{$\begin{array}{l}41 / 2 " 1 \text { OD } \\
\text { CORE BARREL }\end{array}$} & \multirow[t]{2}{*}{$10 \mathrm{FT}$} & \multirow[t]{2}{*}{16} & \multirow[t]{2}{*}{5} & 4 - CRACKED PIN \\
\hline & & & & & 1 - CRACKED $80 \mathrm{X}$ \\
\hline $11 / 19 / 93$ & $\begin{array}{l}41 / 2 " 1 \text { OD } \\
\text { CORE BARREL }\end{array}$ & $5 \mathrm{FT}$ & 2 & 0 & N/A \\
\hline $11 / 19 / 93$ & 7 MISC. SUBS & $\ldots \ldots \ldots$ & 7 & 0 & N/A \\
\hline $11 / 19 / 93$ & $\begin{array}{l}8 \text { 5/8" OD } \\
\text { CASING }\end{array}$ & $5 \mathrm{FT}$ & 1 & 0 & $N / A$ \\
\hline \multirow[t]{3}{*}{$11 / 19 / 93$} & \multirow{3}{*}{$\begin{array}{l}85 / 8 " \text { OD } \\
\text { CASING }\end{array}$} & \multirow[t]{3}{*}{$10 \mathrm{FT}$} & \multirow[t]{3}{*}{20} & \multirow[t]{3}{*}{9} & 4 - CRACKED PINS \\
\hline & & & & & 2 - CRACKED PINS AND BOXES \\
\hline & & & & & 3 - CRACKED BOX \\
\hline $11 / 19 / 93$ & $\begin{array}{l}85 / 8 " \text { OD } \\
\text { SHOE }\end{array}$ & $\ldots \ldots \ldots$ & 1 & 0 & N/A \\
\hline
\end{tabular}




\subsection{CONCLUSIONS AND RECOMMENDATIONS}

To date, the ResonantSonic has drilled more than $274 \mathrm{~m}$ (900 ft) during Phase I testing. The ResonantSonic has exhibited the ability to drill both angle and vertical boreholes effectively in the Hanford soils. This method can also provide relatively undisturbed cores for geologic analysis.

The ResonantSonic drilling system, demonstrated the following advantages:

- Ability to penetrate Hanford semi-consolidated sands, gravels, and cobbles without the addition of circulating media into the borehole

- Ability to minimize cuttings generation and contain waste on hazardous waste sites

- Ability to install 7.6-cm (3-in.), 45 degree angle vapor extraction well at a fast rate $[7.3 \mathrm{~m} /$ day $(24 \mathrm{ft} /$ day $)]$

- Ability to obtain near in situ $3-\mathrm{m}(10-\mathrm{ft})$ core samples from the core barrel

- Decrease in well completion time

- Ability to collect soil samples at temperatures comparable to cable toot.

The primary limitations of the drilling system included:

- The potential heating of soil samples when precautions are not taken

- More operator experience required to run drill system

- Fewer ResonantSonic drill contractors exist than cable tool rig contractors

- Potential for pipe failure because of the damaging vibrational effect on the steel drill pipe.

Further testing and development of the ResonantSonic drill rig and associated components is recommended underneath the existing CRADA. 


\subsection{REFERENCES}

DOE, 1984, Environmental Protection, Safety, and Health Protection Standards, DOE Order 5480.4, U.S. Department of Energy, Washington, D.C.

McLellan, G. W., 1993, Test Plan for Sonic Drilling at the Hanford Site in FY 1993, WHC-SD-EN-TP-028, Rev. 0, Westinghouse Hanford Company, Richland, Washington.

Reynolds, K. D., 1992, Generic Well Specification - Groundwater Monitoring We $77 s$, WHC-S-014, Rev. 7, Westinghouse Hanford Company, Richland, Washington.

Rohay, V. J. and G. W. McLellan, 1992, Integrated Test P7an for Demonstration of a Sonic Drilling System and the SEAMIST System, WHC-SD-EN-AP-075, Rev. 0, Westinghouse Hanford Company, Richland, Washington.

Rohay, V. J., K. J. Swett, G. V. Last, D. C. Lanigan, and L. A. Doremus, 1993, FY 1993 Site Characterization Work Plan for the Volatile Organic Compounds - Arid Integrated Demonstration and the 200 West Area Carbon Tetrach7oride Expedited Response Action, WHC-SD-EN-AP-109, Rev. 1, Westinghouse Hanford Company, Richland, Washington.

Rohay, V. J. and R. J. Cameron, 1993, FY 1993 Wellfield Enhancement Workplan for the Carbon Tetrachloride Expedited Response Action, WHC-SD-EN-AP-114, Rev. 0, Westinghouse Hanford Company, Richland, Washington.

Spicer, T. W., 1993, Specifications for Drilling Geotechnical Test Borings, WHC-S-0105, Rev. 1, Westinghouse Hanford Company, Richland, Washington.

Volk, B. W., G.W. McLellan, and V. L. King, 1992, Results of Testing the Sonic Drilling System at the Hanford Site (September 1991 to May 1992), WHC-SD-EN-TRP-002, Rev. 0, Westinghouse Hanford Company, Richland, Washington.

WAC 173-160, "Minimum Standards for Construction and Maintenance of Wells," Washington Administrative Code, as amended.

29 CFR 1910, 1993, "Occupational Safety and Health Standards," Code of Federal Regulations, as amended.

29 CFR 1910.120, 1993, "Hazardous Waste Operations and Emergency Response," Code of Federal Regulations, as amended. 
WHC-SD-EN-TRP-007, Rev. 0

APPENDIX A

TEMPERATURE MEASUREMENTS OF SOIL SAMPLES

COLLECTED FOR ENVIRONMENTAL ANALYSIS

J. D. Fancher 
WHC-SD-EN-TRP-007, Rev. 0

This page intentionally left blank.

$A-i j$ 


\section{A1.0 INTRODUCTION}

Previous work at the U.S. Department of Energy (DOE) Hanford Site using the Sonic Drilling System indicated some soil core samples had excessive heat (Volk 1992). The high temperature recorded during this work was $47^{\circ} \mathrm{C}$ $\left(116^{\circ} \mathrm{F}\right)$. It was recognized that temperatures in this range could compromise the integrity of samples analyzed for volatile organic compounds (VOCS). Before fiscal year (FY) 1993 ResonantSonic drilling began, an investigation was planned that involved carefully measuring and recording the temperature of selected soil cores. The purpose was to both document the level of soil temperatures reached and, while employing slightly different drilling techniques and refinements to the sampling methods and equipment, chronicle the success of lowering sample temperatures. Collection of this sample temperature data partially fulfills requirements of the Integrated Test Plan for the Sonic. Drilling Method on the Hanford Site FY 1993 (McLellan 1993).

This document reports the results of soil sample temperature measurement. It also discusses the effects of excessive heat on samples, one of which is increased vapor pressure of liquids, which results in volatilization of volatile organic compounds. Although sample temperatures were measured from other drilling methods used at the Hanford Site, this investigation focused on samples taken during demonstration and testing of the ResonantSonic drilling method. Factors contributing to the successful reduction of sample temperatures are explained.

During 1992, temperatures of three soil samples were measured during sonic drilling using a pyrometer. The soil temperatures recorded were $35{ }^{\circ} \mathrm{C}$ $\left(95^{\circ} \mathrm{F}\right), 44^{\circ} \mathrm{C}\left(111^{\circ} \mathrm{F}\right)$, and $47^{\circ} \mathrm{C}\left(116^{\circ} \mathrm{F}\right)$. Also during 1992 , temperature-sensitive tape was used to record sampler temperatures from two split-spoon samples obtained using the cable-tool drilling method. Both of these samples recorded a maximum temperature of $43^{\circ} \mathrm{C}$ (110 ${ }^{\circ} \mathrm{F}$ ) (Volk 1992).

\section{A1.1 OPTIMUM SAMPLING TEMPERATURE}

Before field work for this project began, an attempt was made to locate literature related to sample collection temperatures. No references were found; only guidance for shipment and storage temperatures was found. Current regulatory guidance calls for shipment and storage at $4{ }^{\circ} \mathrm{C}\left(39^{\circ} \mathrm{F}\right)$. Recent publications suggest samples should be shipped and stored at temperatures well below zero, or, preferably, preserved with a solvent (Maskarinec et al. 1992 and Jenkins et a1. 1993). An ideal sample temperature may be one close to the in situ soil temperature.

\footnotetext{
${ }^{1}$ ResonantSonic is a Service Mark of the Water Development Corporation, Woodl and, California.
} 


\section{A2.0 SAMPLE TEMPERATURES AND VAPOR PRESSURE}

Vapor pressure is defined as the pressure exerted by a vapor in equilibrium with its solid or liquid phase. Volatile Organic Compounds having a high vapor pressure will volatilize more rapidly than VOCs having a lower vapor pressure. Carbon tetrachloride has a relatively high vapor pressure of $15.06 \mathrm{kPa}$ at $25^{\circ} \mathrm{C}\left(77^{\circ} \mathrm{F}\right)$ (Devitt 1987). The vapor pressure dependence with temperature is usually highly nonlinear (Thibodeaux 1979).

Antoine's equation is the empirical relationship between temperature and vapor pressure of liquids. Figure Al depicts increasing vapor pressure with increasing temperatures. Antoine's equation is based on using a pure product liquid in a closed system. Field studies at the 200 West Area Carbon Tetrachloride Expedited Response Action site indicate carbon tetrachloride is present in the vapor and liquid phases (Last and Rohay 1993). The liquid was disposed of in an aqueous makeup and is held by interfacial tension and capillary forces in residual concentration. The data used in calculating Antoine's equation (CRC 1993) is valid from -19 to $20^{\circ} \mathrm{C}\left(-2.2\right.$ to $\left.68^{\circ} \mathrm{F}\right)$.

It should be noted that vapor pressure is only one factor affecting the volatilization of VOCs from soil particles. Some of the other factors include the amount of time the sample is exposed to ambient air; whether the sample is immersed in a solvent as a preservative; concentration level of VOCs in the sample; moisture content of the sample; sample particle size; and sample total organic carbon content (Lewis 1991).

$$
\begin{aligned}
& \text { Antoine's Equation } \\
& \log _{p}=\frac{0.05223 * a}{T}+b
\end{aligned}
$$

Where

$$
\begin{aligned}
& p=\text { Pressure } \\
& a=\text { Constant (from CRC 1993) } \\
& b=\text { Constant (from CRC 1993) } \\
& T=\text { Absolute Temperature. }
\end{aligned}
$$

\section{A3.0 TEMPERATURE MEASUREMENT METHODS}

The soil temperature measurements were taken using portable electric thermometers such as the FLUKE $^{2} 52 \mathrm{~K} / \mathrm{J}$ thermometer using a Type $\mathrm{K}$ thermocouple probe. The thermocouple has an accuracy of $\pm-17^{\circ} \mathrm{C}\left( \pm 1.3{ }^{\circ} \mathrm{F}\right)$.

\footnotetext{
${ }^{2}$ FLUKE is a trademark of John Fluke Manufacturing Company, Inc., Everett, Washington.
} 
Figure Al. CC14 Vapor Pressure Variations with Temperature.

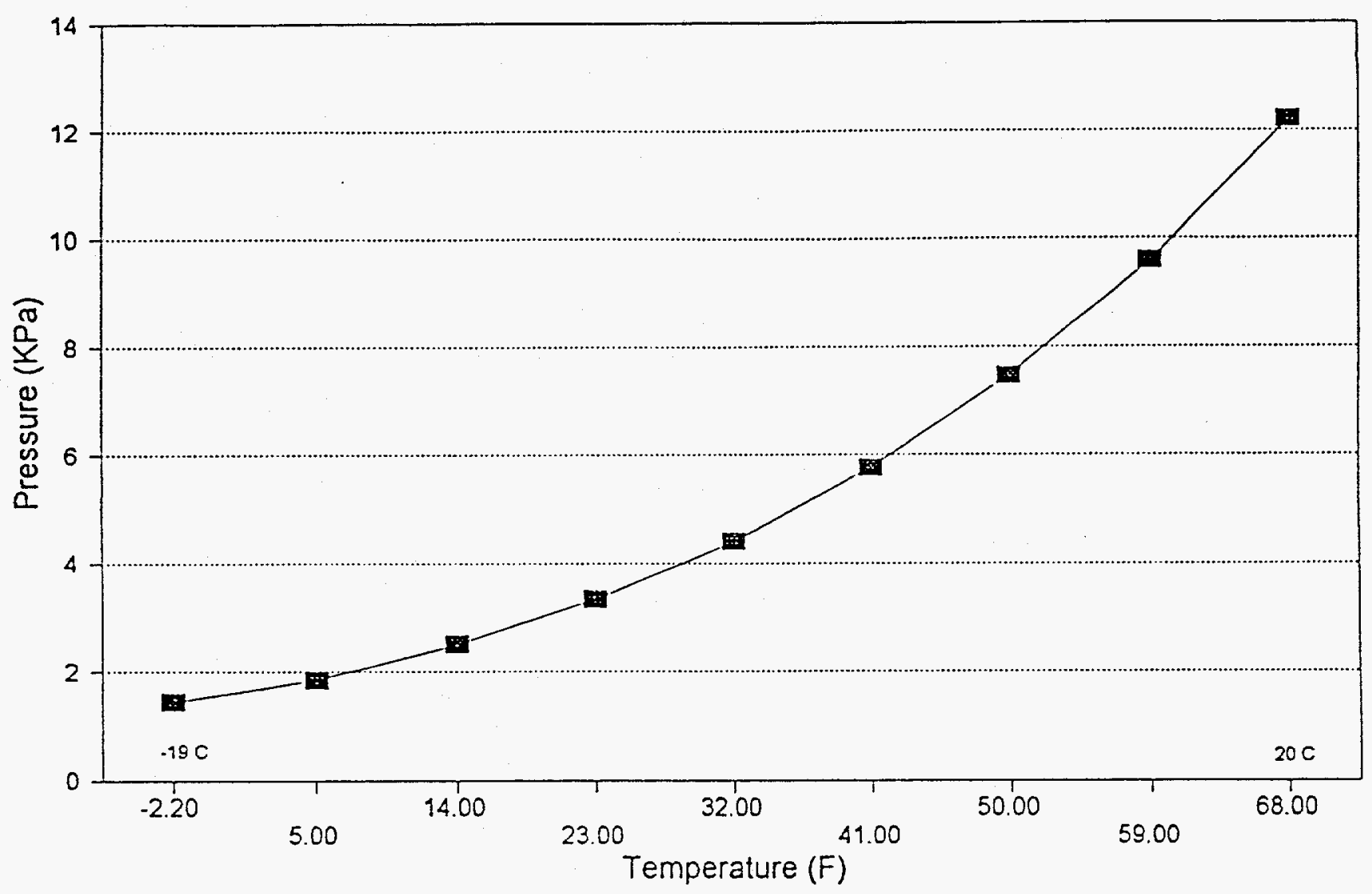

As soon as split-spoon samplers were removed from the borehole, they were placed on a breakdown table. One probe was immediately inserted into the soil in the sampler shoe. After the sampler head was removed, another probe was inserted into the soil in the upper part of the sampler. The sample liners were then moved apart, and a probe was inserted in the middle of the sampler. The temperature measurements were recorded in a field logbook or on data sheets provided for each well.

Temperature sensitive tape was used to record sampler temperature at selected boreholes during FY 1993. Two types of Wahl TEM-PLATE ${ }^{3}$ temperature recording tapes were placed on the inside of split-spoon samplers and also on the outside of the sampler liners. The temperature sensitive tape has an accuracy of $\pm-15^{\circ} \mathrm{C}\left( \pm 5^{\circ} \mathrm{F}\right)$.

${ }^{3}$ TEM-PLATE is a trademark of William Wahl Corporation, Culvur city, California. 
WHC-SD-EN-TRP-007, Rev. 0

\section{A4.0 RESULTS}

\section{A4.1 INITIAL RESULTS}

Initial drilling began July 19, 1993 at the DTTS to familiarize the drillers with the various lithologies of the Hanford Site. The advancing technique consisted of drilling a $11.4-\mathrm{cm}$ (4 1/2-in.) outside diameter (OD) drill pipe 3 or $6 \mathrm{~m}$ (10 or $20 \mathrm{ft})$. A $16.8-\mathrm{cm}(65 / 8-\mathrm{in}$.$) OD casing was then$ reamed over the $11.4-\mathrm{cm}$ (4 1/2-in.) OD drill pipe. The $11.4-\mathrm{cm}(41 / 2-i n$. pipe was removed, and the soil was vibrated from the core tube into core trays. The 11.4-cm (4 1/2-in.) OD pipe was re-inserted to total depth to clean out the borehole. After the 11.4-cm (4 1/2-in.) OD pipe was removed a $12.7-\mathrm{cm}$ (5-in.) OD split spoon sampler was inserted and driven $0.6 \mathrm{~m}(2 \mathrm{ft}$ ) by the ResonantSonic drill head. During this period, occasional sample temperatures were collected. The highest sample temperature recorded during the initial period was $75^{\circ} \mathrm{C}\left(168^{\circ} \mathrm{F}\right)$. As drilling progressed it became evident that the highest heat normally occurred at the shoe of the drill bit. It was further demonstrated that during the overreaming of casing even higher temperatures were generated.

The fourth test borehole (DTTS-S-04A) was chosen for collection of continuous temperature measurements. The temperature of drill cuttings exceeded $60{ }^{\circ} \mathrm{C}\left(140{ }^{\circ} \mathrm{F}\right)$ at $3.6 \mathrm{~m}(12 \mathrm{ft})$, and the split-spoon sample temperature exceeded $99^{\circ} \mathrm{C}\left(210^{\circ} \mathrm{F}\right)$ at $5 \mathrm{~m}(17 \mathrm{ft})$. Sample temperatures in this range were deemed unacceptable.

\section{A4.2 RESULTS AFTER MODIFICATION OF DRILLING METHODS}

Based on the results of the initial temperature measurements, it was decided to modify the drilling technique. The modified technique involves pilot coring 3 to $6 \mathrm{~m}$ (10 to $20 \mathrm{ft}$ ) with $11.4-\mathrm{cm}(41 / 2-\mathrm{in}$.$) outside diameter$ (OD) drill pipe. At the desired depth, coring is stopped, and the continuous core samples are extracted. The $11.4-\mathrm{cm}(41 / 2-i n$.$) OD string is then$ reinserted, and a $15.2-\mathrm{cm}(6-\mathrm{in}$.) inside diameter (ID) by $16.8-\mathrm{cm}(65 / 8-\mathrm{in}$.) $O D$ casing is reamed over the $11.4-\mathrm{cm}(41 / 2-i n$.$) coring string to the base of$ the drilled hole. The 4.5-in. OD string is then removed, and a $12.7-\mathrm{cm}$ (5-in.) $O D$ by $0.6-\mathrm{m}-(2-\mathrm{ft}-)$ long stainless steel split spoon sampler is lowered to the base of the cased hole. The $0.6-\mathrm{m}(2 \mathrm{ft}$ ) sample is driven using the ResonantSonic drill head.

It was hypothesized that the highest heat would occur at the face of the core barrel bit (and in surrounding soil). Thus, as the split spoon sampler is driven through the warm soil at the base of the borehole, this soil would travel up into, and to the top of, the sampler. Consequentiy, the warmest location on a core barrel sample would be the bottom, and the warmest location on a split spoon sampler would be the top (Figure A2). Indeed, this was the case, with a few exceptions. 
Figure A2. Typical Heat Variations in a Split Spoon Sampler.

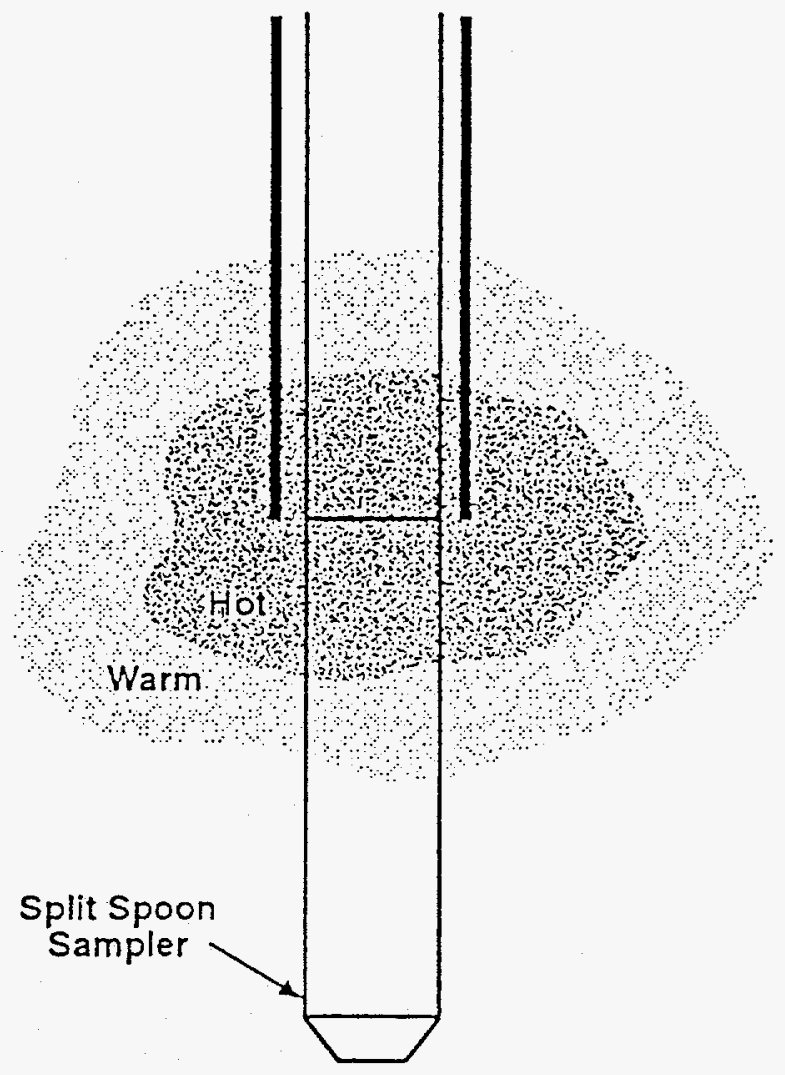

59312016.3

One exception occurred when drilling became difficult (e.g., gravels or cobbles were encountered) during the sampling process: heat was generated at the shoe of the split spoon sampler; thus, the shoe of the sampler was hotter than the top (Figure A3). Advancing the borehole to the desired interval at the end of a drilling shift also caused an exception. In this case, because the warm soil at the base of the borehole equilibrated with the surrounding soil column overnight, in the morning at the beginning of drilling, the soil temperature at the bottom of the borehole likely equalled the natural soil temperature for that depth. When a split spoon sampler was inserted to the base of the borehole and the borehole was advanced, the cool soil travelled to the top of the sampler, and because the highest heat was generated at the face of the sampler shoe, these samples were coolest on top and warmest on the bottom. Temperatures of the first sample of the day typically are -12 to $\left.-1{ }^{\circ} \mathrm{C}\right)\left(10\right.$ to $\left.30^{\circ} \mathrm{F}\right)$ cooler than other samples.

At borehole DTTS-S-04A, it was found that samples with $100 \%$ recovery (either by overdriving or core expansion) commonly had elevated temperatures. Split spoon samplers were then only driven to $75 \%$ of their total length. Samplers underdriven in this manner frequently had lower temperatures. 
Figure A3. Sample Heat when Cobbles Encountered.

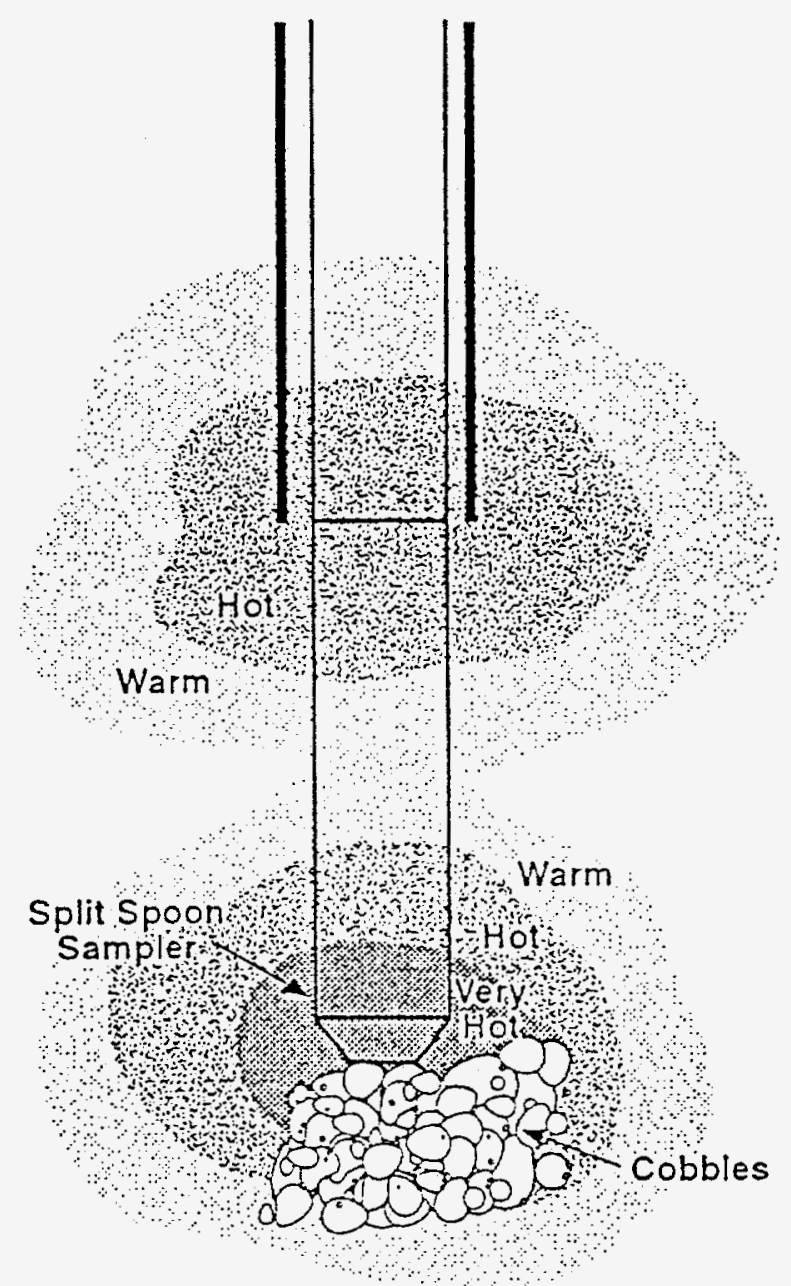

59312016.2

These encouraging results prompted personnel to devise an ice chest to chill the split spoon sampler before insertion into the borehole. A large metal driller's tool box was lined with rigid foil-backed foam to create an ice chest large enough to hold the entire split spoon sampler including shoe and connecting sub (overall length $\approx 3 \mathrm{ft}[1 \mathrm{~m}]$ ). The sampler was decontaminated in accordance with WHC-CM-7-7, EII 5.5 (WHC 1988). This foil-wrapped, decontaminated sampler was lowered onto blocks to elevate it above the floor of the ice chest.

Blocks of dry ice were added to chill the sampler. When possible, samplers were left in the ice chest for at least two hours to become thoroughly chilled. A thermometer in the ice chest commonly indicated $-34{ }^{\circ} \mathrm{C}$ $\left(-30^{\circ} \mathrm{F}\right)$. A metallurgist indicated temperatures in this range would cause no reduction in the tensile strength of stainless steel samplers. 
Because of the alternate drilling techniques implemented, as drilling progressed at borehole DTTS-S-04A, sample temperatures generally decreased. By the final run of borehole DTTS-S-04A, the highest core barrel sample measurement was $35^{\circ} \mathrm{C}\left(95^{\circ} \mathrm{F}\right)$. The final split spoon sample temperature measured $20^{\circ} \mathrm{C}\left(69^{\circ} \mathrm{F}\right)$.

\section{A4.3 RESULTS AT BOREHOLE 299-W15-223}

Borehole 299-W15-223 is located at the 200 West Area Carbon Tetrachloride Expedited Response Action (ERA) site in the 200 West Area. This is an area of known contamination, with high concentrations of carbon tetrachloride detected during recent investigations (Last and Rohay 1993; Rohay 1993).

Chilled samplers described previously were used extensively at borehole 299-W15-223. Additionally, Tonger split tube samplers were used to increase the distance the sample would be collected below the warm soil located at the bottom of the drive tube run (Figure A4). Split tube samplers up to $1.5 \mathrm{~m}$ $(1.5 \mathrm{ft})$ long (overall length $\approx 1.8 \mathrm{~m}[6 \mathrm{ft}]$ ) were successfully chilled with dry ice in an alternate container made of heavy-wall polyvinyl chloride (PVC) pipe with threaded end caps. This method worked well for cooling long samplers if the cooler was kept in a horizontal position.

Figure A4. Sample Heat While Using Extended Length Samplers.

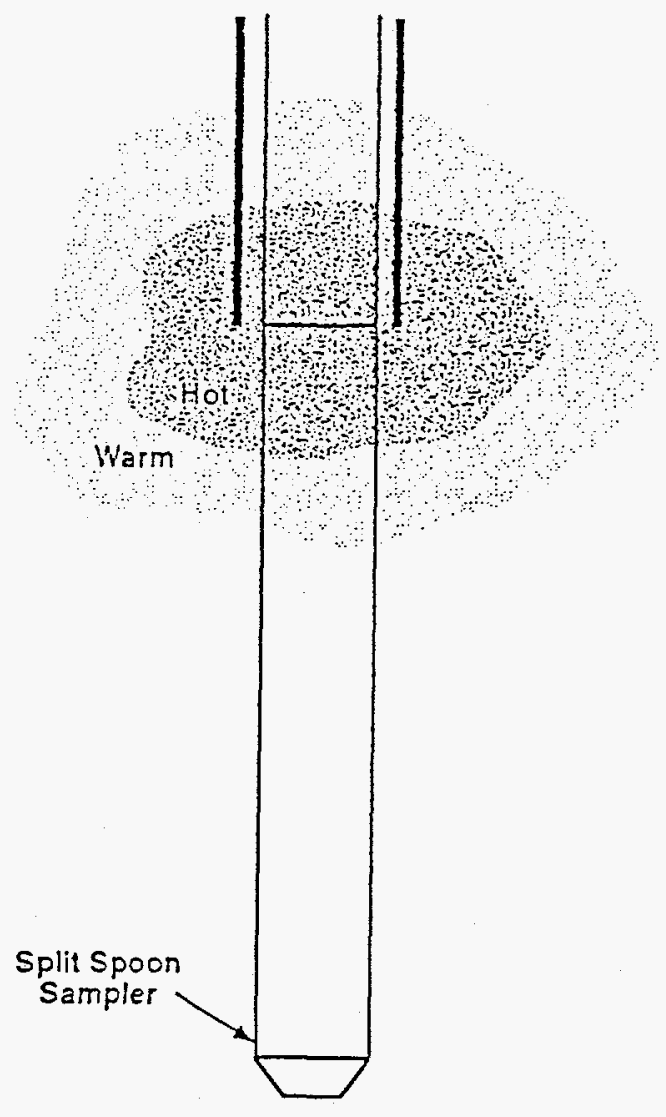


In sample intervals for which the sampler was completely chilled, sample temperatures were commonly in the 15 to $21^{\circ} \mathrm{C}\left(60\right.$ to $70^{\circ} \mathrm{F}$ ) range. When samplers could not be fully chilled, sample temperatures ranged from 27 to $38^{\circ} \mathrm{C}\left(80\right.$ to $\left.100{ }^{\circ} \mathrm{F}\right)$.

An attempt was made to correlate sample temperature and 1 ithology. The lithology at 299-W15-223 is predominantly sand, but includes gravelly sand and a minor gravel layer. One carbonate stringer at $30 \mathrm{~m}$ (98 ft) may have caused an elevated core barrel temperature. Additional correlations are difficult to surmise.

\section{A4. 4 COMPARISON OF RESULTS}

Table Al lists the maximum and minimum temperatures from split spoon samples and core barrel samples measured from borehole DTTS-S-04A. Table A2 Tists the maximum and minimum temperatures from split spoon samples and core barrel samples measured from borehole 299-W15-223. Multiple measurements were often collected from a sampler or core barrel. The maximum and minimum temperatures used to complie Table $A 1$ and $A 2$ were not based on location within the sample interval (top or bottom) but on actual maximum or minimum temperature. As an example, at Borehole 299-W15-223, in the 5.6 to $6.2 \mathrm{~m}$ (18.8 to $20.5 \mathrm{ft}$ ) interval the high temperature was $40.9{ }^{\circ} \mathrm{C}\left(134.2{ }^{\circ} \mathrm{F}\right.$ ) and the low was $20.5^{\circ} \mathrm{C}\left(68.9^{\circ} \mathrm{F}\right)$. The low temperature interval was sampled for voC analysis.

Figure $A 5$ and Figure $A 6$ graph the temperatures at various intervals within split spoon and drive barrels borehole DTTS-S-04A and 299-W15-223, respectively.

\section{A5.0 EFFECT OF THERMAL CONDUCTIVITY ON SAMPLE TEMPERATURES}

Split spoon samplers commonly contain liners that the soil is contained within. These liners are then subsampled or capped and sent for analysis. At a borehole that was drilled using the cable-tool method, on some samplers, temperature sensitive tape was applied to the outer surface of the liner and to the inner surface of the split spoon. Results indicate that liners made of material having low thermal conductivity such as Lexan ${ }^{4}$ consistently have a lower temperature than the stainless steel split spoon temperature. The Lexan liner commonly was $5.5^{\circ} \mathrm{C}\left(10^{\circ} \mathrm{F}\right)$ cooler than the split spoon sampler temperature. The liner acts as an insulator to isolate the soil core from the heat of the split spoon. The warmer soil and split tube sampler transmits heat within the split tube sampler and the soil. Table A3 lists the thermal conductivities of various materials. Lexan 7 iners were used in all samples drilled using the ResonantSonic method. The oscillation of the Resonantsonic method destroyed the temperature sensitive tape on the sampler and Tiners.

\footnotetext{
${ }^{4}$ Lexan is a trademark of the General Electric Company, Pittsfield, Massachusetts.
} 


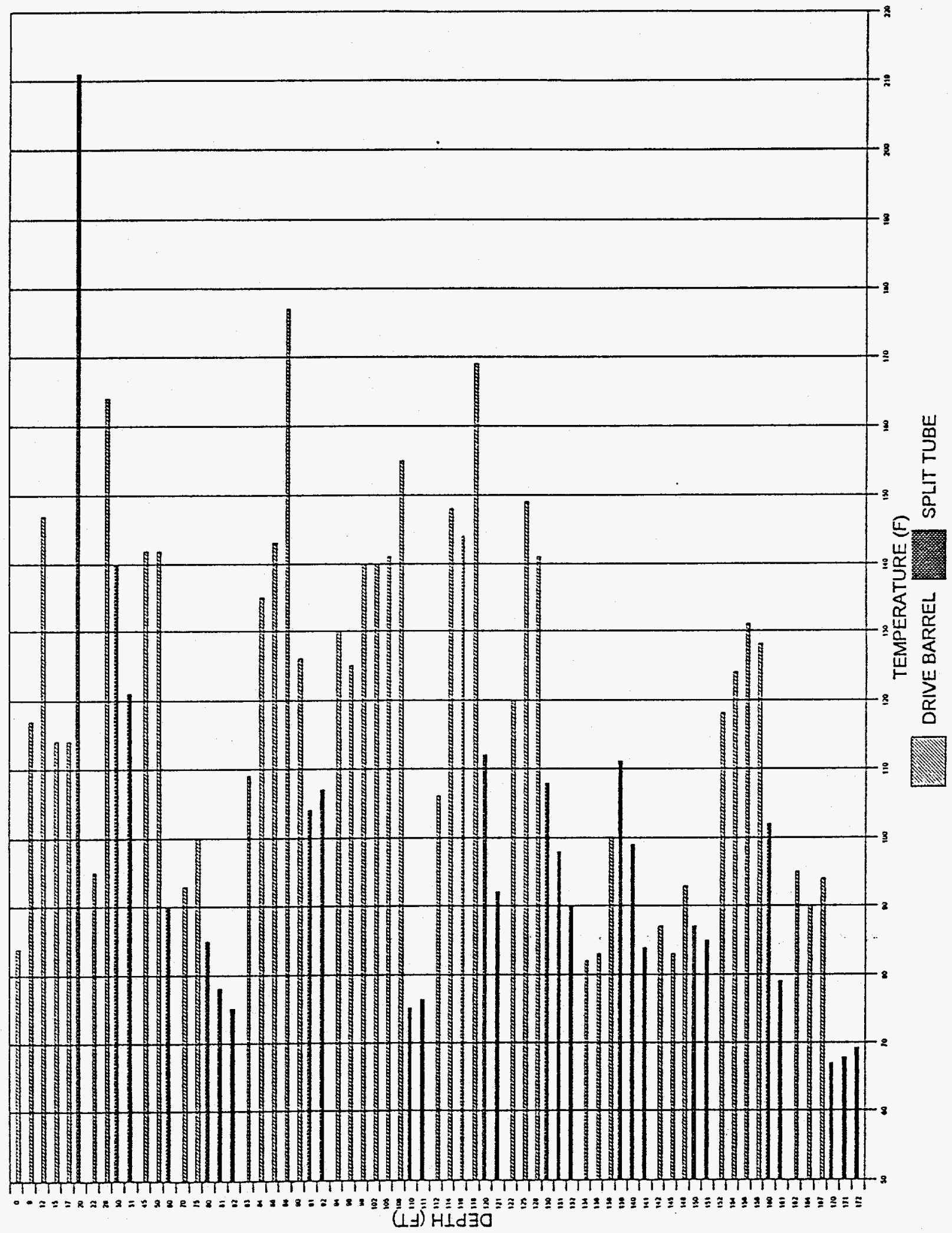

$$
\begin{aligned}
& \text {-f a } \\
& 0 \cdot \wedge \partial y \text { ' } L O 0-d y 1-N]-O S-J H M
\end{aligned}
$$




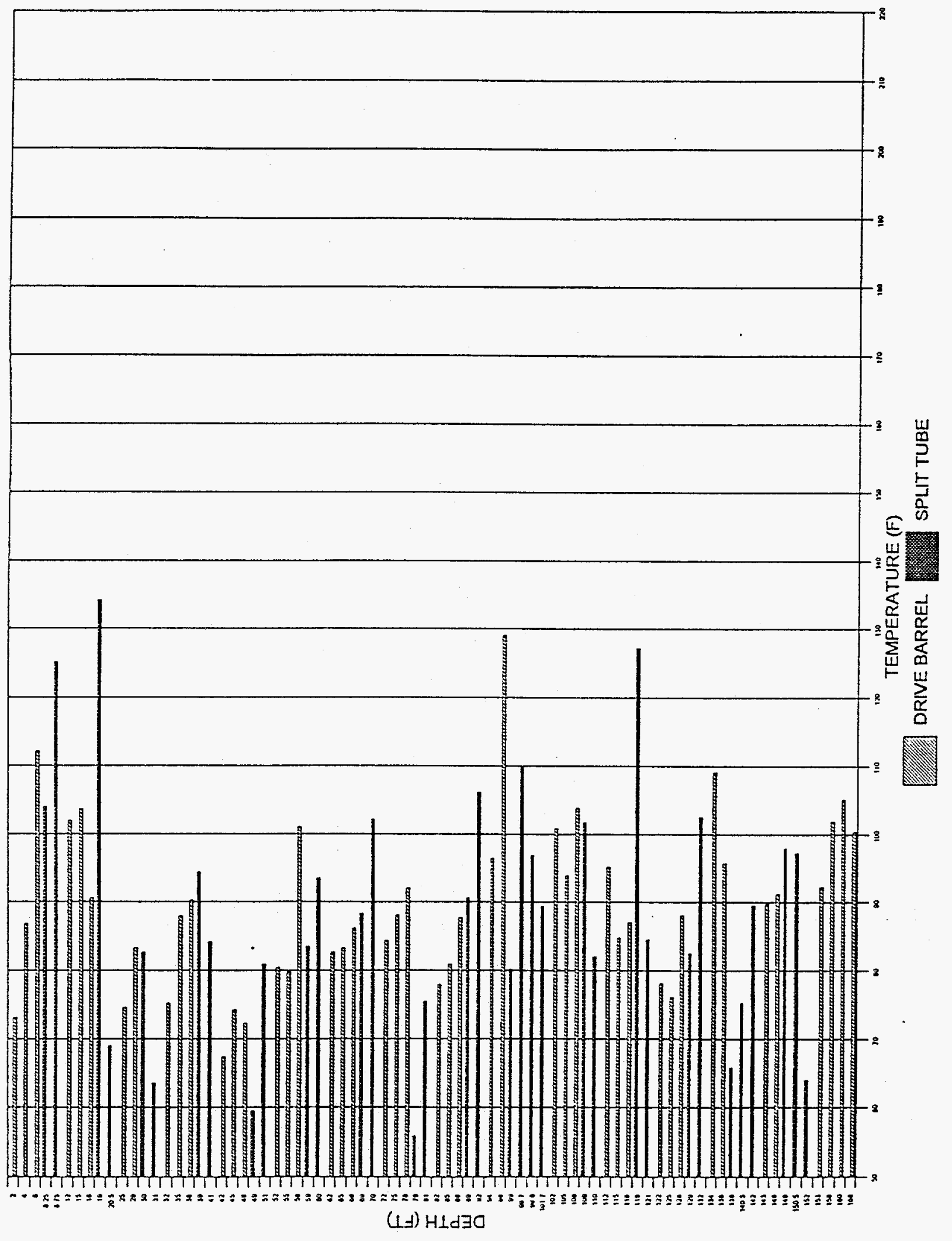

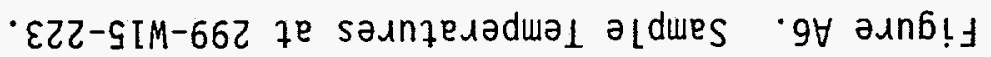


Table Al. Soil Temperatures for Drilling Technology Test Site Borehole DTTS-S-04A

\begin{tabular}{||c|c|c||}
\hline \multicolumn{3}{|c|}{ Sp1 it Spoon } \\
\hline Interval Feet & $\begin{array}{l}\text { Maximum } \\
\text { Temp (F) }\end{array}$ & $\begin{array}{l}\text { Minimum } \\
\text { Temp (F) }\end{array}$ \\
\hline $20.0-22.0$ & $211.0^{\mathrm{a}}$ & $211.0^{\mathrm{a}}$ \\
\hline $30.0-32.0$ & 140.0 & 121.0 \\
\hline $80.0-81.5$ & 85.0 & 75.0 \\
\hline $90.0-91.5$ & 126.0 & 104.0 \\
\hline $110.5-111.5$ & 78.2 & 75.0 \\
\hline $120.0-121.5$ & 112.0 & 92.0 \\
\hline $130.0-131.5$ & 108.0 & 90.0 \\
\hline $140.0-141.5$ & 111.0 & 84.0 \\
\hline $150.0-151.5$ & 87.0 & 81.0 \\
\hline $160.0-161.5$ & 102.0 & 78.0 \\
\hline $170.5-171.5$ & 69.2 & 67.0 \\
\hline & & \\
\hline & & \\
\hline & & \\
\hline AVERAGE & 111.8 & 98.0 \\
\hline \hline
\end{tabular}

\begin{tabular}{||c|c|c|}
\hline \multicolumn{3}{|c|}{ Drive Barrel } \\
\hline Interval Feet & $\begin{array}{l}\text { Maximum } \\
\text { Temp (F) }\end{array}$ & $\begin{array}{l}\text { Minimum } \\
\text { Temp (F) }\end{array}$ \\
\hline $0.0-9.0$ & 84.0 & 84.0 \\
\hline $9.0-20.0$ & 147.0 & 114.0 \\
\hline $22.0-30.0$ & 164.0 & 95.0 \\
\hline $70.0-80.0$ & 100.0 & 93.0 \\
\hline $81.5-90.0$ & 176.6 & 109.0 \\
\hline $91.5-100.0$ & 140.0 & 125.0 \\
\hline $101.5-110.0$ & 155.0 & 140.0 \\
\hline $111.5-120.0$ & 169.0 & 106.0 \\
\hline $121.5-130.0$ & 149.0 & 120.0 \\
\hline $131.5-140.0$ & 100.0 & 82.0 \\
\hline $141.5-150.0$ & 93.0 & 83.0 \\
\hline $151.5-155.7$ & 124.0 & 118.0 \\
\hline $155.7-160.0$ & 131.0 & 128.0 \\
\hline $161.5-170.0$ & 95.0 & 90.0 \\
\hline AVERAGE & 130.5 & 106.2 \\
\hline \hline
\end{tabular}

a This is from a single temperature measurement collected from the spl it tube. 
Table A2. Soil Temperatures for Well 299-W15-223.

\begin{tabular}{||c|c|c|||c|c|c||}
\hline \multicolumn{3}{|c|}{ Split Spoon } \\
\hline Interval Feet & $\begin{array}{l}\text { Maximum } \\
\text { Temp (F) }\end{array}$ & $\begin{array}{l}\text { Minimum } \\
\text { Temp (F) }\end{array}$ \\
\hline $8.25-8.75$ & 125.5 & 104.0 \\
\hline $18.8-20.5$ & 134.2 & 68.9 \\
\hline $29.2-31.5$ & 82.6 & 63.5 \\
\hline $39.4-40.9$ & 94.4 & 84.1 \\
\hline $49.5-51.0$ & 80.9 & 59.4 \\
\hline $58.3-60.7$ & 93.7 & 83.6 \\
\hline $69.3-70.8$ & 102.2 & 88.4 \\
\hline $79.5-81.0$ & 75.5 & 55.8 \\
\hline $89.3-92.0$ & 106.1 & 90.7 \\
\hline $99.4-99.8$ & 109.7 & 80.2 \\
\hline $99.8-101.7$ & 97.7 & 89.3 \\
\hline $109.3-110.8$ & 101.7 & 82.2 \\
\hline $119.8-121.6$ & 127.2 & 84.5 \\
\hline $129.9-132.7$ & 102.6 & 82.5 \\
\hline $139.5-142.2$ & 89.5 & 65.7 \\
\hline $149.3-152.5$ & 98.0 & 63.9 \\
\hline AVERAGE & 101.3 & 77.9 \\
\hline
\end{tabular}

Table A3. Thermal Conductivity of Certain Materials.

\begin{tabular}{|l|r|}
\hline \multicolumn{1}{|c|}{ Common Name } & Btu/hr $\mathrm{ft}^{\circ} \mathrm{F}$ \\
\hline Stainless Steel (304) & 19.0 \\
\hline Carbon Steel (1020) & 56.0 \\
\hline Lexan & 1.35 \\
\hline Dry Soi1 & .14 \\
\hline Wet Soi1 & 1.21 \\
\hline Water & .34 \\
\hline Granite & 1.57 \\
\hline Sandstone & 1.50 \\
\hline
\end{tabular}


WHC-SD-EN-TRP-007, ReV. 0

\section{A6.0 SAMPLE TEMPERATURES FROM OTHER DRILLING METHODS}

Research indicates no previous publications on sample collection temperatures. Interviews with numerous drillers, drilling engineers, geologists, and personal knowledge indicate excessive sample temperatures do occur during drilling with other methods. Temperatures collected with temperature sensitive tape and electric temperature probes during FY 92 and Fy 93 at wells drilled using the cable-tool method ranged between 21 and $60{ }^{\circ} \mathrm{C}$ $\left(70\right.$ and $\left.140^{\circ} \mathrm{F}\right)$. Temperatures were commonly at the lower end of this range.

Friction created during hollow-stem auger sampling has been known to elevate the sample temperatures during difficult drilling conditions. Temperature measurements from hollow-stem auger samples collected at numerous boreholes on an environmental project in California. Sample temperatures averaged $24{ }^{\circ} \mathrm{C}\left(76^{\circ} \mathrm{F}\right)$ (Barrow 1994) but temperatures up to $42{ }^{\circ} \mathrm{C}\left(107{ }^{\circ} \mathrm{F}\right.$ ) were recorded. The driller noted the plastic liners within the hollow-stem auger continuous sampler had melted together on one run. Still, these liners were dutifuliy capped and sent to a laboratory for analysis.

Somewhat elevated sample heat was measured in split spoon samples obtained using a rotary drill rig with a split spoon sampler driven by an air hammer. Samples were collected for geologic and geotechnical investigation purposes. Temperatures recorded reached $25^{\circ} \mathrm{C}\left(78^{\circ} \mathrm{F}\right)$.

\section{A7.0 CONCLUSIONS}

Drilling a borehole creates varying degrees of heat depending on the type of drilling equipment and local subsurface conditions. Because increased sample temperatures may adversely affect environmental samples, the temperature of samples collected for VOC analys is should be kept as low as practical.

A number of factors contributed to the significant reduction in sample temperatures achieved. The most significant factor involves collecting sample temperatures and conveying this information to the driller. The driller can affect sample temperature by varying the rate of penetration, rotational speed, and the number of oscillations, based on his knowledge of the local geologic formation. Penetration rates may have to be sacrificed to obtain acceptable sample temperatures.

Using a long split spoon sampler ( $1.5 \mathrm{~m}[5 \mathrm{ft}]$ ) and underdriving to only $75 \%$ of length allows the sample to be collected a considerable distance from the warmer soil below the drive bit. Sampler liners with a low thermal conductivity should be used to insulate the sample from the outer metal sampler body. Finally, if the sample temperature still must be decreased, the split spoon sampler should be chilled before sampling. Dry ice for pre-chilling has proven successful. 
Improvements in drilling techniques and sampling methods have resulted in the collection of samples near ambient temperature that are comparable to samples collected using other drilling methods.

Areas requiring additional work include developing methods to reduce initial ResonantSonic sample temperature generation, achieving a better understanding of the effects of above-ambient temperatures on environmenta? samples, and studying elevated sample temperatures of samples generated using other drilling methods.

\section{A8.0 REFERENCES}

CRC Press, Inc., 1993, CRC Handbook of Chemistry and Physics, CRC Press, Inc., Boca Raton, Florida.

Devitt, D. A., R. B. Evans, W. A. Jury, T. R. Starks, B. Eklund, A. Gnolson, J. J. Van Ee, 1987, Soil Gas Sensing for Detection and Mapping of Volatile Organics, National Ground Water Association, Dublin, Ohio.

General Electric Company, 1992, Lexan Product Data Sheet, General Electric Company, Pittsfield, Massachusetts.

Last, G. V. and V. J. Rohay, 1993, Refined Conceptual Model for the Volatile Organic compounds-Arid Integrated Demonstration and 200 West Area Carbon Tetrachloride Expedited Response Action, PNL-8597, Pacific Northwest Laboratory, Richland, Washington.

Lewis, T. E., A. B. Crockett, R. L. Seigrist, and K. Zarrabi, 1991, Soi7 Sampling and Analysis for Volatile Organic Compounds, Ground Water Issue, EPA/540/4-91/001, Environmental Protection Agency, Environmental Monitoring Systems Laboratory, Las Vegas, Nevada.

Jenkins, R. A., C. K. Bayne, M. P. Maskarinec, L. H. Johnson, S. K. Holladay, and B. A. Tomkins, 1993, Experimental Determination of Maximum Pre-Analytical Holding Times for Volatile Organics in Selected Soils, presented at the National Symposium on Measuring and Interpreting VOCs in Soils: State of the Art and Research Needs, Las Vegas, Nevada, January 12-14, 1993.

Maskarinec, M. P., C. K. Bayne, R. A. Jenkins, L. H. Johnson, and S. K. Holladay, 1992, Stability of Volatile Organics in Environmental Soi7. Samples, ORNL/TM-12128, Oak Ridge National Laboratory, Oak Ridge, Tennessee.

McLellan, G. W., 1993, Integrated Test Plan for the Sonic Drilling Method on the Hanford Site FY 1993, WHC-SD-EN-TP-028, Rev. 0, Westinghouse Hanford Company; Richland, Washington.

Rohay, V. J., 1993, FY93 Site Characterization Status Report and Data Package for the Carbon Tetrachloride Site, WHC-SD-EN-TI-202, Rev. 0, Westinghouse Hanford Company, Richland, Washington. 
WHC-SD-EN-TRP-007, Rev. 0

Thibodeaux, L. J., 1973, Chemodynamics Environmental Movement of Chemicals in Air, Water, and Soil, John Wiley \& Sons, New York.

Volk, B. W., 1992, Results of Testing the Sonic Drilling System at the Hanford Site (September 1991 to May 1992), WHC-SD-EN-TRP-002, Rev. 0, Westinghouse Hanford Company, Richland, Washington.

WHC-CM-7-7, Environmental Investigations and Site Characterization Manual, Westinghouse Hanford Company, Richland, Washington. 
WHC-SD-EN-TRP-007, Rev. 0

This page intentionally left blank. 
WHC-SD-EN-TRP-007, Rev. 0

\section{APPENDIX B}

EDDY CURRENT EXAMINATION OF SONIC DRILL PIPE

B-i 
WHC-SD-EN-TRP-007, Rev. 0

This page intentionally left blank. 
WHC-SD-EN-TRP-007, Rev. 0

\section{Eddy Current Examlnation Of Sonlc Drll Plpe}

Report from work performed in September 1993

R.L. Hockey, R.H. Ferris, D.M. Riechers

Feburary 1994

Prepared for

Ground Water Well Services

Westinghouse Hanford Company

By

Pacific Northwest Laboratories

Richland, Washington 99352 
Executive Summary

The Nondestructive Evaluation (NDE) group at The Pacific Northwest Laboratory (PNL) completed a phase I feasibility study showing that eddy current technology could detect cracks in sonic drill pipe. It was not determined, however, if this same technology could predict when pipe failure is most likely to occur based on a single eddy current examination. To answer questions related to predicting the likelihood of pipe failure, the results from eddy current tests on each pipe thread, both before and after each use, would be required.

Objective and Background

The steel pipe used for sonic drilling has a history of developing circumferential cracks in the threaded section where two lengths of pipe are joined. It is unknown how the cracks initiate or if there is some detectable precursor to pipe failure during drilling. This brief feasibility study concentrated on discovering if an eddy current technique could detect abnormal electric or magnetic features in the threaded fastener region, where pipe failure occurs most often. No effort went into the engineering problems associated with implementing this technology for routine pipe inspection.

Eddy current inspections normally involve a coil of wire wound in such a way as to maximize coil impedance changes due to the effect of interest and minimize impedance changes caused by other effects. Such a coil is connected to an ac impedance bridge of some kind to measure changes in the coil's impedance when an ac voltage source is applied to the coil. The coil is normally mounted in some type of fixture (called a probe) that allows a convenient means of scanning questionable parts for a particular property sensitive to eddy currents.
Electrical conductivity and magnetic permeability are two properties of a metallic part that most often affect an eddy current coil's impedance. The frequency of the ac current applied to the coil can be adjusted to emphasize either of these two properties. In many cases, multiple frequencies are applied to the coil to differentiate between properties that may cause an impedance change.

\section{Procedure}

The male threaded portion from a 4 inch diameter drill pipe (shown in Figure 1) was selected for eddy current evaluation. This particular sample was chosen because a through-wall crack was found to extend $3 / 4$ of a turn around the bottom of the 2 nd thread from the end. A special eddy current probe, able to conform to the thread shape, was chosen to scan along the thread bottom to determine how eddy currents interact with the visible, through-wall crack and other conceivable features invisible to optical inspection. Figure 2 shows the probe as it was used to scan the thread surfaces.

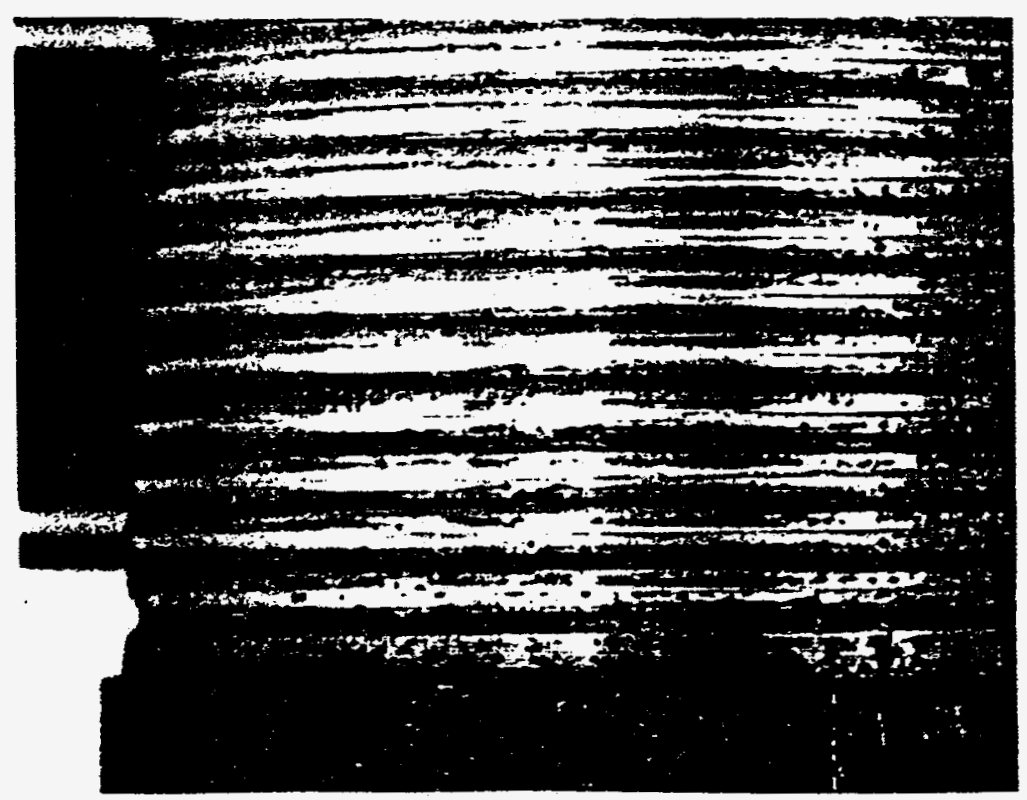

Figure 1. Male Threaded End Of 4 Inch Sonic Drill Pipe. 


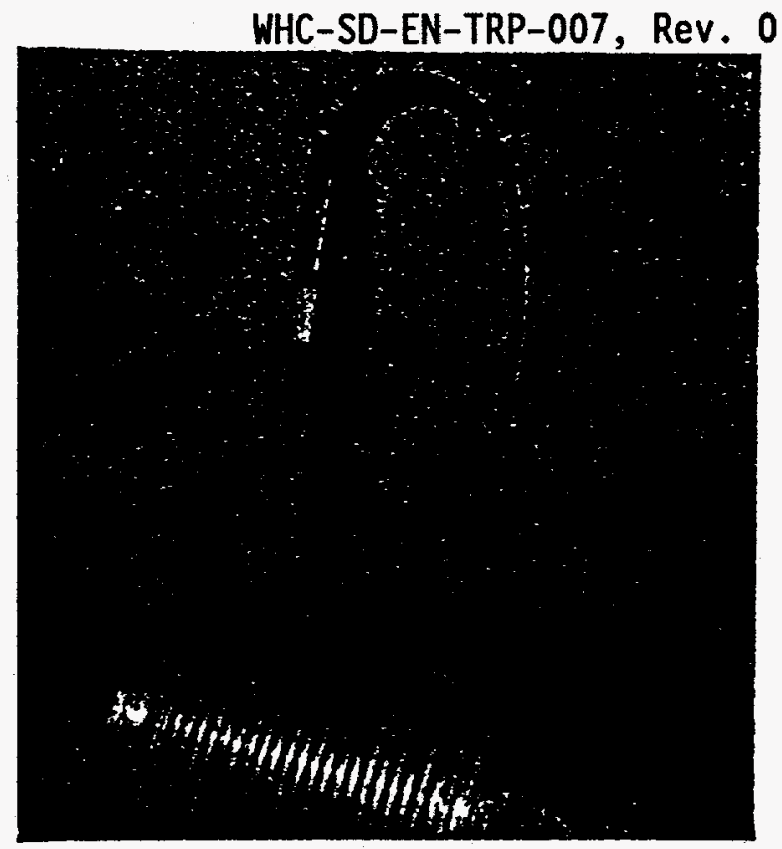

Figure 2. Eddy Current Probe In Position To Scan Bottom Groove In Pipe Threads

As the eddy current probe scanned the thread surface, eddy current response signals were examined and recorded. The objective was to locate and mark areas along the thread groove where the eddy current signal deviates from its average response. Areas marked as causing unusual interference to eddy current flow were later examined under a low-power microscope to determine if some type of surface breaking flaw was present. Metallography could have provided additional information about subsurface flaws but the cost associated with this procedure is not always warranted without first performing a surface inspection.

\section{Results}

A large through-wall crack, visible to the naked eye, had a large affect on the eddy current signal. As the probe moved past the most visible portion of the crack and onto areas where the crack could not be seen, eddy current signals continued to indicate the presence of cracking. These same regions were inspected under a microscope at 7.5 and 26 magnification. In one area, shown in Figure 3 , cracking could be seen at $7.5 \mathrm{X}$ and even better at $26 \mathrm{X}$. However, two different locations were found where the eddy current signal displayed the same "crack-like" behavior as measured for a surface breaking crack, but with slightly less amplitude. Optical inspection under a microscope yielded no evidence of cracking at the thread surface. It is very possible that a metallographic analysis will show subsurface cracking but schedule and scope limitations prevented this.

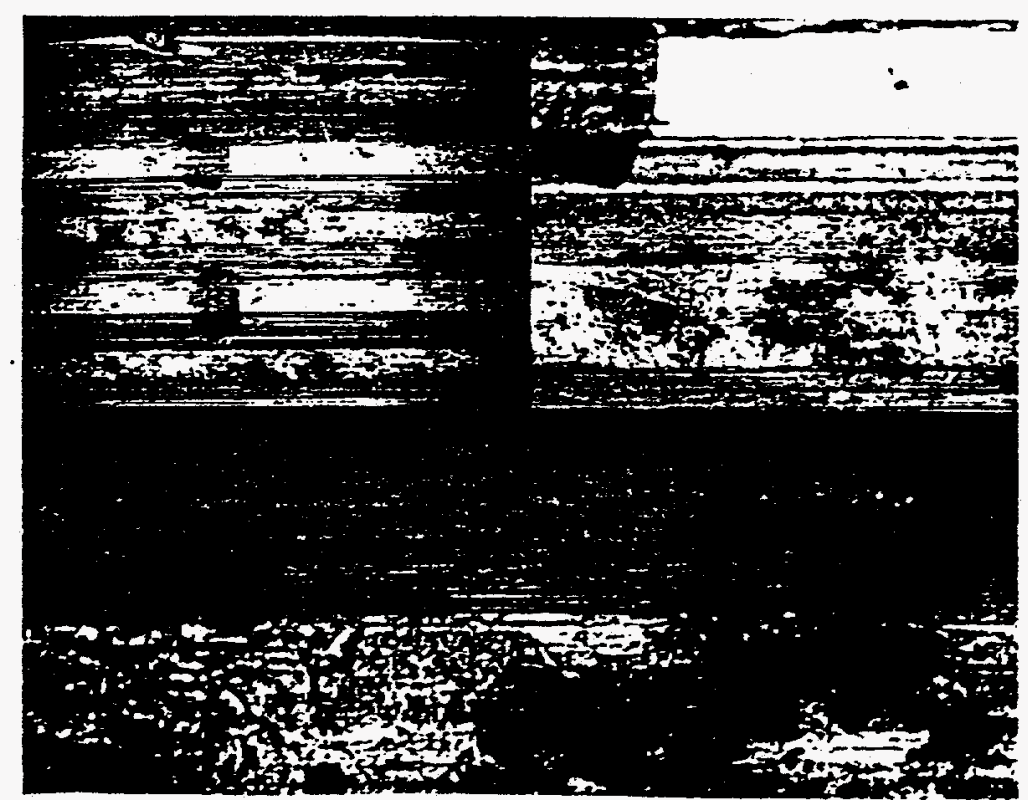

Figure 3. Cracked Sonic Drill Pipe Thread. Upper Left is $2.2 X$, Upper Right is $7.5 X$ And Lower Half is $26 \mathrm{X}$. 


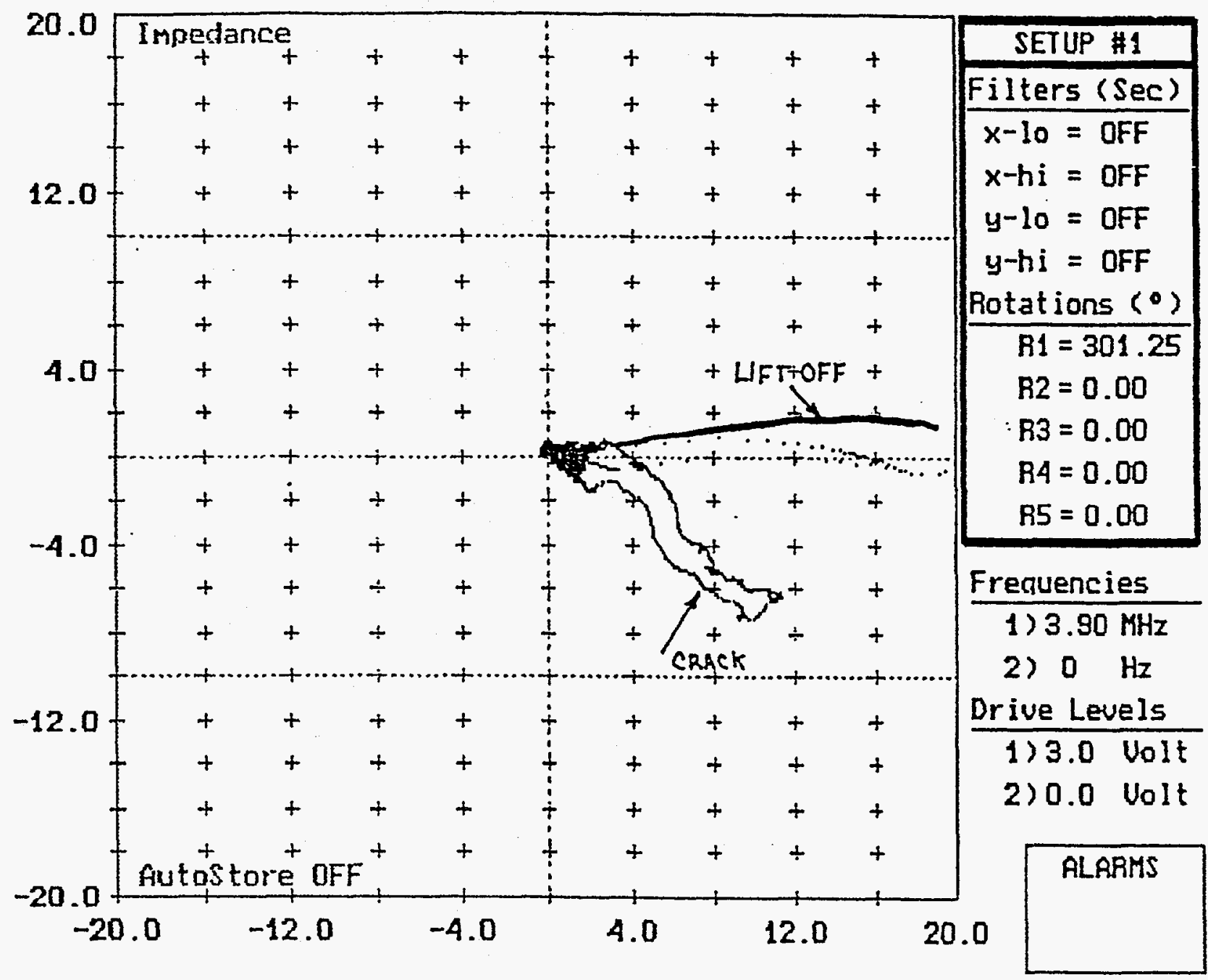

Figure 4. Impedance Of Eddy Current Probe When Passing Over Crack.

Conclusion

This brief feasibility study shows that it is possible to detect cracking beneath a threaded surface using an eddy current method. It was also found possible to detect tight surface breaking cracks only visible with a microscope, that would otherwise be difficult to detect using magnetic methods. Whether or not detection of the type of cracks examined in this study could prevent pipe failure during drilling operations could not be determined from the above results without additional information.

The additional information required to discover if an eddy current technique can predict when pipe failure can occur could be extracted from eddy current tests on all pipe threads both before and after each drilling operation. A database of this kind would be examined for correlation between eddy current signal evolution and the history of how a pipe was handled before it failed. 
WHC-SD-EN-TRP-007, Rev. 0

\title{
APPENDIX C
}

\section{FAILURE ANALYSIS SUMMARY DRILLING TECHNOLOGY} DEVELOPMENT PROJECT

\author{
S. G. Pitman \\ Pacific Northwest Laboratory
}


WHC-SD-EN-TRP-007, Rev. 0

This page intentionally left blank. 


\section{BACKGROUND}

Sonic (or harmonic) drilling is a fast and relatively inexpensive method for drilling shallow wells. It offers an additional advantage for sampling potentially contaminated areas because no drilling fluid is used, and the soil adjacent to the drilled hole is not disturbed by the drilling process.

A significant limitation in the use of sonic drilling for the Hanford Project has been fracture of the drill pipe and casing. Two methods have been used to fabricate drill pipe; pipe has been threaded directly, and threaded tool pieces have been thermally fit and welded into lengths of pipe.

In addition to occasional failures of drill pipe, a significant problem occurred in using $85 / 8-i n$. diameter casing. A new casing string was fabricated from API Grade P110 steel, using accepted practice. A break in the casing occurred after drilling to a depth of approximately $200 \mathrm{ft}$, and a subsequent inspection revealed that nine of the twenty connections were cracked. This unexpected failure of the casing prompted a metallurgical investigation to determine whether premature failure was due to defective casing material or to an operational problem.

Representative sections from failed drill pipe and casing have been obtained and examined. Examination techniques included macroscopic examination of the failures and scanning electron microscopy. The $85 / 8-i n$. diameter casing material was also examined using hardness testing, spectrographic analysis for chemical composition, and metallographic analysis.

\section{FAILURE ANALYSIS RESULTS}

Failures were found to be distinctly different in pipe that was threaded directly and in pipe that utilized threaded tool pieces.

\section{Direct-threaded pipe}

As would be expected, direct-threaded pipe fails in the threaded sections and failure occurs typically in the first loaded thread. Examples are given in Figures 1 and 2.

Scanning electron micrographs showing the fractography of the fracture surface and direction of crack propagation are given in Figures $3-5$. In each case the crack started at the outside of the pipe in a thread root and propagated quickly through the thickness before traversing the circumference. The origin of the crack in specimen $D$ is shown at the 10:00 position in Figure 1 and is shown in greater detail in Figures 3 and 4 . Multiple crack origins were found, which indicates that failure occurred under high-cycle fatigue (under relatively low stresses).

Although the cracks initiate under relatively low stress, it is clear that cracking is rapid by the time cracking has progressed to the opposite side of the pipe. In order to estimate the rate of fatigue crack growth and the corresponding stress intensity, the spacing of fatigue striations was measured on the side of the pipe opposite the fracture origin. Each of these 
striations represents one loading cycle, so the rate of crack propagation can be determined by measuring the distance between striations. The average striation spacing measured from Figure 5 is 0.02 in., indicating that crack propagation was very rapid at this point. At an operating frequency of $100 \mathrm{~Hz}$, crack propagation would be about $2 \mathrm{in.} / \mathrm{sec}$ as the pipe broke.

The rapid rate of crack propagation over the final increments of crack growth is not unexpected because of the high stresses imposed on the drill string. As is the case with most fatigue failures, most of the cyclic lifetime is spent prior to crack initiation. Once cracks begin to grow, crack growth rates increase exponentially and failure is eminent. This is an important consideration in planning inspection intervals, as small cracks or other defects can grow to significant size in a short time.

The crack shown in Figures $1,3,4$, and 5 is perpendicular to the axial direction of the pipe, indicating that the stresses were predominantly axial or bending (not torsional). The rapid propagation through the thickness indicates that some bending moment was present. Bending loads could have occurred as a result of uneven steel cross section relative to the threaded joints or as a result of uneven loading due to drilling conditions.

\section{Threaded Tool Pieces}

An advantage of using threaded tool pieces is that relatively inexpensive drill pipe can be used for the pipe, while the connecting threads are fabricated from hardened steel. Although there are advantages associated with this approach, failures still occur. An example is given in Figure 6 where a fatigue failure initiated in the pipe at the end of the tool-piece insert. Stress is concentrated in this region due to the change in cross section. It is also apparent that circumferential gouging is present in this region, presumably due to contact with jaws of the drilling assembly. This gouging may have contributed to crack initiation due to increase in local stress at the root of each gouge, and due to tensile residual stresses.

While threaded tool pieces appear to increase the 1 ifetime of drill pipe, the pipe is still susceptible to failure in mid-section. Examples are given in Figures 7 and 8 , where fatigue crack growth occurred in a spiral configuration. This configuration suggests that either torsional fatigue may be responsible for the failure, or that spiral-welded pipe may have been used, with the crack propagating through the weld. It should noted that a taper tap was used to retrieve the failed pipe. The use of this tool may also explain

the spiraled appearance of the pipe. It does not however give any indication to the nature of the failure.

\section{Casing material}

Casing has been relatively free of cracking problems. However, a recent change to 8 5/8-in. casing from $65 / 8$-in. casing resulted in rapid casing failure. The threaded connections were examined, and it was determined that 9 of the 20 connections were cracked. 
WHC-SD-EN-TRP-007, Rev. 0

One of the box-pin connections was sent to PNL for examination. Both the older pipe and the new pipe were fabricated from steel designated as API grade P110. The hardness of the two casing pipes was measured to determine whether an insufficient hardness was responsible for the decrease in fatigue resistance.

The hardness of the two pipes is given in Table 1 along with the approximate tensile strength corresponding with the measured hardness values.

Table 1. Results of hardness tests in casing material.

$\begin{array}{llc}\text { Pipe Diameter } & \text { Hardness, Rc }{ }^{1} & \text { Strength, } \text { ksi }^{2} \\ 65 / 8 \text { in. } & 35 / 33 & 157 / 146 \\ 85 / 8 \text { in. } & 29 / 27 & 132 / 126\end{array}$

(1) Rockwell "C" scale hardness. First number is longitudinal; second number is transverse. Each number is the average of five hardness measurements.

(2) Approximate tensile strength from hardness correlations. First number is from longitudinal hardness data; second number is from transverse hardness data.

The strength of both steels is in compliance with the requirements of the specification for P110 steel, so there is no obvious reason that the new lot of casing failed early.

Samples of both steels were sent for chemical analysis to determine whether there was a significant difference in composition that would explain the poor performance of the new casing material. The results of these tests, done by Koon-Hall testing of Milwaukee, OR are given in Table 2.

Table 2. Chemical analysis of casing steels.

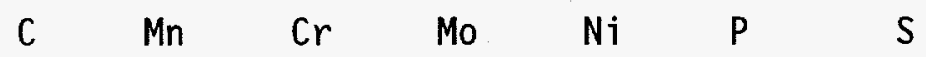
$65 / 8$
$0.28 \quad 1.55$
0.33
0.10
0.01
0.015
0.008
$85 / 8$
$0.29 \quad 1.39$
0.25
0.19
0.02
0.010
0.016

The chemical analyses indicate that there is no significant difference between the two steels. The composition is consistent with a relatively inexpensive material with limited hardenability. This steel is useful only in limited thicknesses, where a rapid quench can be achieved.

A metallographic examination was done to check for any obvious differences in microstructure that may affect fatigue life. The 
microstructure of the casing steels is shown in Figures 9 and 10 . Both steels were found to be tempered martensite, which is the structure most desirable in fatigue-resistant steels.

There is no apparent difference between the two structures, such as prior austenitic grain size or subgrain structure that would make one steel more resistant to fatigue.

\section{CONCLUSIONS}

The efficiency of sonic drilling could be significantly improved by reducing the incidence of drill pipe and casing failures. Several examples of pipe and casing failures were examined to determine the mode of crack propagation. The following conclusions were obtained:

1. As expected, fatigue crack growth is the principal mode of failure in both pipe and casing used for sonic drilling.

2. Most fatigue failures are perpendicular to the longitudinal axis, consistent with predominantly axial loading. The cracks grow quickly through the wall thickness before proceeding circumferentially, indicating that a bending load is also present. This bending load may be caused by axial misalignment in the threads or by the normal inconsistency in pipe wall thickness.

3. The spiraled appearance in the mid-section of mild steel pipes is the result of retrieving failed pipe which required a taper tap to be used.

4. Rapid crack growth rates were observed after significant crack growth had occurred. This underscores the need for sufficient inspection to detect small cracks.

5. Examination of the new $85 / 8$-in. diameter casing indicated that the composition and heat treatment of the new casing material is very similar to that of the older $65 / 8$-in. diameter material. There is no metallurgical explanation for the poor performance of this material, so it is suspected that the performance was caused by insufficient control of drilling parameters.

6. Further investigation of pipe failures is necessary. 
Figure Cl. Fracture Surface of Specimen D. Failure Initiated by Fatigue in the Flat Region Shown at the 10:00 Position.

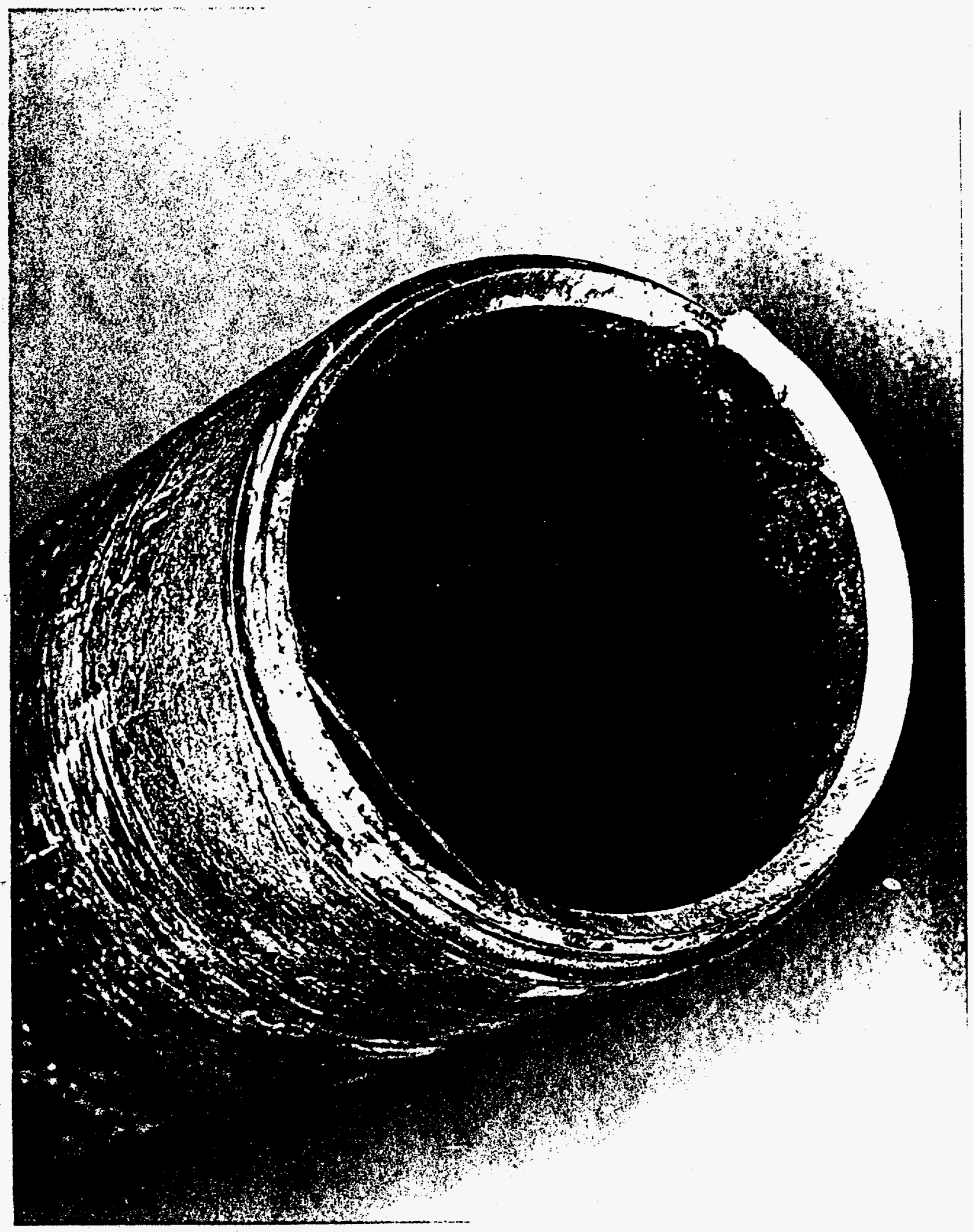


WHC-SD-EN-TRP-007, Rev. 0

Figure C2. Fracture Surface of Specimen E. Crack Initiation Occurred in the Thread Root and Cracking Progressed Circumferentially.

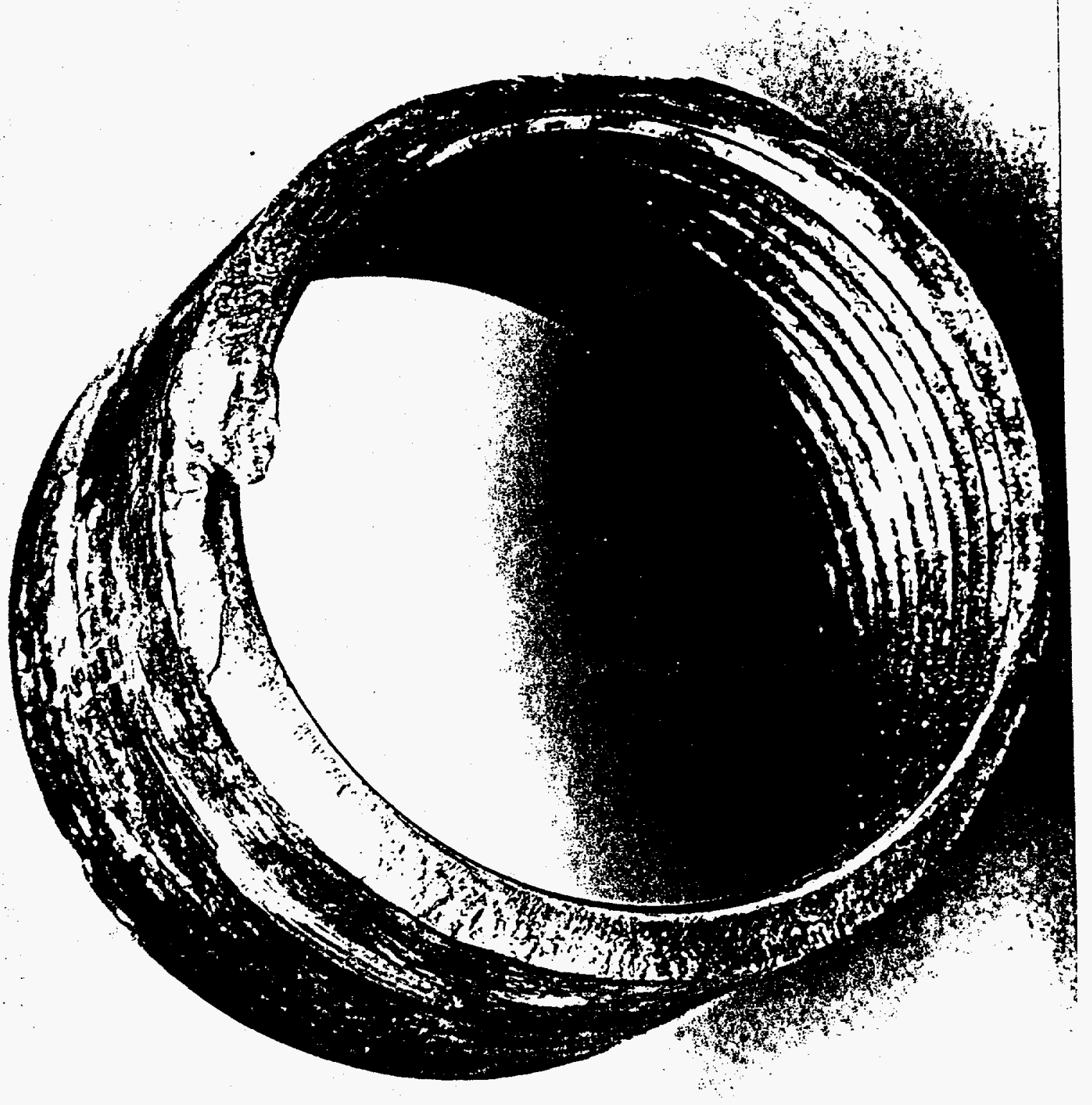


Figure C3. Fracture Origin Region in Specimen D. Magnification 20X. The Benchmark Patterns Show the Position of the Crack Front as Cracking Progressed. The Vertical Lines Near the Top of the Micrograph are the Result Fatigue Cracks Growing Together on S1ightly Different Planes.

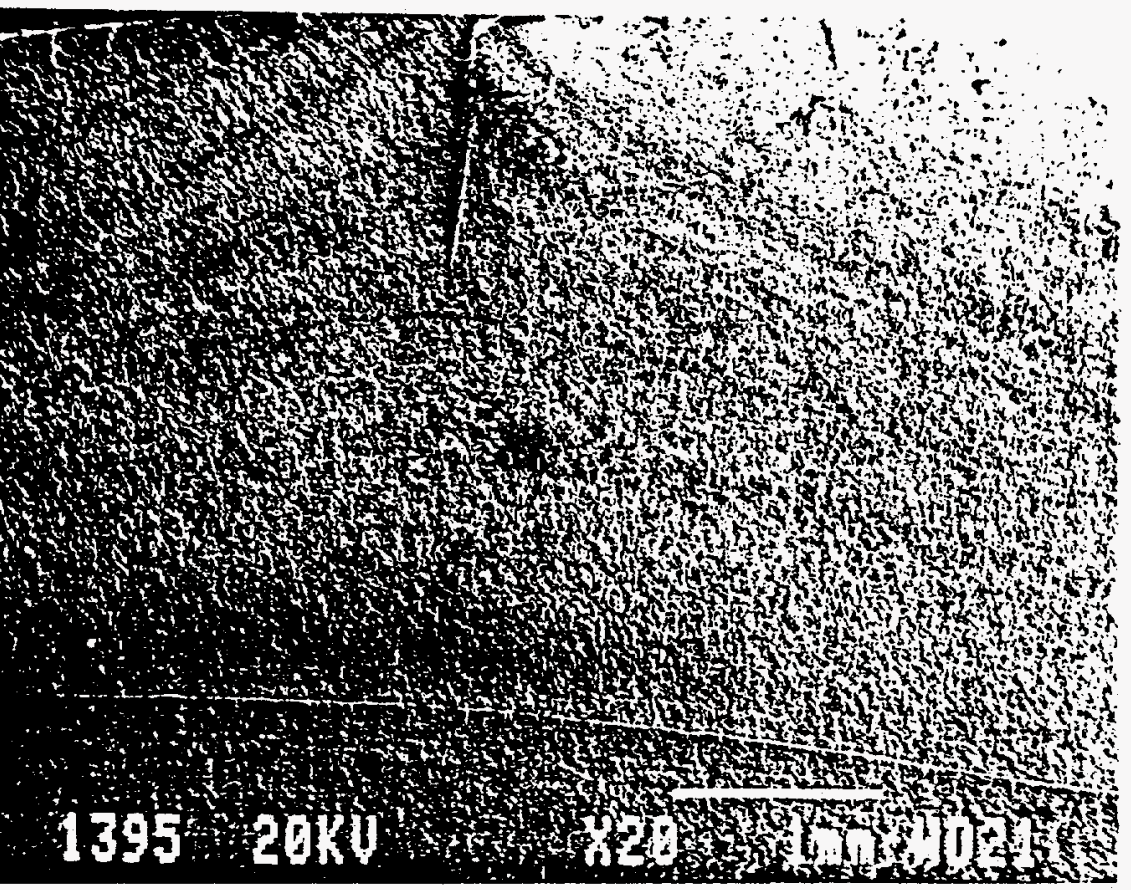


Figure C4. Fracture Origin Region Specimen D. Magnification 50X. The Fatigue Crack Origins are Shown at the Top of the Photograph.

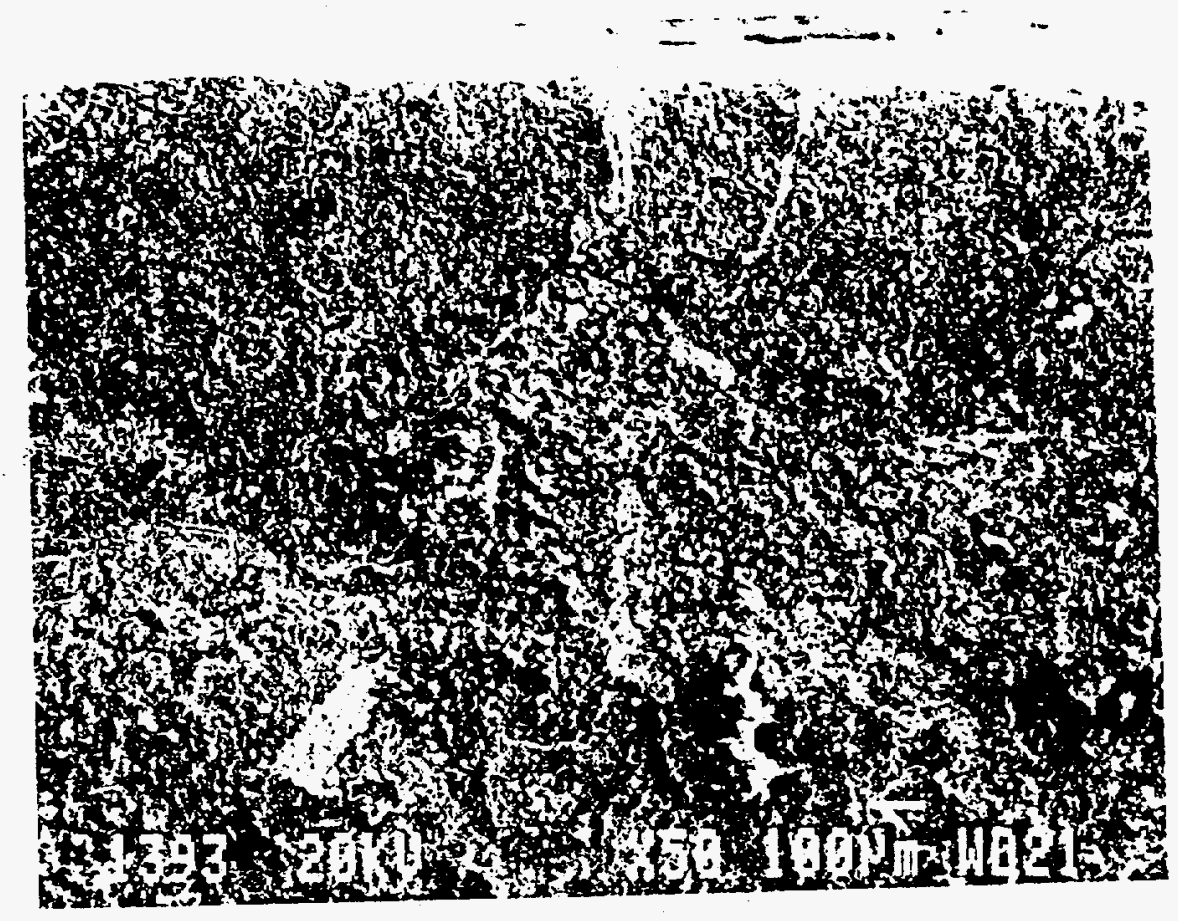


Figure C5. Fracture Surface of Specimen D, Near Final Fracture Region. Magnification 20X. The Nearly Vertical Lines are Fatigue Striations. These Striations Show Both the Direction of Crack Growth

(circumferential) and Rate of Crack Growth

(about $0.02 \mathrm{in} / \mathrm{cycle}$ ).

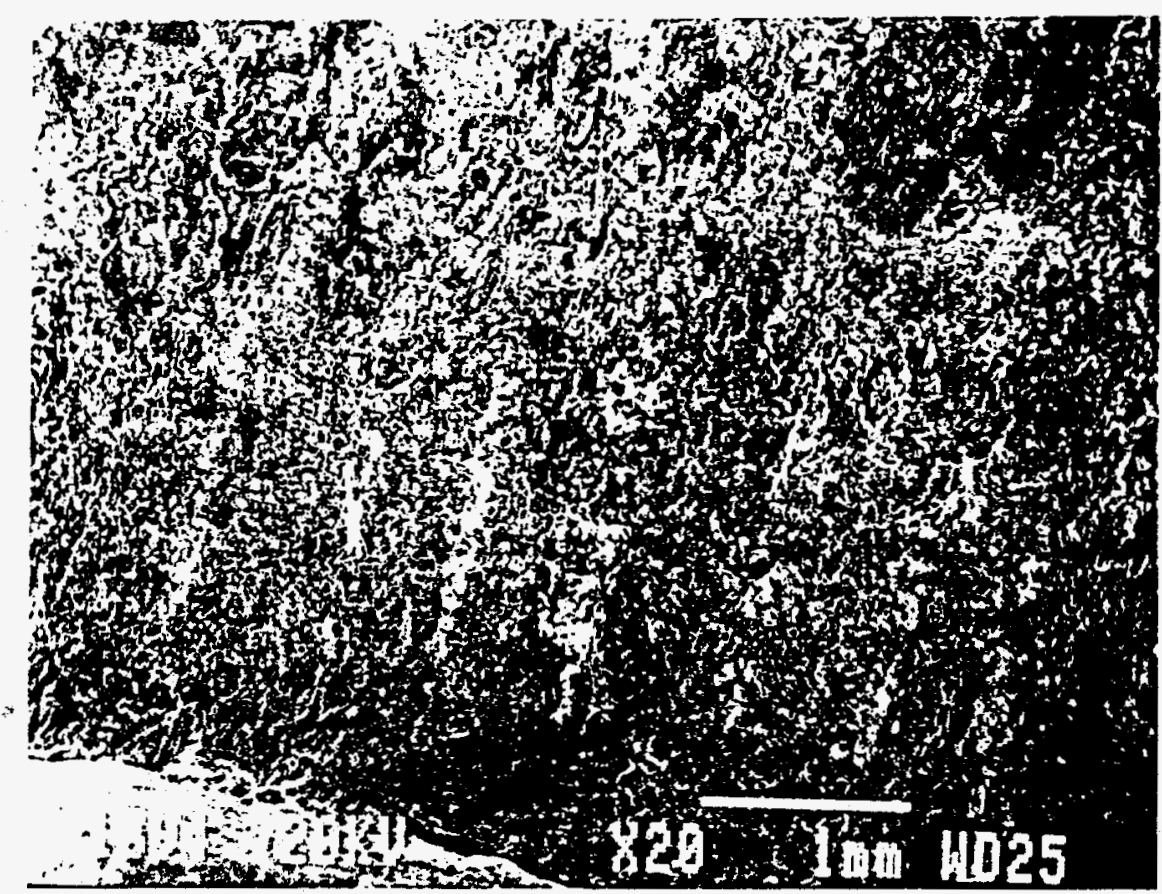


Figure C6. Fracture Surface of Drill Pipe, Near End of Tool Piece. Cracking Initiated at the End of the Tool Piece, Beginning at the Inside of the Pipe.

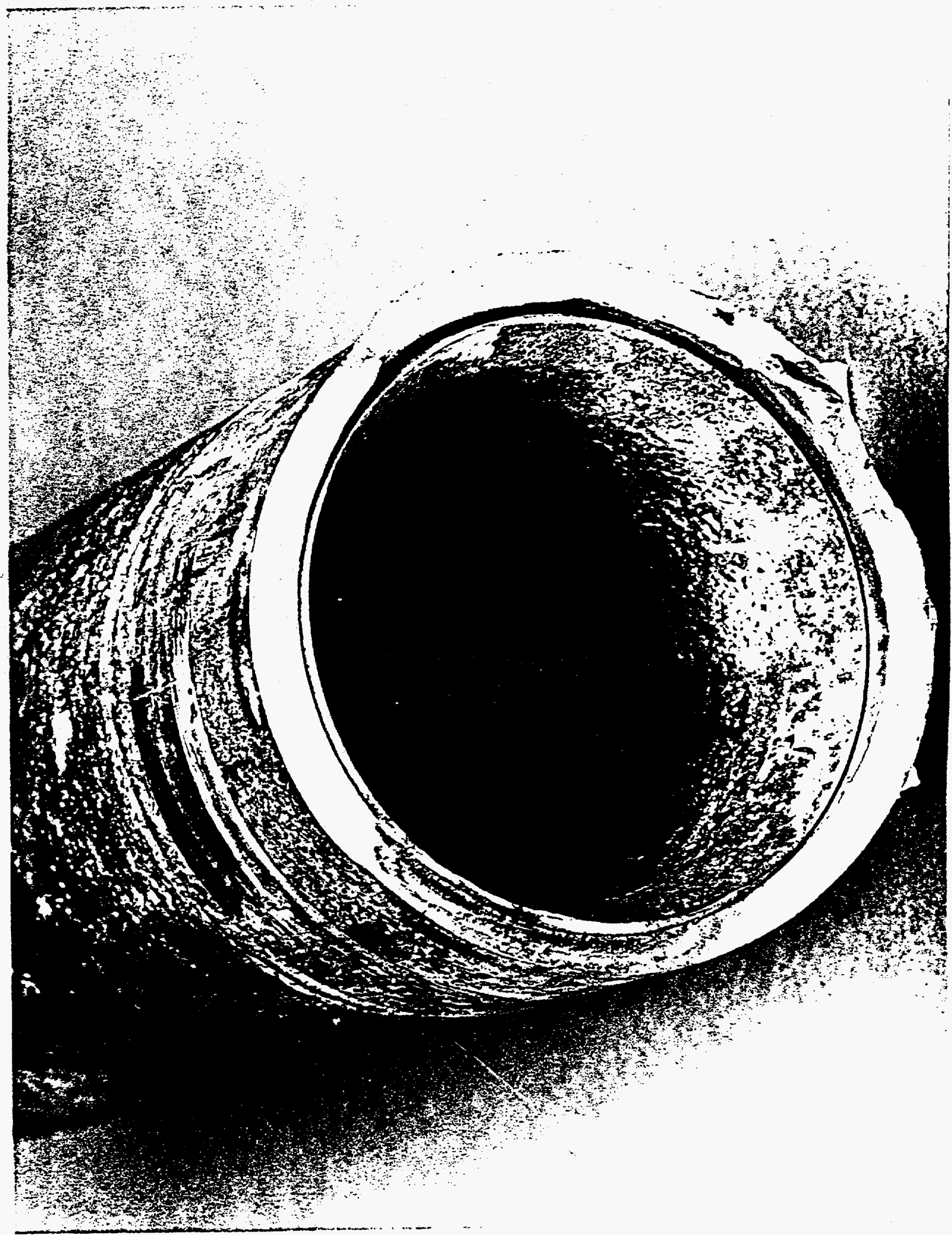


Figure C7. Failed Drill Pipe Retrieved Using a Taper Tap. Potential Spiral Failure of Drill Pipe.

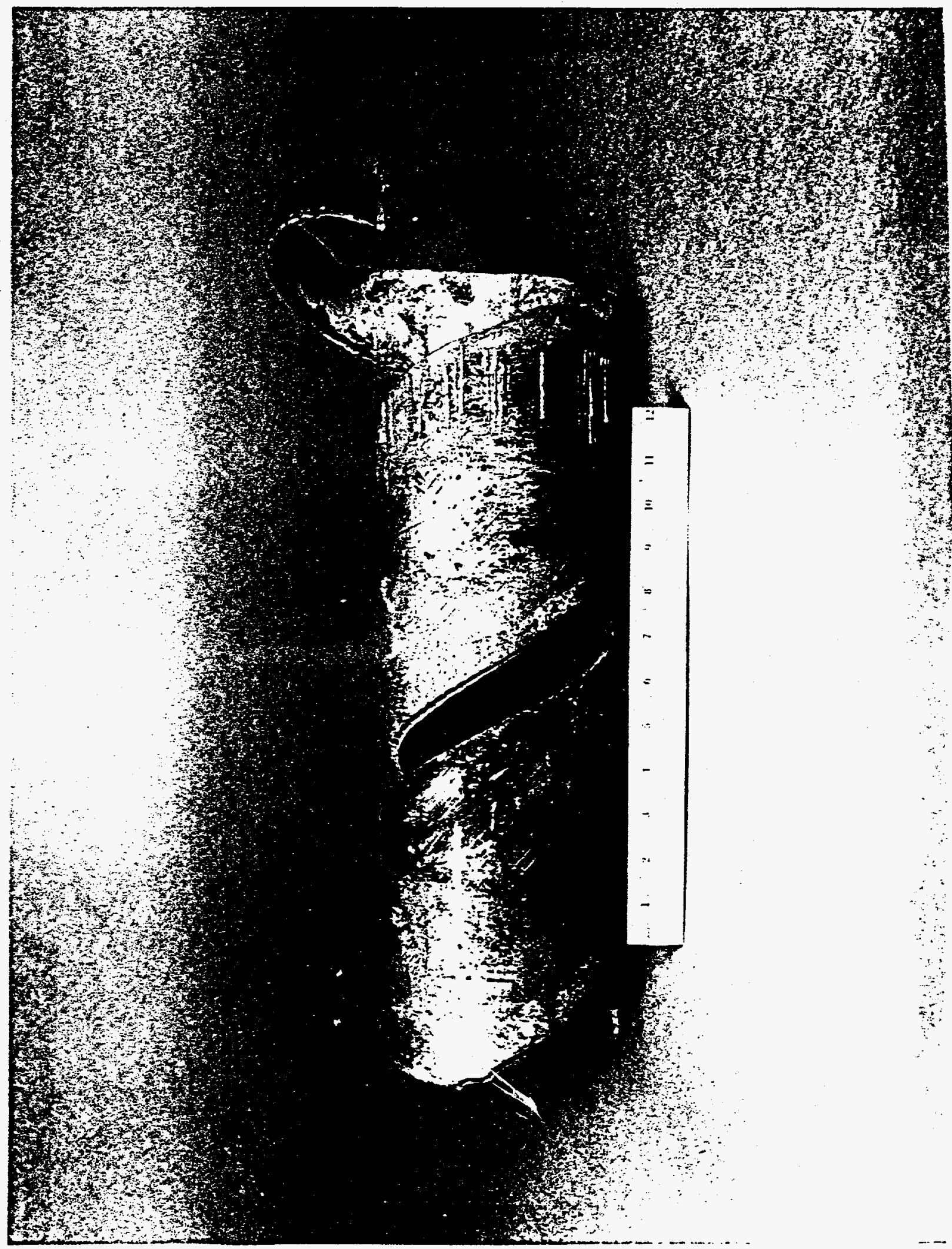


Figure C8. Failed Drill Pipe, Similar to that Shown in Figure 7.

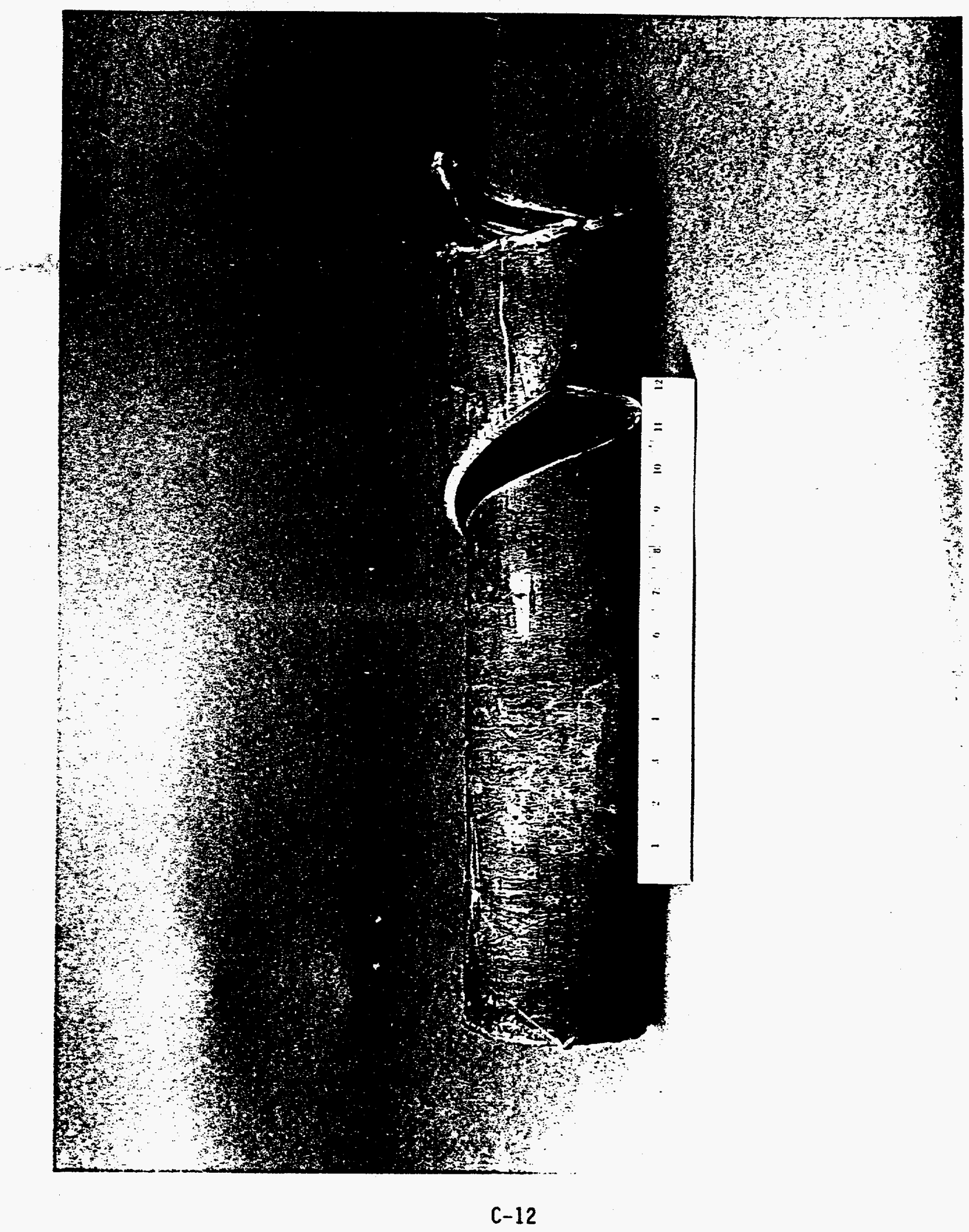


Figure C9. Microstructure of 6 5/8-in Diameter Casing. Magnification 500X. Top; Longitudinal Microstructure, Bottom; Transverse Microstructure. Typical Tempered Martensite Structure.
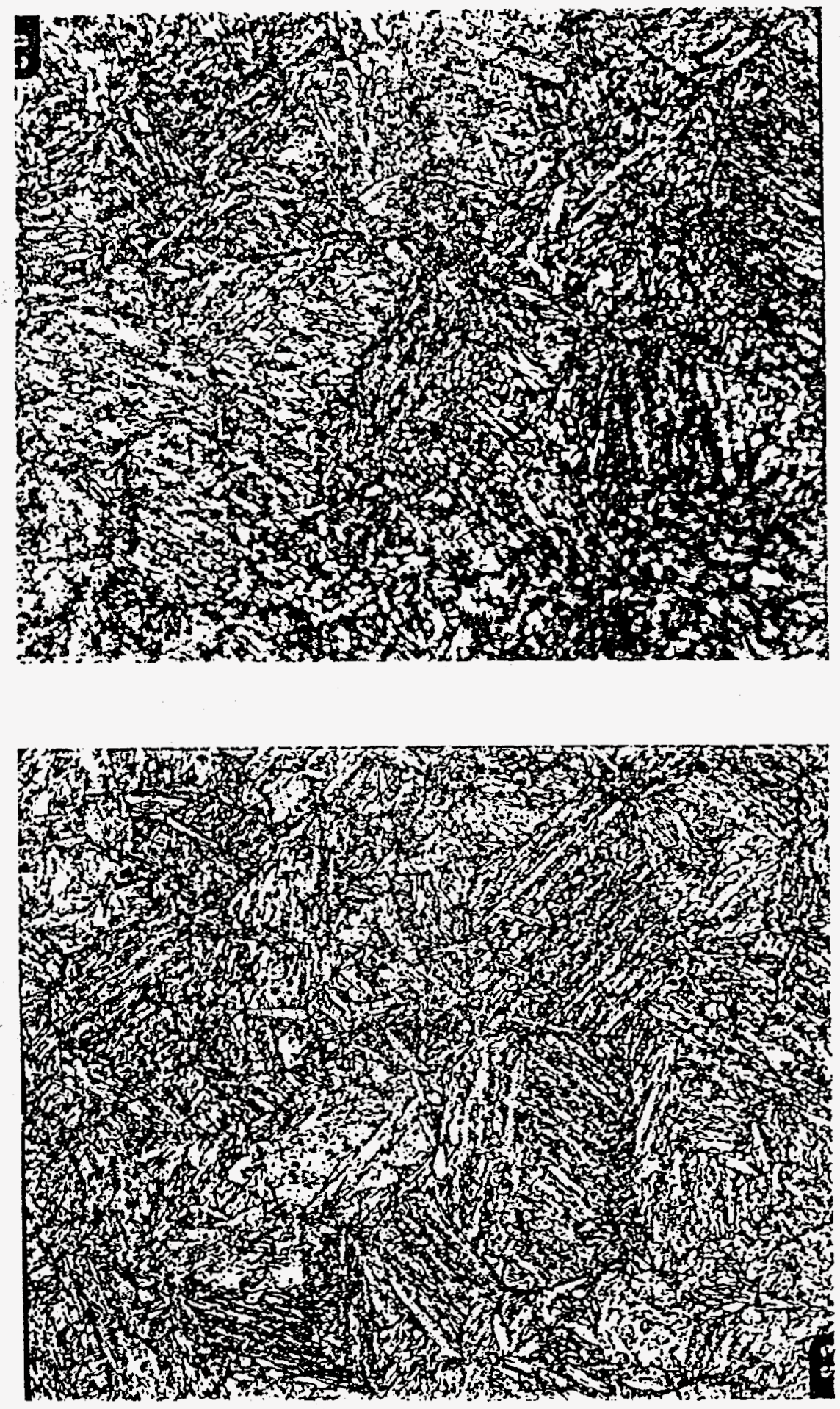
Figure C10. Microstructure of 6 5/8-in Diameter Casing. Magnification 500X. Top; Longitudinal Microstructure, Bottom; Transverse Microstructure. Typical Tempered Martensite Structure.
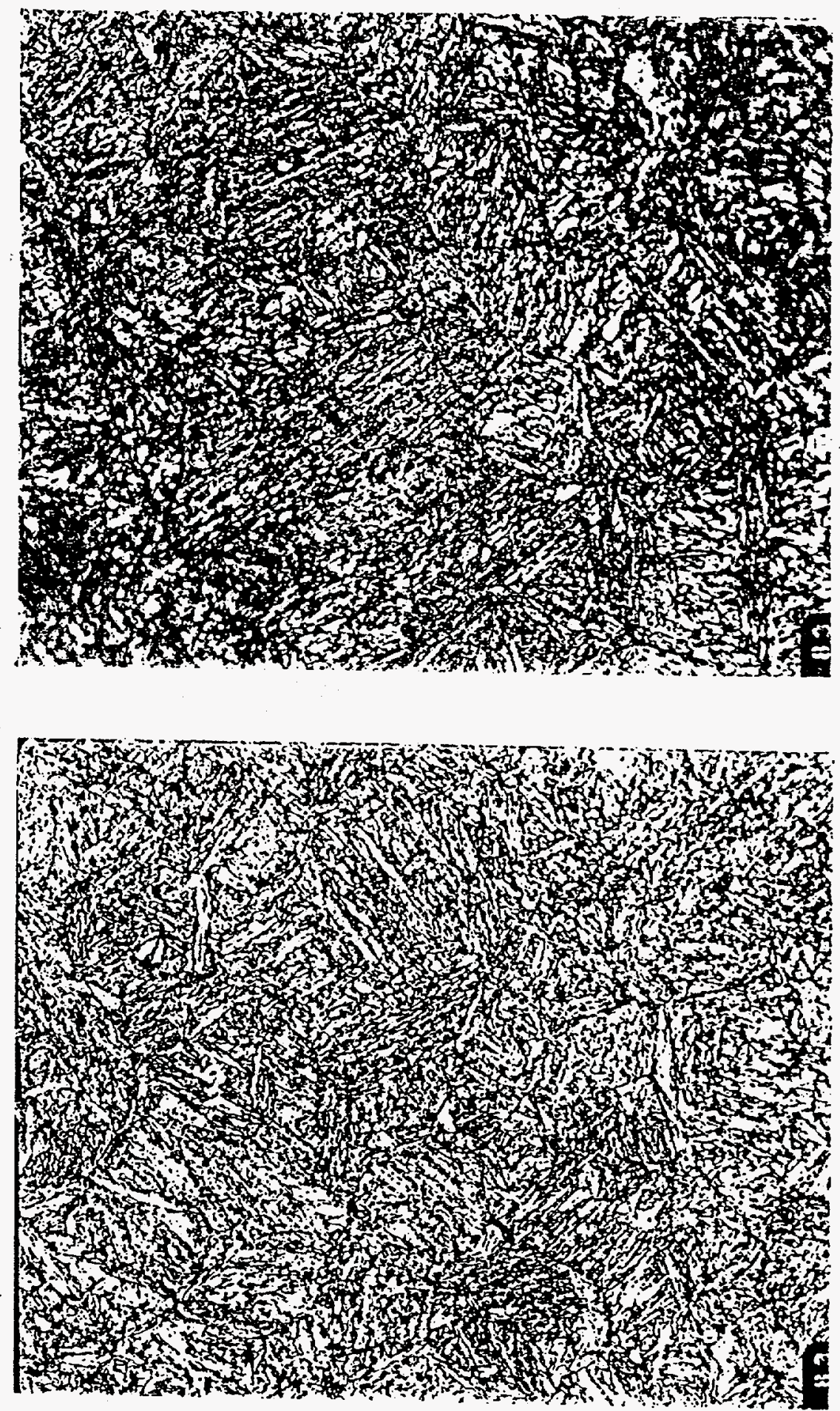